\title{
Información Importante
}

La Universidad Santo Tomás, informa que el(los) autor(es) ha(n) autorizado a usuarios internos y externos de la institución a consultar el contenido de este documento a través del catálogo en línea, página web y Repositorio Institucional del CRAI-USTA, así como en las redes sociales y demás sitios web de información del país y del exterior con las cuales tenga convenio la Universidad.

Se permite la consulta a los usuarios interesados en el contenido de este documento, para todos los usos que tengan finalidad académica, siempre y cuando mediante la correspondiente cita bibliográfica se le dé crédito al trabajo de grado y a su autor, nunca para usos comerciales.

De conformidad con lo establecido en el Artículo 30 de la Ley 23 de 1982 y el artículo 11 de la Decisión Andina 351 de 1993, la Universidad Santo Tomás informa que "los derechos morales sobre documento son propiedad de los autores, los cuales son irrenunciables, imprescriptibles, inembargables e inalienables."

Centro de Recursos para el Aprendizaje y la Investigación, CRAI-USTA

Universidad Santo Tomás, Bucaramanga 
Evaluación de los subsistemas del SIGA en los procesos del centro de gestión administrativa y fortalecimiento empresarial - CEGAFE Boyacá 2018

Pierre Harviary Amaya Plata

Trabajo de grado para optar al título de Magister en Administración

\author{
Directora \\ Angélica María Zambrano Mantilla \\ Magíster en Educación Universitaria
}

Universidad Santo Tomás, Bucaramanga

División de Ciencias Administrativas, Económicas y Contables

Maestría en Administración 


\title{
Dedicatoria
}

\author{
A Dios. \\ Por su infinita clemencia, por \\ resguardarme a cada instante para lograr \\ mis objetivos, además de caridad y \\ cariño. \\ A mi familia, quienes con sus \\ palabras de aliento no me dejaban \\ declinar para que siguiera adelante $\mathrm{y}$ \\ terminar este escalafón importante en mi \\ vida personal y profesional.
}




\section{Agradecimientos}

Agradezco a la Universidad Santo Tomas de Bucaramanga, por la oportunidad brindada para terminar mis estudios como Magister en Administración, a mis docentes por su orientación y guía en este camino académico.

Agradezco a mi directora Angélica María Zambrano Mantilla, por su dedicación, soporte y enseñanzas, a mis compañeros estudiantes por la disposición en la realización de este proyecto y el acompañamiento en cada proceso. 


\section{Tabla de contenido}

Pág.

Introducción 12

1 Evaluación de los subsistemas del SIGA en los procesos del centro de gestión administrativa y fortalecimiento empresarial - CEGAFE Boyacá 2018 15

1.1 Planteamiento del problema.................................................................................... 15

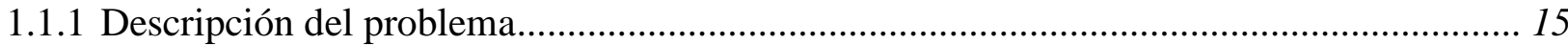

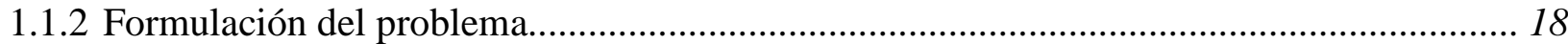

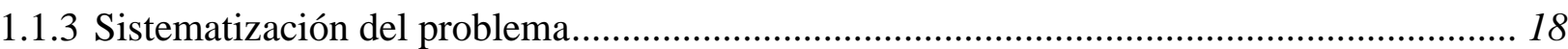

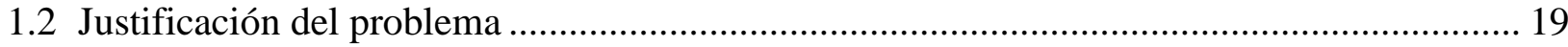

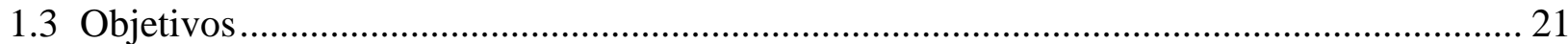

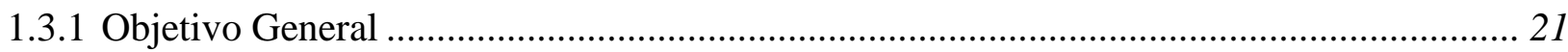

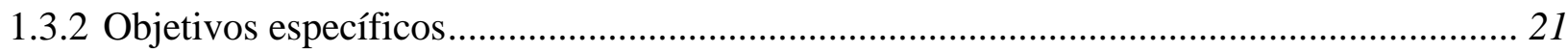

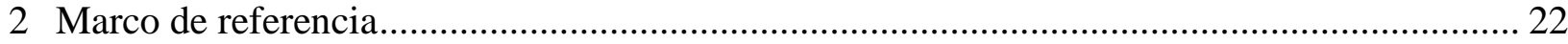

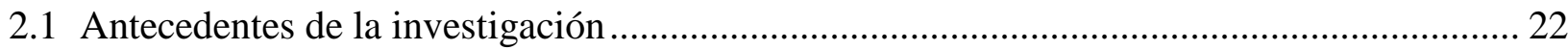

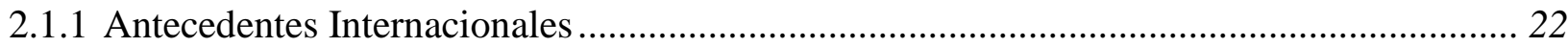

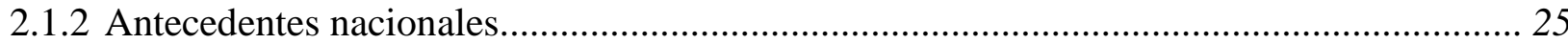

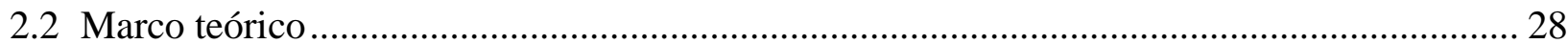

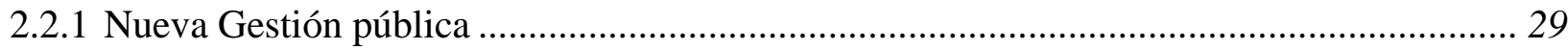

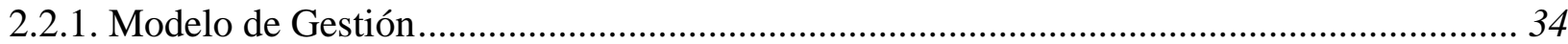

2.2.2 Sistemas de Gestión de calidad .................................................................................. 38

2.2.3 Principios de la Gestión de la Calidad........................................................................... 41

2.2.4 Sistema integrado de Gestión ...................................................................................... 43

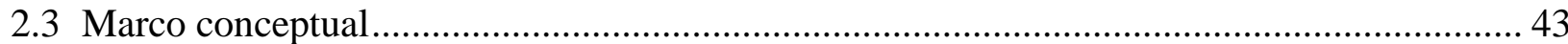

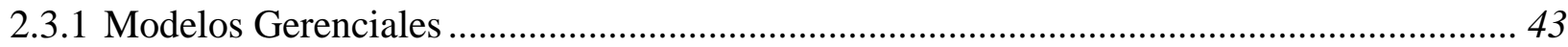

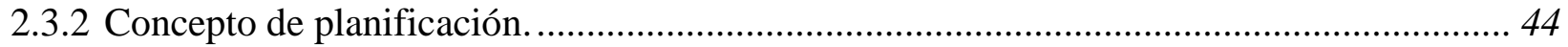

2.3.3 Concepto de Planeación Estratégica (Leiber Alberto, sf). ............................................. 44

2.3.4 Concepto básico de estrategia. .................................................................................. 46

2.3.5 Etapas del proceso de administración estratégica. ...................................................... 48

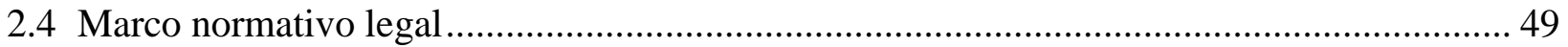




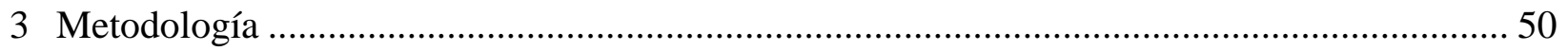

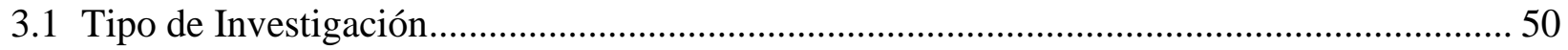

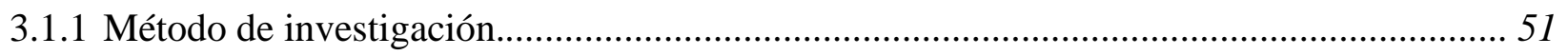

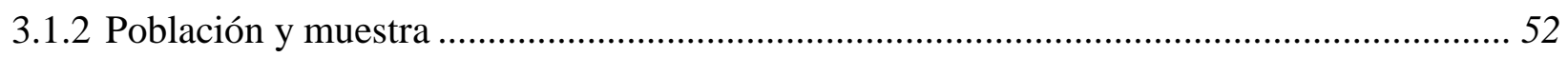

3.2 Fuentes de recolección de información ........................................................................... 54

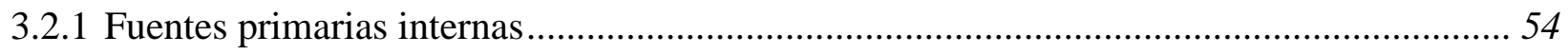

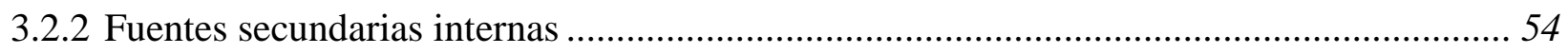

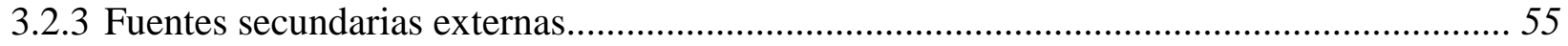

3.3 Herramientas de Análisis y Recolección de la Información ............................................. 55

4 Estado de implementación de las políticas (Calidad, Ambiental, Seguridad en el trabajo e

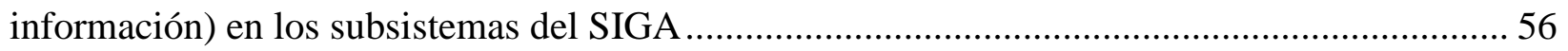

4.1 Articulación SIGA y Planeación Estratégica................................................................ 56

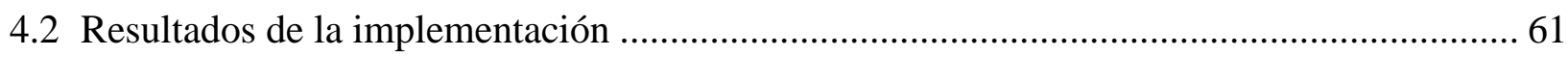

5 efectividad del cumplimiento y el seguimiento y control de indicadores ............................ 71

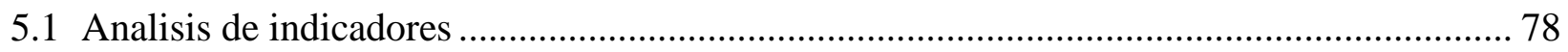

5.1.1 Comparativo indicadores de la sede vs percepcion del diagnostico............................. 79

6 Plan de mejora para efectuar un seguimiento efectivo en los subsistemas del SIGA............. 84

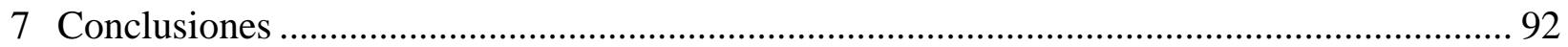

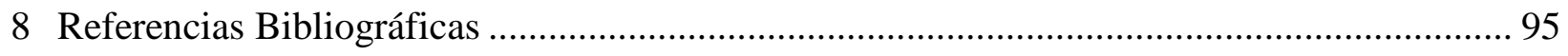

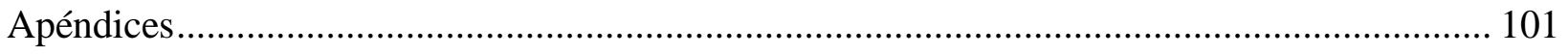




\section{Lista de tablas}

Tabla 1. Personal del Centro de Formación ......................................................................... 52

Tabla 2. Principales Elementos del Sistemas de Desarrollo Administrativo, de Gestión de la

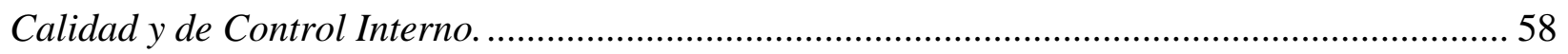




\section{Lista de figuras}

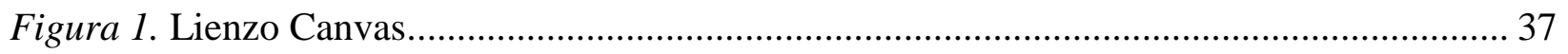

Figura 2. Niveles de estrategia de la empresa ............................................................... 47

Figura 3. Pasos del pensamiento estratégico ................................................................... 47

Figura 4. Cálculo de muestras para poblaciones finitas ..................................................... 53

Figura 5. Modelo integrado de planeación ........................................................................... 57

Figura 6. Modelo integrado de planeación ............................................................................ 58

Figura 7. Liderazgo de la Gerencia / dirección ................................................................ 61

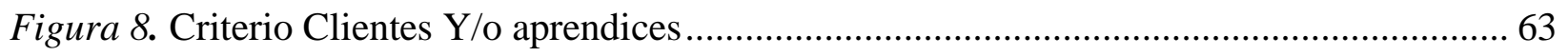

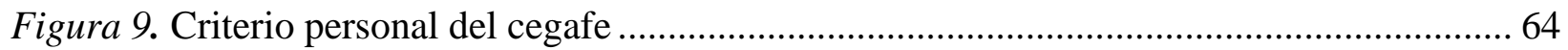

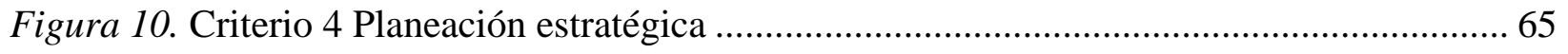

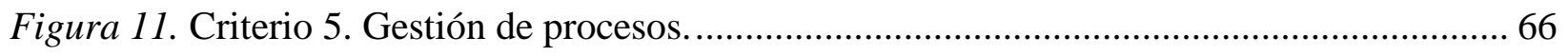

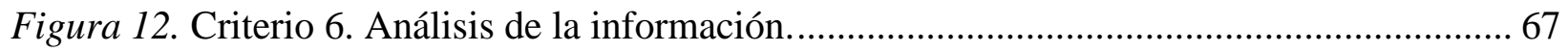

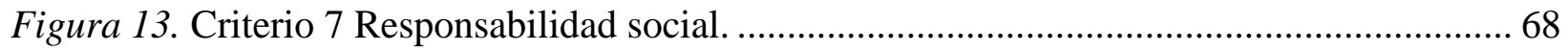

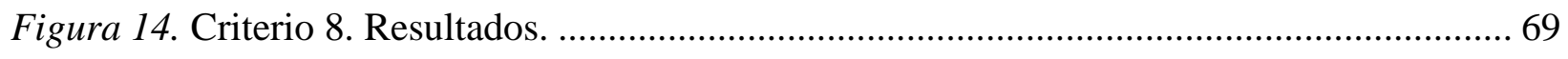

Figura 15. Percepción de la implementación según criterio de lideres .................................... 70

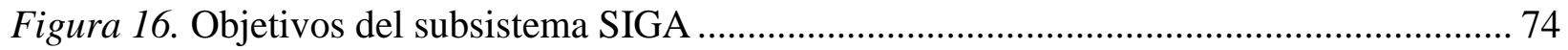

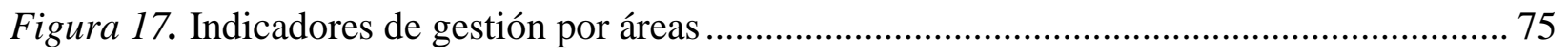

Figura 18. Cobertura versus cupos asignados CEGAFE Boyacá 2018.................................. 76

Figura 19. Certificaciones entregadas versus certificaciones expedidas................................. 77

Figura 20. Esquema para el planteamiento de una metodología inicial para el desarrollo de este

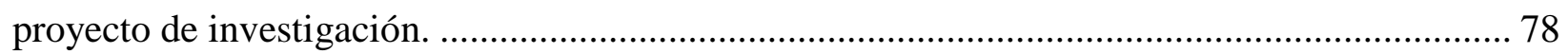

Figura 21. Comparativo de indicadores SIGA Vs instrumento diagnostico percepción ............. 80

Figura 22. Continuación comparación de indicadores....................................................... 82

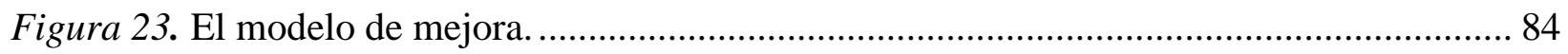

Figura 24. Tabla 5 Plan de mejora - plan de acción - indicadores CEGAFE - SENA.............. 90

Figura 25. Plan de mejoras procesos estratégicos SIGA ................................................... 91 


\section{Lista de apéndices}

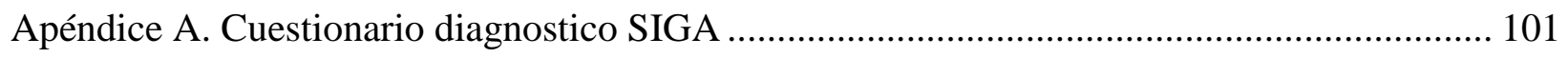

Apéndice B. Carta validación instrumento ………….............................................................. 108 


\section{Resumen}

Dado que solo las actividades que pueden medirse y evaluarse son manejables, la evaluación de las mismas es una parte integral de la función de gestión que realiza la empresa, los resultados pueden darse a conocer a través de ítems o índices medibles y cuantificables en términos financieros, de efectividad o eficiencia que por sí solos no son suficientes para reflejar la situación real de la empresa, es necesario evaluar los factores que influyen en el éxito a largo plazo de la organización, como satisfacer las necesidades y expectativas del cliente, mejorar constantemente, etc. Se conoce que muchas investigaciones hacen énfasis hasta el momento, que las empresas que implementaron el Sistema de Gestión de Calidad ISO obtienen cierta ventaja competitiva, sin embargo, solo hay algunas investigaciones que evalúan con precisión la efectividad del sistema de gestión de la calidad y pueden asegurar la mejora continua de la práctica de la empresa.

En esta investigación se pretende evaluar la efectividad del cumplimiento de las políticas de los subsistemas del SIGA dentro de los procesos misionales y de soporte del CEGAFE Boyacá, 2018, generando a través de un diagnóstico conocer el estado de implementación de las políticas (Calidad, Ambiental, Seguridad en el trabajo e información) en los subsistemas del SIGA del SENA, así como apoyados en un análisis de la efectividad del cumplimiento y el seguimiento y control de indicadores, se presentará una propuesta de mejoras para efectuar un seguimiento efectivo en los subsistemas del SIGA.

En una primera parte se realiza una revisión documental, seguida de la aplicación de instrumentos cuantificables sobre la efectividad de indicadores de subprocesos al interior del subsistema y generando un informe de las falencias y obstáculos de calidad detectados durante el desarrollo de la presente investigación.

Palabras claves: Sistemas de gestión, Calidad, Procesos, Fortalecimiento, Empresarial, subsistemas. 


\begin{abstract}
Since only the activities that can be measured and evaluated are manageable, the evaluation of the activities of the company is an integral part of the management function, the results can be disclosed through items or indexes measurable and quantifiable in financial terms, of effectiveness or efficiency that by themselves are not enough to reflect the real situation of the company, it is necessary to evaluate the factors that influence the long-term success of the organization, how to satisfy the needs and expectations of the client, constantly improve, etc. . It is known that many investigations emphasize so far, that the companies that implemented the ISO Quality Management System obtain a certain competitive advantage, however, there are only a few investigations that accurately assess the effectiveness of the quality management system and can ensure the continuous improvement of the practice of the company.

This research intends to evaluate the effectiveness of compliance with the policies of the subsystems of the SIGA within the mission and support processes of CEGAFE Boyacá, 2018. Specific objectives, through a diagnosis of the state of implementation of the policies (Quality, Environmental, Workplace Safety and Information) in SENA's SIGA subsystems, as well as supported by an analysis of the effectiveness of compliance and the monitoring and control of indicators, will present a proposal for improvements to effectively monitor subsystems of the SIGA.

In the first part, a documentary review is carried out, followed by the application of quantifiable instruments on the effectiveness of indicators of subprocesses within the subsystem and generating a report of the shortcomings and quality obstacles detected during the development of the present investigation.
\end{abstract}

Keywords: Management systems, Quality, Processes, Strengthening, Business, subsystems. 


\section{Introducción}

El Centro de Gestión Administrativa y Fortalecimiento Empresarial de Tunja, adscrito a la regional Boyacá se creó en 1965, inicialmente con el nombre de Centro de Comercio y Servicios, siete (7) años después de creada, la Regional Boyacá. Esta sede, comenzó la formación con cursos en las áreas de Archivística y Secretariado complementando año tras año la formación enfocada hacia los servicios de oficina. El Centro actualmente ofrece formación Técnica, Tecnológica y Complementaria en diversas áreas atendiendo 122 de los 123 municipios que tiene el Departamento (Sena centro gestión Tunja, 2015).

El Centro de Gestión Administrativa y Fortalecimiento Empresarial tiene una sede principal ubicada en la ciudad de Tunja, además de sedes adscritas propias y en arriendo en las ciudades de Tunja, Moniquirá y Villa de Leyva. Dentro de los planes de organización y gestión, la entidad a través de los requerimientos de la nueva gestión pública implemento el Sistema de Gestión y Control basado en procesos de calidad bajo un esquema de eficiencia a través del seguimiento de los procesos pilares del centro de formación.

Según dicha plataforma, la herramienta en el SENA, SIGA es un instrumento de gestión que contribuye a aumentar el desempeño institucional a través de sus procesos, lo cual se ve reflejado en el mejoramiento continuo de la calidad de los servicios de la entidad, en el cumplimiento de los objetivos institucionales con eficiencia, eficacia y efectividad, y en la satisfacción de las necesidades, intereses y expectativas de los clientes - usuarios, partes interesadas y grupos de interés. (Sena, 2015).

Esta herramienta posee una serie de subsistemas así: 
- Subsistema de Gestión de la Calidad: Este busca incrementar la calidad, oportunidad, pertinencia y calidez en la prestación de servicios.

- Subsistema de Gestión Ambiental: que busca fortalecer la aplicación de buenas prácticas ambientales, e incrementar la generación de conductas amigables con el medio ambiente.

- Subsistema de Gestión de Seguridad y Salud en el Trabajo: que busca incrementar el fortalecimiento de las acciones en el crecimiento humano, mejorar las condiciones de vida de seguridad y salud ocupacional, entre otras metas.

- Subsistema de Seguridad de la Información: la cual busca incrementar la capacidad de las herramientas TIC para fortalecer los controles y la integración de la información en los procesos y servicios de la entidad. (SIGA - SENA, 2015).

- los que a su vez se articulan con el Modelo Estándar de Control Interno- MECI. Estos Subsistemas conforman el Sistema Integrado de Gestión y Autocontrol (SIGA). (SENA, 2017).

De acuerdo a lo anterior, es fundamental entender que la calidad no solo se mide por la pertinencia de un servicio o la durabilidad de un producto, esto va más allá de la satisfacción final del cliente, ya sea interno o externo, puesto que reúne un conjunto de elementos que permiten que ésta se dé, por lo tanto, los sistemas de gestión permiten juzgar el valor de la calidad dentro de esos elementos que llevan a lograr la satisfacción de necesidades concretas, en este sentido se encuentran las normas ISO y genera actividades organizadas, coordinadas y dirigidas a controlar la organización en lo relativo a la calidad. (Sánchez, 2013)

Por tanto, y bajo este orden de ideas, un Sistema de Gestión Integral es aquel en donde la organización integra al máximo todas sus actividades y además les hace seguimiento documental para compararlo con el entorno o con una media en donde la empresa pueda implementar un proceso de mejora continua, a través del Planear, Hacer, Actuar y Verificar, que son 
consideraciones para que la compañía logre la competitividad en un mundo globalizado, en otras palabra busca que la empresa se adecue a las condiciones interpuestas por los entes predominantes y el entorno que la rodea. (ICONTEC, 2008, Citado por Mejía 2015).

Por lo anterior, se pretende en este documento evaluar la efectividad del cumplimiento de las políticas de los subsistemas del SIGA dentro de los procesos (soporte y Misionales) que permitan dilucidar falencias con el ánimo de emitir mejoras para garantizar la correcta adopción del Sistema Integrado de Gestión y Autocontrol en la institución, a través de un diagnóstico del estado actual de la implementación de dichas políticas, soportando un análisis de la efectividad del cumplimiento, generando una propuesta entorno a las mejoras para efectuar un adecuado seguimiento y control de los subsistemas del SIGA. 


\section{Evaluación de los subsistemas del SIGA en los procesos del centro de gestión administrativa y fortalecimiento empresarial - CEGAFE Boyacá 2018}

\subsection{Planteamiento del problema}

\subsubsection{Descripción del problema}

La adopción de un sistema de gestión basado en indicadores no es una tarea fácil para cualquier organización, máxime que debe ser involucrado cada uno de los actores internos y externos que interactúan con los objetivos operacionales y misionales de la misma.

Dentro de los retos más importantes, las empresas deben asumir la delegación de procesos fundamentales en su misión, que conlleven a la generación de riqueza y además satisfacer necesidades en ciertos mercados, es importante entonces, destacar que las organizaciones desarrollan un conjunto de actividades o procesos para satisfacer las necesidades de todos sus stakeholders (colaboradores).

En este orden de ideas, dentro de la formalización de procesos, las actividades entendidas como el conjunto de acciones en pro del cumplimiento de objetivos para generar satisfacción estas conectadas entre sí, ellas generan el conglomerado de procesos que deben funcionar de forma sistémica y en concordancia con las metas propuestas, así como en pro de los objetivos de la organización o empresas, esto lleva a un compromiso importante de todos quienes interactúan al interior y exterior de la misma que permita sobrellevar los diferentes retos estratégicos que esto genera.

En otros referentes, citando a Ortiz y Martínez (2003), el impacto de los sistemas de gestión hacen de la organización un conjunto de parámetros que orientan su cambio dentro de los niveles 
más básicos, siguiendo que la adopción permite hacer uso de los recursos de la compañía ya que permite mejorar la organización de la misma, al ayudar la sistematización de las operaciones, se consigue que las producción e innovación de los procesos vayan en concordancia con la satisfacción de clientes internos y externos, de igual forma, vuelve eficiente al personal que atiende la ejecución de los procedimientos de la empresa.

Sumado a ello los autores Torralba Chaves, X., Betancourth Romero, H., y Fandiño Benavides, R. (2016) hacen énfasis, en la modernización de los costes de producción es decir, detectar recursos ociosos que no generan valor, permite a su vez controlar dicho desempeño y la organización en sí, es por ello que un sistema de gestión de la calidad, coadyuva a cumplir de manera más adecuada la normatividad relacionada con los productos y servicios de la compañía, mejora la capacitación de empleados y trabajadores, puesto que al contar con más información la ejecución de las fases, etapas y procedimientos será más ágil y dinámica.

De igual forma es de destacar, que los sistemas de gestión tienen en cuenta los requisitos y expectativas del cliente, por lo que su implementación incide positivamente en la satisfacción de los mismos, generando fidelización y mejor posición en el mercado con objetivos claros y estratégicos, esto suma valor, mejora la imagen del producto y del servicio ofrecido, así como la mejora continúa buscando alcanzar metas medibles y un aprendizaje constante.

Con base en lo anterior el Sistema Nacional de Aprendizaje -SENA, adoptó un sistema de Gestión y control que le permite centralizar los diferentes reportes de sus diferentes dependencias y sedes circunscritas, este es el caso del Centro de Gestión Administrativa y Fortalecimiento Empresarial - CEGAFE Boyacá, que a través del SENA se ha definido como herramienta para fortalecer su gestión y facilitar el logro de los objetivos institucionales, la implementación e integración de los sistemas de gestión basados en estándares internacionales. 
Así pues, se estructuraron el Subsistema de Gestión de la Calidad con base en la norma ISO 9001, el Subsistema de Gestión Ambiental basado en la norma ISO 14001, el Subsistema de Seguridad y Salud en el Trabajo bajo el decreto 1072 de 2015 y el Subsistema de Seguridad de la Información basado en la norma ISO 27001, los que a su vez se articulan con el Modelo Estándar de Control Interno- MECI bajo el decreto 943 de 2014. Estos Subsistemas conforman el Sistema Integrado de Gestión y Autocontrol (SIGA). (SENA, 2017).

A partir de la aplicación del sistema y subsistemas referenciados, existe una serie de problemáticas a tener en cuenta, Entre las más concurrentes, es posible mencionar:

- Certificaciones erradas de quienes participan en las inscripciones, hallazgos dentro de la política de información, el indicador de entregas de certificaciones versus aprendices no corresponde.

- Los recursos del centro de formación no son suficientes para facilitar el cumplimiento de metas.

- Apoyos insuficientes de acuerdo con el volumen de trabajo del centro de formación que impiden el cumplimiento oportuno de las tareas.

- Espacios insuficientes para puestos de trabajo.

- Seguimientos ineficaces al cumplimiento de requisitos de la formación.

- Líneas jerárquicas mitigadas por la forma de vinculación de contratación y planta.

Así mismo las políticas de los subsistemas del SIGA poseen indicadores que son monitoreados a través de plataforma, sin embargo, no hay seguimiento, existen siete sedes adscritas al CEGAFE, pese a ello los errores son mínimos, pero requieren a largo plazo control; existe una descentralización de procesos, pero responsabilidad en centro de costos que sobre 
carga el funcionamiento eficaz del CEGAFE, esto hace que no sea efectivo el sistema integrado de gestión y autocontrol.

Con base en lo anterior, se pretende realizar una evaluación de dicha efectividad en el cumplimiento de las políticas de los subsistemas del SIGA dentro de los procesos (soporte y Misionales) teniendo como resultado una propuesta entorno a las mejoras para efectuar un adecuado seguimiento y control de los subsistemas del SIGA, determinando con ello los avances en términos de calidad que deben mejorarse para brindar servicios que vayan acordes con las necesidades de la región, así como las proyecciones profesionales de quienes acceden a los mismos en pro de una capacitación laboral.

\subsubsection{Formulación del problema}

¿Cuál es el estado y efectividad de los subsistemas del SIGA en los procesos misionales y de soporte del centro de gestión administrativa y fortalecimiento empresarial - CEGAFE Boyacá $2018 ?$

\subsubsection{Sistematización del problema}

- ¿De qué manera se puede evaluar y diagnosticar el estado actual de implementación de las políticas del SIGA CEGAFE Boyacá?

- ¿Qué tan efectivo es el cumplimiento de indicadores en los subsistemas del SIGA CEGAFE Boyacá?

- ¿Qué tipo de propuestas pueden diseñarse para mejorar el seguimiento y control de los procesos orientados a cumplir las políticas de los subsistemas del SIGA CEGAFE Boyacá? 


\subsection{Justificación del problema}

De acuerdo con diferentes autores, entre los que pueden citarse Bueno (2007), la estrategia es una respuesta que representa la utilización de recursos con base en necesidades y capacidades específicas, logrando con ello cumplir metas específicas, teniendo en cuenta determinados condicionantes del entorno y una situación de rivalidad en la que se encuentre.

Con base en lo anterior, el SENA a través del SIGA, que es una herramienta de gestión que contribuye a aumentar el desempeño institucional a través de sus procesos, ha coadyuvado a mejorar los servicios en la entidad, dando cumplimiento de los objetivos institucionales con eficiencia, eficacia y efectividad, y en la satisfacción de las necesidades, intereses y expectativas de los clientes - usuarios, partes interesadas y grupos de interés. (SENA, 2017).

Se centra en los siguientes pilares:

- Centrado en las Personas.

- Enfoque en Resultados (servicios - productos).

- Integralidad en la gestión.

- Simplificación.

Dentro de su alcance el SENA en los límites físicos y organizacionales y la aplicabilidad de los requisitos de las Normas Técnicas y Legales bajo las cuales se implementan los Subsistemas que lo conforman: NTCGP 1000:2009, ISO 9001:2015, ISO 14001:2015, DECRETO 1072 DE 2015, ISO 27001:20013 y el Modelo Estándar de Control Interno MECI: 2014. (Centro de Gestión SIGA 2016).

Pese a que existen políticas de subsistemas dentro de la estrategia desarrollada por el SENA, se generan cuellos de botella administrativos que no permiten el control y seguimiento adecuado, 
cabe destacar que la Regional Boyacá posee 14 sedes y de ellas hay centralización parcial en algunos procesos, así como en centros de costos que limitan el buen funcionamiento del CEGAFE, debido a una limitante importante: los recursos; esto ha causado un retroceso en algunos indicadores de gestión que vulneran los objetivos estratégicos y disminuyen la efectividad de los mismos.

Con base en lo anterior y de acuerdo a lineamientos estratégicos, esto significa que la Dirección del CEGAFE debe establecer una gestión encaminada hacia una mejora, de manera sistemática, que busque generar innovaciones, que le ayuden a diferenciarse y a ser más competitiva, es ahí la justificación de la presente propuesta en aras de evaluar la efectividad de dicho control y seguimiento y generar alternativas de mejora que agreguen valor al servicio brindado en el CEGAFE.

La investigación es determinante para el mejoramiento de la gestión de la organización, puesto que existen falencias en el seguimiento de los controles al interior del sistema en el CEGAFE, de las cifras que pueden ser publicadas, existen rubros como el consumo de papelería que puede incidir en centros de costes relevantes para el SENA, que al determinar los cuellos de botella del proceso puedan tomarse correcciones y planes de mejora para incentivar la era digital cero papeles.

Por lo anterior, sustentando como se expresó en el planteamiento del problema, existen otros referentes, citando a Ortiz y Martínez (2003), el impacto de los sistemas de gestión hacen de la organización un conjunto de parámetros que orientan su cambio dentro de los niveles más básicos, siguiendo que la adopción permite hacer uso de los recursos de la compañía ya que permite mejorar la organización de la misma, al ayudar la sistematización de las operaciones, se consigue que las producción e innovación de los procesos vayan en concordancia con la 
satisfacción de clientes internos y externos, de igual forma, vuelve eficiente al personal que atiende la ejecución de los procedimientos de la empresa.

Sumado a ello los autores Torralba Chaves, X., Betancourth Romero, H., y Fandiño Benavides, R. (2016) hacen énfasis, en la modernización de los costes de producción es decir, detectar recursos ociosos que no generan valor, permite a su vez controlar dicho desempeño y la organización en sí, es por ello que un sistema de gestión de la calidad, coadyuva a cumplir de manera más adecuada la normatividad relacionada con los productos y servicios de la compañía, mejora la capacitación de empleados y trabajadores, puesto que al contar con más información la ejecución de las fases, etapas y procedimientos será más ágil y dinámica.

Por todo lo anterior, se evidencia que es fundamental evaluar qué tan eficiente ha sido la implementación, seguimiento y control del sistema integrado SIGA en los procesos del CEGAFE Boyacá.

\subsection{Objetivos}

\subsubsection{Objetivo General}

Evaluar la efectividad del cumplimiento de los subsistemas del SIGA dentro de los procesos misionales y de soporte del CEGAFE Boyacá, 2018.

\subsubsection{Objetivos específicos}

- Diagnosticar el estado de implementación de las políticas (Calidad, Ambiental, Seguridad en el trabajo e información) en los subsistemas del SIGA.

- Analizar la efectividad del cumplimiento y el seguimiento y control de indicadores 
- Presentar una propuesta de mejoras para efectuar un seguimiento efectivo en los subsistemas del SIGA

\section{$2 \quad$ Marco de referencia}

\subsection{Antecedentes de la investigación}

\subsubsection{Antecedentes Internacionales}

Pelayo (2012), a través de su tesis magistral titulada Determinación del grado de calidad de una empresa a partir de los indicadores de gestión, permite mostrar evaluar en las distintas empresas el grado de calidad que han alcanzado. Uno de los factores que se tiene en cuenta para realizar la selección de un proveedor es el grado de calidad que este posee. Sus aportes se centran en la revisión de las metas alcanzadas por las empresas que han implementado el sistema de gestión de calidad, generando expectativas importantes al conocer los aciertos e inciertos que desde la organización han tenido que superar para implementar con éxito los procesos documentados, el autor por tanto, tomando como base los sistemas de gestión conocidos, tal como lo es el modelo de excelencia de los premios nacionales se han identificado todas las variables que actúan sobre un sistema de gestión, uso el modelo de excelencia del premio nacional a la calidad, para generar variables medibles, las cuales fueron analizadas mediante el método del análisis estructural y se han procesado todas las variables identificadas mediante una herramienta del análisis estructural como es el MIC-MAC. Con el uso de estas herramientas se han identificado las variables claves del sistema y se ha propuesto un modelo para medirlas. Sus conclusiones reflejan que las variables que inciden en un adecuado control de los sistemas de 
gestión radican en la aceptación y compromiso de quienes interactúan en la organización, así como la disposición para asumir los roles y cambios necesarios para generar eficiencia.

Otro documento escrito por Seppälä (2015), titulado Implementando un Sistema de Gestión de Calidad para una empresa de ingeniería y servicios, esta tesis se llevó a cabo para una empresa de ingeniería y servicios como parte de una actualización de la estrategia mediante la implementación de un sistema de gestión de calidad en las operaciones de la compañía de casos. El objetivo principal de la Tesis fue proporcionar una solución sobre cómo implementar el sistema de gestión de calidad ISO 9001 con éxito. El enfoque de investigación seleccionado fue el análisis de datos. Para implementar el sistema de gestión de calidad ISO 9001 en las operaciones de la compañía de casos, se revisaron los estándares actuales y las mejores prácticas del sistema de gestión de calidad y gestión de cambios, de igual forma, paralelamente al análisis de la literatura, se realizó una recopilación de datos de la compañía de casos a través de talleres, discusiones, revisiones y auditorías.

Los resultados de la implementación fueron a) el análisis de preparación ISO 9001, que aclaró el estado de la compañía de casos respecto a los requisitos ISO 9001; b) el plan de implementación, que determinó las acciones de mejora que debían estar en línea con el estándar antes de realizar la auditoría interna. El plan de implementación también fue una herramienta para monitorear el progreso de las acciones, y c) el plan de auditoría interna y los resultados de la auditoría interna. Como resultado general, la compañía de casos obtuvo una forma de operación más consistente y está más cerca de obtener la certificación ISO 9001. Sobre la base de los resultados y los resultados de la auditoría, la compañía de caso debe realizar mejoras en las operaciones para que los requisitos de la norma ISO 9001 se ajusten a la siguiente auditoría 
corporativa. Esta tesis proporciona un marco general del proceso de implementación, que puede aplicarse a todos los sistemas de gestión de la calidad.

De igual forma, un documento titulado Sistemas de gestión de calidad para proveedores de educación y formación, escrito por Ronel Heyns (2011), hizo referencia específicamente a que los proveedores de educación y capacitación se encuentran en la base del sistema de educación y capacitación en el sentido de que son las organizaciones que realmente participan en la enseñanza y el aprendizaje y tratan directamente con los estudiantes, los "clientes" a quienes el sistema de educación y capacitación está destinado a servir. Por lo tanto, es de vital importancia que los proveedores desarrollen sistemas de gestión de calidad (SGC) y que reciban el apoyo necesario para operar dentro del Marco Nacional de Cualificaciones (NQF).

Este documento abordó lo siguiente:

- Problemas generales relacionados con el SGC para proveedores;

- Paradigmas en la gestión de la calidad y el aseguramiento de la calidad;

- Elementos que constituirían un enfoque QMS; y

- La plantilla de calidad SAQA.

Además, este documento proporcionó una elaboración de los criterios básicos que deben cumplir los proveedores para recibir la acreditación de sus ETQA constituyentes. La inclusión de estos criterios elaborados es una respuesta directa a las necesidades percibidas de los proveedores y está destinada a facilitar el desarrollo del SGC entre los proveedores. Este documento también señaló la necesidad de permitir que se desarrollen criterios básicos específicos del sector, si se considera que son necesarios. Sin embargo, se enfatiza que tales criterios de sectores específicos no pueden contradecir los criterios básicos y solo pueden 
agregarse a los criterios básicos. Sin embargo, dichos criterios específicos del sector deben ser sancionados por SAQA.

La gestión eficaz en el mundo globalizado requiere un sistema de gestión eficaz, eficiente y flexible. Efectivamente se podría interpretar que aborda todas las inquietudes relevantes de las partes interesadas en un contexto de Responsabilidad Social Corporativa (RSC). Eficiente significaría que hace el trabajo con un bajo uso de recursos. La flexibilidad requiere que las condiciones cambiadas y los nuevos requisitos puedan ser incluidos fácilmente. Muchas organizaciones ya están trabajando con sistemas de gestión integrados (IMS). Las preguntas interesantes son hasta qué punto la integración actual cubre las necesidades mencionadas anteriormente y, en caso contrario, qué cambios son necesarios.

Las posibilidades para el desarrollo de sistemas de gestión totalmente integrados se estudian desde la perspectiva de la gestión de las necesidades de las partes interesadas, con la próxima ISO 26000 - "Orientación sobre responsabilidad social", como inspiración. Los resultados muestran que hay ventajas en la integración, pero que el alcance y el nivel de integración a menudo son limitados. Se presenta un modelo conceptual para integrar todas las necesidades de las partes interesadas en las redes de valor.

\subsubsection{Antecedentes nacionales}

Hurtado Pedraza (2017), a través de su escrito titulado Fortalecimiento a la implementación del subsistema Interno de gestión documental y archivos (SIGA) en el Instituto para la investigación educativa y el desarrollo pedagógico - IDEP; de la Universidad Nacional Abierta y a Distancia "UNAD”, se fundamentó en diseñar y aplicar un instrumento mediante el cual se pueda verificar la implementación de los procedimientos que hacen parte integral del proceso de 
Gestión Documental del IDEP, en concordancia con el Programa de Gestión Documental y la normatividad vigente, mediante la realización de un análisis del estado actual de la implementación del proceso de Gestión Documental del IDEP, posteriormente se aplicó una herramienta en donde se evidenciara el grado de conocimiento e implementación del proceso de gestión documental por parte de los funcionarios y contratistas de apoyo del IDEP, logrando implementar controles de seguimiento y evaluación de manera trimestral que permitieron evaluar periódicamente el estado de implementación del SIGA en el IDEP, sus resultados estuvieron enfocados a brindar estrategias efectivas de evaluación, así como una falencia notoria era la falta de información del sistema de quienes colaboran activamente en el IDEP, lo cual sugirió la autora que se incluyera en el marco del Plan Institucional de Capacitación, jornadas de formación para los funcionarios responsables del archivo de gestión de cada una de las áreas, en donde se incluyan entre otros, los siguientes temas: Organización y foliación de expedientes; diligenciamiento de la hoja de control de documentos y el inventario de los expedientes en el archivo de gestión utilizando el Formato Único de Inventario Documental - FUID, así como la socialización de manera periódica y sistemática la adopción del Subsistema Interno de Gestión Documental y Archivos - SIGA, su conformación, políticas, funciones y el estado de su implementación. (Hurtado, 2017).

Otro documento relevante para el propósito de esta investigación, es el aportado por Arboleda, Balcázar y Estupiñan (2013), titulado Evaluación institucional y de resultados del Subsistema Nacional de la Calidad, en este a través de una análisis por parte de FEDESARROLLO, se hace una revisión de la infraestructura de la calidad como un requisito fundamental para impulsar la actividad comercial, fortalecer el sector productivo, proteger los derechos de los consumidores, la vida, la salud y el medio ambiente. La expedición de normas y 
reglamentos técnicos, la metrología y la evaluación de la conformidad son elementos claves para establecer estándares de calidad y de eficiencia del sector productivo que permitan mejorar su competitividad y productividad, son algunas de las expectativas que desde un sistema de gestión se proyecta, asimismo, garantizar la protección de los derechos legítimos de los consumidores y del país en general, se requiere de seguimientos y mediciones estrictas que permitan vislumbrar las estrategias a seguir en un plan de mejora futuro. En este escrito los autores hacen énfasis en la importancia que la evaluación toma como marco de análisis dos elementos centrales, el enfoque sistémico y la cadena de valor. El enfoque sistémico permite analizar el Subsistema a partir de sus diferentes propósitos, componentes (actores, funciones, políticas), interrelaciones, entradas, procesos y salidas. Sus conclusiones estuvieron dirigidas a hacer seguimiento sobre las problemáticas evidenciadas, las cuales se centran en que la secretaría técnica no tiene las herramientas para hacer efectivas las tareas que se asignan en la comisión por lo que sólo puede hacer llamados, esto fomenta que muchos de los compromisos se terminen aplazando indefinidamente, lo que refuerza la percepción de la comisión como una instancia de socialización pero no de toma de decisiones y hay deficiencia en las operaciones y procesos.

Torres Becerra y Suna Landino (2012), a través de su documento titulado del sistema integrado de gestión al sistema de gestión integral: la gestión del conocimiento como estrategia en el Cuerpo Oficial de Bomberos de Bogotá, en este escrito los autores hace énfasis que en Colombia, desde la promulgación de la Ley 872 de 2003, la cual reza: "Por la cual se crea el sistema de gestión de la calidad en la Rama Ejecutiva del Poder Público y en otras entidades prestadoras de servicios", y por ende han implementado en las entidades del sector público sistemas de gestión, tales como el de calidad, el ambiental y el de la seguridad y salud ocupacional, pese a ello aún existen comportamientos al interior de los procesos que no hacen de 
dicha labor un indicador de eficiencia, esto se debe a un rechazo contra la implementación de estos sistemas de gestión por parte de los funcionarios, quienes obstaculizan su cabal funcionamiento afectando los procesos, las políticas e, incluso, a las personas de las entidades, en el diagnóstico refleja la situación que predomina en el Cuerpo Oficial de Bomberos frente al conocimiento; todavía este se genera a través de la experiencia del personal más antiguo de la entidad y se transfiere a los nuevos de la misma manera. Pese a lo anterior, es claro reconocer la generación del conocimiento a través de, formación formal y documentada, es decir, se valora la necesidad de cambiar hacia un conocimiento cada vez más explícito.

De los documentos descritos anteriormente es de destacar que cada uno centro su investigación, que los resultados de las mismas sugirieron estrategias efectivas de evaluación, así como la identificación de falencias en cuanto a la falta de información del sistema de quienes colaboran activamente, así mismo, se enfatizó en la importancia que la evaluación toma como marco de análisis dos elementos centrales, el enfoque sistémico y la cadena de valor. En todos y cada uno de los aportes investigativos de los autores, se hizo énfasis en la importancia de las variables que inciden en un adecuado control de los sistemas de gestión, radica en la aceptación y compromiso de quienes interactúan en la organización, así como la disposición para asumir los roles y cambios necesarios para generar eficiencia, lo cual sugiere valorar la necesidad de cambiar hacia un conocimiento cada vez más explícito de los procesos y los sistemas de gestión.

\subsection{Marco teórico}

Dentro de los lineamientos que el Gobierno nacional gestiona, se encuentra la formalización de los procesos en cada uno de los organismos que brindan atención a la población, entre los que 
se destacan las agencias nacionales y los Servicios Nacionales de Aprendizaje SENA, los cuales proporcionan servicios que ayudan a jóvenes y adultos a acceder a beneficios importantes para el desarrollo profesional y personal.

En este orden es fundamental referenciar lo concerniente a la teoría que soporta el presente documento en cuanto a los diferentes modelos de gestión, que es el sistema de gestión de calidad, el control de procesos entre otros.

\subsubsection{Nueva Gestión pública}

En el idioma discursivo gubernamental se habla de rendición de cuentas, transparencia, eficiencia, eficacia y legitimidad, conceptos por demás llanos ante una realidad inconmensurable que impide su operación dentro de un sistema estructural e institucional por demás intrincado por las luchas políticas, en una transición inacabada donde los diversos actores políticos pierden legitimación al representar más a sus intereses grupales y personales que a los sociales (De la Cruz, 2003, pág. 2), sin embargo, algunas experiencias exitosas y la persistencia de organizaciones internacionales para adoptar este tipo de estrategias, sin duda, han contribuido a un "efecto de imitación" o isomorfismo, que ha llegado a una gran variedad de países. Hoy en día, los países desarrollados y emergentes, así como los que están sumidos en el subdesarrollo, aspiran y se esfuerzan por adoptar "recetas del Norte" para encontrar un camino más rápido y efectivo para construir gobiernos "menos caros y más eficientes", parece reforzarse en un contexto en el que las ideologías políticas siguen perdiendo fuerza y continúan subordinándose al equilibrio simple de los resultados ofrecidos por los partidos políticos en el poder.

La nueva gestión pública hace alusión a los nuevos términos enraizados a la estrategia, el cual ha sido mal utilizado e incluso abusado, esto quiere decir que la prospectiva emerge dado el 
interés del hombre por conocer el futuro y desarrollar mecanismos para poder controlarlo, sin embargo, la prospectiva generalmente no puede disgregarse de la estrategia; por lo tanto, el término prospectivo estratégico el cual hace de las situaciones de análisis y previsibles. La prospectiva estratégica no es solo un enfoque exploratorio (anticipación estratégica), sino también normativo. Continuando con la tradición de la planificación estratégica y la gestión estratégica, la perspectiva estratégica enfatiza la importancia del pensamiento de largo alcance y alternativo en los procesos estratégicos de toma de decisiones. Sin embargo, la complejidad de los problemas estratégicos y la necesidad de resolverlos colectivamente significa utilizar métodos que sean lo más rigurosos y participativos posible para reconocer el problema y encontrar soluciones aceptables. (Arellano y Cabrero, 2005).

La Nueva gestión pública - NGP, está creando una teoría de las organizaciones que no le da la suficiente importancia a la discusión de la justicia para ser un enfoque que busque mejorar los gobiernos en todo el mundo. La suposición puede expresarse de esta manera: en la medida en la que la eficiencia sea el impulsor de las organizaciones públicas y la meritocracia y el sector público orientado a resultados sean los principales valores organizacionales, se estarán proporcionando todos los elementos necesarios para crear un gobierno bueno y racional (Arellano y Cabrero, 2005, p 603). Ciertamente, la dificultad de construir la teoría desde la práctica es sustancial. En parte, este dilema siempre ha estado presente en las disciplinas del gobierno y la administración pública, dado que la agenda práctica del gobierno frecuentemente define la agenda de investigación.

Los conceptos de prospectiva, estrategia y planificación están íntimamente relacionados en la práctica; como resultado, a lo largo de este texto se mencionarán la planificación estratégica, la gestión y el enfoque estratégicos prospectivo. Cada uno de estos enfoques se refiere a un 
conjunto de definiciones, problemas y métodos cuya especificidad es débil, dada la vaga terminología. Lo que se ha redescubierto con la nueva gestión pública, es que las personas y las organizaciones están en el centro de la diferencia entre las empresas eficientes e ineficientes. Una parte de la parcialidad introducida por la moda gerencial se deriva del hecho de que los consultores constantemente necesitan rehacerse para destacarse de la competencia. Con demasiada frecuencia, la impresión de novedad se adquiere al menor costo al cambiar el nombre de un viejo concepto (Chica, 2011).

De igual forma, el autor hace énfasis en la definición de la demanda ciudadana, y es descrito a través de un gráfico que reúne las elites de los partidos políticos, el sistema político y la sociedad - actores que compendien acciones en pro de todos y para todos. De igual forma, es fundamental la identificación de los actores políticos, ya que ellos se basan en la ponderación del Nivel de Presión y Movilidad de estos, haciendo que las decisiones políticas se centren en los aspectos relevantes de la gestión estratégica pública.

Otro autor que se refiere a la Nueva Gestión pública como el enfoque moderno de la administración, es Moyano (2002), el cual a través de su artículo publicado Gestión pública y calidad: hacia la mejora continua y el rediseño de las instituciones del sector público, menciona "la Administración pública reconoce la capacidad de hacer las cosas que no depende del poder del gobierno para ordenar o usar su autoridad". (Pero, aun así, pueden ocurrir fallas del gobierno); es en esta proposición se encuentra una progresión natural desde la teoría de gobierno más amplia hasta las nociones más prescriptivas de la Nueva Gestión Pública. Se advierte que dentro de la gestión de gobernanza hay un énfasis concertado en nuevas herramientas y técnicas para dirigir y guiar. El lenguaje se toma directamente de la reinvención de temas. El dilema de la gobernanza en este contexto es que existe una preocupación más amplia sobre el potencial muy 
real de fracaso del liderazgo, las diferencias entre los socios clave en los horizontes de tiempo y las prioridades de los objetivos, y los conflictos sociales, todo lo cual puede dar como resultado un fallo de gobierno.

Un aparte interesante está en el título de la NGP y la discusión de la justicia: hacia un nuevo ethos organizacional, en él se distinguen corrientes, La NGP produce una pérdida de la misión organizacional: las organizaciones públicas existen no sólo para producir servicios para los clientes, sino también para evitar la imposición de un valor social mejor. Las organizaciones públicas son creadoras de significado social. Las organizaciones públicas existen en una compleja red interorganizacional.

El lado libertario de la NGP parece apoyar la idea de que las organizaciones públicas son necesarias sólo en la medida en la que trabajan eficientemente para la sociedad. Una vez que se tiene en cuanto individuos, que lidiar con las organizaciones públicas, éstas deben formar parte de una red que tiene como única misión la de servir a sus clientes. Es por ello que en el ámbito interno de los gobiernos este conjunto de transformaciones confluye en lo que se ha dado en llamar como nueva gestión pública, concepto cuya aplicación implica asumir una serie de principios que definen una nueva forma de pensar la gestión gubernamental y la incorporación de nuevas pautas de desempeño institucional.

Según Chica (2011), según lo citado dentro de su artículo,

La administración pública en las sociedades contemporáneas se enfrenta hoy a ser transformada por una nueva racionalidad que fue definida, desde finales del siglo $\mathrm{XX}$, por diversos autores como una nueva gestión pública (NGP). Esta NGP pretende tomar distancia de la racionalidad burocrática, racionalidad que definió históricamente a la Administración Pública (p. 9). 
De acuerdo a ello, se está produciendo una gran transformación y está surgiendo una nueva civilización, mientras que la civilización industrial establecida y tradicional se desvanece, ante tanta innovación y globalización, es por ello que el término éxtasis ha reemplazado a la palabra rápido para describir el cambio, que se ha vuelto constante; los cambios instantáneos son extremadamente difíciles, si no imposibles de predecir, y tienen consecuencias potenciales tanto de devastación como de desarrollo en las sociedad, la gobernabilidad y la gestión pública.

Es por ello que García (2007), a través de su artículo la nueva gestión pública: evolución y tendencias afirma que el nuevo paradigma para construir una nueva cultura de gestión pública implica un razonamiento con la intención de invertir para cambiar o mejorar; invertir para ayudar a las personas a cambiar en lugar de tratar de imponer los mejores programas elaborados por las jerarquías decisorias, es ahí donde el dinero global no tiene lealtad ni apego a ningún espacio, nación o comunidad de la gente.

Es por ello por lo que entrar a explicar sobre la administración pública, requiere hacer un pequeño recuento sobre las teorías científicas de la administración, las cuales partieron de identificar los elementos claves para lograr la coordinación de decisiones en torno a cumplir metas y objetivos organizacionales en pro de una rentabilidad palpable. Esto también fue adaptado y ajustado a la función pública, puesto que este concepto para la administración pública fue el modelo de burocracia de Max Weber: impersonal no político, racional, jerárquico y organizado de acuerdo con funciones técnicamente especializadas.

Las ciencias administrativas deben inspirarse en las nuevas reformas y desarrollos, ya que la reforma en la administración pública se considera el tema principal para el avance y el mejoramiento de la ciencia administrativa. Los requisitos actuales para la expansión del conocimiento para la administración tienen en cuenta las necesidades de un nuevo acceso teórico 
y práctico a la administración en las nuevas condiciones de desarrollo del orden democrático en las sociedades modernas, dado que la administración es una actividad sin la cual no se puede Imaginé la actividad de un estado legal (Stavileci, Sokoli y Batalli, 2010).

La actividad administrativa dentro del escenario público es ahora el producto de un complejo sistema funcional que encierra acciones determinadas a prestar servicios públicos con el objetivo de emprender acciones encaminadas a garantizar el bienestar de sus ciudadanos, así como el desarrollo cultural y el progreso económico de la sociedad. La administración pública actual requiere instrumentos consistentes para mantenerla funcional y dinámica. La teoría y la práctica administrativa deben ser un símbolo de transformación en línea con los nuevos desarrollos y reformas en la administración pública.

Así como lo expresa García (2007), la pérdida de credibilidad del sector público como gestor del bienestar ciudadano viene acompañado de manifestaciones que exigen y obligan a que las instituciones públicas actúen aplicando principios de economía, eficiencia y eficacia. Estas nuevas demandas, cada vez más importantes como consecuencia de la magnitud del déficit público en prácticamente la totalidad de países, tuvieron en un primer momento un importante impacto en los procesos de construcción de políticas públicas, pero en la actualidad no se circunscriben únicamente a la esfera política o ministerial, sino que se han ampliado a todas las actuaciones de la administración en sus diferentes órdenes territoriales.

\subsubsection{Modelo de Gestión}

Como empresas emprendedoras las organizaciones hospitalarias se ven enfrentadas a múltiples situaciones, donde es necesario tomar decisiones, irrumpir en nuevas áreas, analizar nuevas oportunidades para formular proyectos estratégicos como diversificar y penetrar 
mercados mediante incursión internacional. Todas estas situaciones generalmente se desarrollan en un contexto de incertidumbre y riesgo. (Baca, 2010).

En el planteamiento de estos proyectos es vital incluir procesos organizados y planeados, que incluyen una metodología precisa que soporte desenlaces exitosos.

La planeación estratégica es el proceso mediante el cual quienes toman decisiones en una organización obtienen, procesan y analizan información pertinente interna y externa, con el fin de evaluar la situación presente de la empresa, así como su nivel de competitividad con el propósito de anticipar y decidir sobre el direccionamiento de la institución hacia el futuro. (Serna, 2008).

La planeación estratégica tiene cinco componentes fundamentales:

a. Diagnóstico Estratégico.

b. Direccionamiento Estratégico.

c. Formulación Estratégica.

d. Operación de la Estrategia.

e. Implementación de la Estrategia.

Una vez definida la estrategia y hacia donde se deben dirigir todas las acciones se recurre a una de las herramientas claves en la parte de formulación estratégica, que es la aplicación de herramientas gerenciales para determinar los modelos de negocio a desarrollar, planeando los procesos que se requieren para dar cumplimiento a los objetivos y misión de la organización.

Dentro de los modelos gerenciales y estrategias más idóneas para el desarrollo de modelos de gestión orientados al sector salud se encuentran:

REINGENIERIA (Hammer, 2005): Es la revisión y replanteamiento fundamental de la organización enfocada al rediseño radical y rápido de toda clase de procesos de valor agregado y 
de todos aquellos sistemas de apoyo con el fin de alcanzar mejoras espectaculares en el rendimiento de los costos, la calidad, los servicios, la productividad (eficiencia más eficacia), y la optimización de las tareas.

CANVAS: El Canvas fue creada por Alex Osterwalder con la ayuda de Yves Pigneur, "es una herramienta de gestión estratégica y empresarial, que le permite describir, diseñar, desafiar, inventar, y rediseñar su modelo de negocio. (Osterwalder, 2011). Se trata de una herramienta que permite detectar sistemáticamente los elementos que generan valor al negocio. Dentro de este paradigma, la única regla fija que hay es la de no auto-inhibirse y acoger todas las ideas que emanen del proceso.

Uno de los mayores retos después de tener "esa" idea innovadora es el cómo desarrollarla y materializarla y no solo basta con definir la idea emprendedora, además debe elegirse, desarrollarse y también innovar en el modelo de negocio para lograr el éxito deseado.

Pensando en lo difícil que es llevar a cabo generar un modelo de negocio, A. Osterwalder junto a Y. Pigneur, reconocidos conferencistas y expertos en innovación aplicada a los negocios, en su libro "Generación de modelos de Negocio", crearon el lienzo - o canvas - del modelo de negocio, una forma práctica para la generación de modelos empresariales.

El lienzo consiste en la conexión esquemática de nueve módulos que refleja la lógica de una empresa para alcanzar sus ingresos, cubriendo las cuatro áreas principales: Cliente, oferta, infraestructura y viabilidad económica. 


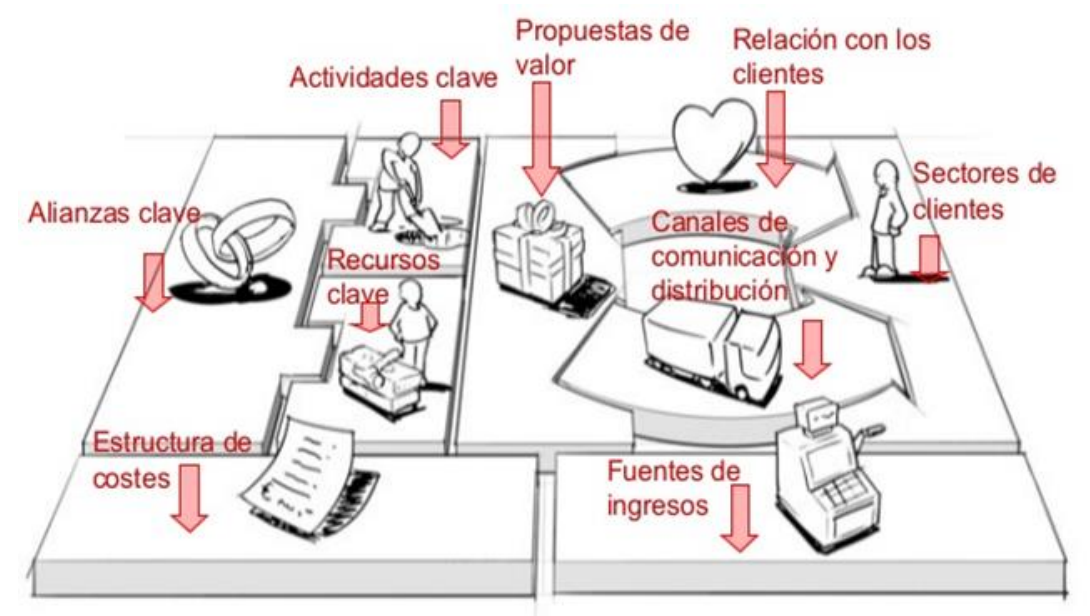

Figura 1. Lienzo Canvas.

Fuente: Plano de los módulos para el lienzo de modelos de negocio, Meriño Córdoba Et al (2018).

- Procedimiento y Aspectos Para Considerar

Como se menciona al inicio, esta herramienta consiste en conectar esquemáticamente nueve módulos para ayudar a desarrollar la estrategia de la empresa. A continuación, se establece la forma de cómo analizar cada módulo para luego poder interrelacionarlos. Si bien es cierto el análisis de cada módulo es individual, la secuencia de análisis lleva su lógica, sintetizando así el plan de negocios.

Balance Score Card (Kaplan, et, 2001): Según Robert Kaplan y David Norton, el BSC es la representación en una estructura coherente, de la estrategia del negocio a través de objetivos claramente encadenados entre sí, medidos con los indicadores de desempeño, sujetos al logro de unos compromisos (metas) determinados y respaldados por un conjunto de iniciativas o proyectos. Un buen Balanced Scocerard debe "contar la historia de sus estrategias", es decir, debe reflejar la estrategia del negocio. 
Proporciona una estructura para transformar la estrategia en acción. Posibilita a través del diagrama causa efecto establecer las hipótesis estratégicas (a través de la secuencia sí /entonces.) Permitiendo anticipar a futuro, como el negocio creará valor para los clientes.

Lo que uno mide, es lo que logrará. Así, si usted mide únicamente el desempeño financiero, solo obtendrá un buen desempeño financiero. Si por el contrario amplía su visión, e incluye medidas desde otras perspectivas, entonces tendrá la posibilidad de alcanzar objetivos que vayan más allá de lo financiero.

El proceso de crear un "Balanced Score card" incluye la determinación de:

1.- Objetivos que se desean alcanzar

2.- Mediciones o parámetros observables, que midan el progreso hacia el alcance de los objetivos

3.- Metas, o el valor específico de la medición que queremos alcanzar

4.- Iniciativas, proyectos o programas que se iniciarán para lograr alcanzar esas metas.

Los diferentes enfoques permiten desarrollar planes y procesos detallados que reflejan los objetivos estratégicos a cumplir, así como las metas a corto y largo plazo, definidos en metodologías prácticas y con indicadores que evalúan la gestión de estos.

\subsubsection{Sistemas de Gestión de calidad}

Un sistema de gestión de calidad (SGC) es un sistema formalizado que documenta procesos, procedimientos y responsabilidades para lograr políticas y objetivos de calidad. Un SGC ayuda a coordinar y dirigir las actividades de una organización para cumplir con los requisitos regulatorios y de los clientes y mejorar su eficacia y eficiencia de forma continua, adicional a ello ISO 9001: 2015, el estándar internacional que especifica los requisitos para los sistemas de 
gestión de calidad es el enfoque más destacado de los sistemas de gestión y se soporta en los documentos que solo sirven para describir el sistema.

La importancia de la calidad solo creció después de la guerra, los japoneses disfrutaron de una revolución de calidad, mejorando su reputación de exportaciones de mala calidad al abrazar por completo la opinión de pensadores estadounidenses como Joseph M. Juran y W. Edwards Deming y cambiar el enfoque de inspección a mejorar todos los procesos de organización a través de las personas que los utilizaron. En la década de 1970, los sectores industriales de EE. UU. Como la electrónica y los automóviles se vieron afectados por la competencia de alta calidad de Japón.

La norma NTC ISO 9001:2015 sistemas de gestión de calidad vienen acompañada de otras normas las cuales ayudan a complementar y entender fácilmente como se puede planificar, implementar y desarrollar un sistema de gestión de la calidad. Este grupo de normas relacionadas con la calidad se conocen como familia de normas, las cuales según Marín (2007) son:

- $\quad$ ISO 9000: Sistemas de Gestión de Calidad Fundamentos, vocabulario.

- ISO 9001: Sistemas de Gestión de Calidad, requisitos, elementos del sistema de calidad, calidad en diseño, fabricación, inspección, instalación, venta, servicio post venta, directrices para la mejora del desempeño.

- $\quad$ ISO 9004: Considera la eficacia y la eficiencia de un Sistema de Gestión de la Calidad.

- $\quad$ ISO 14000: Sistemas de Gestión Ambiental de las Organizaciones.

- Principios ambientales, etiquetado ambiental, ciclo de vida del producto, programas de revisión ambiental, auditorías.

- ISO 19011: Directrices para la Auditoría de los SGC y/o Ambiental A medida que los encargados de la toma de decisiones se involucran más en la implementación 
de la Gestión de calidad total, surgen preguntas sobre qué prácticas de gestión se deben enfatizar, se centra tanto en las prácticas de gestión de la calidad central como en la infraestructura que crea un entorno favorable para su uso. Además, incorpora dos medidas de desempeño de calidad y su papel en el establecimiento y mantenimiento de una ventaja competitiva, así como las relaciones con los proveedores y las actitudes laborales también se relacionaron con algunas de las prácticas centrales de calidad y medidas de desempeño de calidad.

La eficiencia de los sistemas de gestión radia en la evaluación de procesos, la cual no requiere grandes costos o reducciones de calidad. Es importante tener los conocimientos y la experiencia suficientes, así como el potencial técnico cuando se implementan cambios en una organización, para aprovechar las experiencias y buenas prácticas de las empresas exitosas. La mejora del rendimiento no debe limitarse a la implementación de medios de mejora de procesos y aplicación de métodos; es importante observar la influencia de los cambios en la efectividad de los procesos y tomar las medidas de ajuste apropiadas si es necesario (Gitlow et al., 2005).

El impacto del sistema de gestión de la calidad sobre el éxito en la toma de decisiones de gestión importantes, los estudios de este efecto confirmaron que la introducción e implementación del sistema de gestión de la calidad mejora significativamente los objetivos del equipo de gestión en cualquier organización, es por ello que este tipo de sistemas se define como una serie de actividades coordinadas realizadas en una organización para mejorar la eficiencia y la eficacia de su desempeño. Una organización que ha implementado un sistema de gestión de calidad se gestiona con procesos definidos que incluyen procedimientos operativos, pautas o procedimientos escritos, resultantes con productos o servicios de calidad. Implementar el sistema de gestión de calidad en una organización significa establecer y aceptar completamente todas las reglas y principios que establecen el sistema para alinear todos los procesos y actividades 
comerciales, comenzando desde el gerente más alto hasta el empleado ubicado en el lugar más bajo de la organización. Con la implementación del sistema de gestión de calidad también se implementa un concepto completamente nuevo en una organización que requiere consistencia y compromiso de todos los empleados. El término gestión se refiere al control directo de todas las actividades que se llevan a cabo en una organización y son controladas por la administración y brindan la oportunidad de tomar las decisiones correctas en el momento adecuado.

\subsubsection{Principios de la Gestión de la Calidad}

La NTC ISO 9001:2015 se basa en siete principios los cuales se describen a continuación:

ENFOQUE AL CLIENTE: el enfoque hacia los clientes se trata de cumplir con los requisitos del cliente e incluso superar sus expectativas, se reflexiona el principio principal de la gestión de la calidad, favorece al éxito de la organización y algunos de sus beneficios son el aumento del valor para el cliente, incremento de la satisfacción del cliente e incremento de la notoriedad de la organización. (ISO, 2015, p.9)

LIDERAZGO: el liderazgo y los dirigentes en todas las áreas o niveles de la organización crean los propósitos y direccionan a las personas involucradas en el logro de los objetivos de la calidad de la organización. Algunos de sus beneficios son: el aumento de la eficacia y eficiencia la cumplir los objetivos de la calidad; mejora en la coordinación en los procesos de la organización y mejora en la comunicación. (ISO, 2015, p.10)

COMPROMISO DE LAS PERSONAS: el compromiso y la capacidad de las personas que acceden la organización son esenciales para que esta pueda aumentar la capacidad de generar valor y conseguir el logro de los objetivos de la calidad. Algunos de sus beneficios son: mejora de la intuición de los objetivos por parte de las personas y aumento de la estimulación para 
lograrlos; aumento de la participación de las personas en las actividades de mejora y aumento de la confianza y colaboración en toda la organización. (ISO, 2015, p.11)

ENFOQUE A PROCESOS: el sistema de gestión de la calidad se basa en la interrelación de procesos, al entender cómo se formalizan las actividades como procesos que se corresponden y que funcionan como un solo sistema, la organización incrementara su desempeño y asegurara el cumplimiento de los objetivos. Algunos de sus beneficios son: resultados coherentes y previsibles mediante un sistema de procesos alineados; optimización del desempeño mediante la gestión eficaz de proceso y el uso eficiente de los recursos y la reducción de las barreras interdisciplinarias.

MEJORA: las organizaciones que tienen un enfoque hacia la mejora continua mantienen niveles actuales de desempeño y es capaz de reaccionar a los cambios internos y externos y crea nuevas oportunidades para crecer. Algunos de sus beneficios son: mejora del desempeño del proceso, de las capacidades de la organización y de la satisfacción del cliente; aumento de la promoción de la innovación y mejora del enfoque en la investigación y la determinación de la causa raíz seguida de la prevención y acciones correctivas.

TOMA DE DECISIONES BASADA EN LA EVIDENCIA: la toma de decisiones en una organización puede ser decisiva y siempre implica un grado de incertidumbre, por lo general implica varios tipos y entradas de información. Es importante tener en cuenta las relaciones causa y efecto y las consecuencias no previstas, analizando los datos y evidencias se tendrá mayor objetividad y confianza en la toma de decisiones. Algunos de sus beneficios para la organización son: mejora de los procesos de toma de decisiones; mejora de la evaluación del desempeño del proceso y de la capacidad de lograr los objetivos y aumento de la capacidad de revisar, cuestionar y cambiar las opiniones y las decisiones. (ISO, 2015 p 14). 


\subsubsection{Sistema integrado de Gestión}

Es una herramienta de gestión que contribuye a aumentar el desempeño institucional a través de sus procesos, se enfoca principalmente en las personas, los resultados, la integralidad y la simplificación, lo cual se ve reflejado en el mejoramiento continuo de la calidad de los servicios de la Entidad que lo adopta, en el cumplimiento de los objetivos y expectativas de los clientes usuarios, partes interesadas y grupos de interés.

Este tipo de integraciones conjugan una serie de estrategias que permiten fusionar metodologías en pro de agilizar procesos es el caso de los sistemas entorno a la calidad, seguridad y salud en el trabajo, el medio ambiente, la protección de información entre otros que hacen parte de la ISO en las diferentes normas que lo caracterizan como ISO 9001, ISO 14001, OHSAS 18001 e ISO 27001 respectivamente, pero no es la única.

En este orden, los colaboradores o Stakeholders, cumplen un papel fundamental en la organización, puesto la integración de los sistemas de gestión demandan desempeños específicos, así como metas y objetivos claros que coadyuven a mejorar los servicios y procesos desarrollado, en otros ejercicios administrativos, pueden evidenciarse situaciones de acoplamiento del cambio, es decir una integración parcial, es decir que la integración de sistemas esté formada solo por dos de los sistemas de gestión que se nombraron al comienzo.

\subsection{Marco conceptual}

\subsubsection{Modelos Gerenciales}

Teniendo en cuenta que la mayoría de los modelos de gestión empresarial trabajan con sistemas informáticos y tics, el adelanto de estas herramientas ha permitido que se encuentre en 
un nivel muchísimo más alto la eficacia con la cual los recursos humanos de una empresa trabajan, colocándolos en un lugar especial para que la empresa pueda lograr definir cada uno de los objetivos planteados.

Los modelos de gestión son muy diferentes entre sí, pero es importante destacar que todos y cada uno de ellos poseen niveles de eficiencia que deben aplicarse según el tipo de empresa en la que se practique la gestión correspondiente. (Jörgensen, T. H. \& Remmen, A. \& Mellado, M. D.2006)

\subsubsection{Concepto de planificación.}

Planear es sin duda de las actividades características del mundo contemporáneo, la cual se vuelve más necesaria ante la creciente interdependencia y rapidez que se observa en el acontecer de los fenómenos económicos, políticos, sociales y tecnológicos.

"La planeación es el proceso de establecer objetivos y escoger el medio más apropiado para el logro de estos antes de emprender la acción”. Russio (2015). La Planeación es la función que tiene por objetivo fijar el curso concreto de acción que ha de seguirse, estableciendo los principios que habrán de orientarlo, la secuencia de operaciones para realizarlo y las determinaciones de tiempo y números necesarios para su realización. Esta se constituye entonces en uno de los elementos principales de la administración en la teoría clásica propuesta por Luther Gulick.

\subsubsection{Concepto de Planeación Estratégica (Leiber Alberto, sf).}

Planeación estratégica que fue nombrado a partir de la década de los años setenta haciendo referencia a técnicas de planeación de productos y mercados, centrándose en términos de 
administración comúnmente nombrados de portafolio (el conjunto de inversiones y productos de una empresa o conglomerado) y posición competitiva de la empresa en el mercado.

La planeación está relacionada con el futuro. Un proceso de planificación implica diferentes grados de futuro. Algunas partes de la organización requieren planificación durante muchos años en el futuro, mientras que otras requieren planificación durante un período corto solamente.

La planeación estratégica puede definirse como el proceso de determinación de los objetivos de la organización y los recursos que se utilizarán para alcanzar estos objetivos, como también las políticas que rigen la adquisición, utilización y disposición de estos recursos.

Algunos ejemplos de planeación estratégica en una organización son la diversificación de negocios en nuevas líneas, la tasa de crecimiento planificada en ventas, el tipo de productos que se ofrecerán, etc. La planificación estratégica abarca todas las áreas funcionales de los negocios y se ve afectada dentro de los plazos existentes y de largo plazo, marco de factores económicos, tecnológicos, sociales y políticos.

También implica el análisis de varios factores ambientales, particularmente con respecto a cómo una organización se relaciona con su entorno. En general, para la mayoría de las organizaciones, el período de planificación estratégica oscila entre tres y cinco años.

El proceso de planeación estratégica consta de los siguientes pasos:

- Determinación de la misión y los objetivos:

La planeación estratégica comienza con la determinación de la misión de la organización. Los objetivos principales para los cuales se ha establecido la organización deben estar claramente definidos. La planificación estratégica se refiere a la relación a largo plazo de una organización con su entorno externo. Por lo tanto, la misión comercial debe ser fijada en términos de impacto social de la organización (Cepal, 2012). 
- Análisis ambiental:

Con el fin de identificar las oportunidades y amenazas, se analiza el entorno externo de la organización. Se prepara una lista de factores importantes que pueden afectar las actividades de la organización (Cepal, 2012).

- Autoevaluación:

En el siguiente paso, se analizan las fortalezas y debilidades de la organización. Tal análisis permitirá a la empresa capitalizar sus fortalezas y minimizar sus debilidades. La empresa puede utilizar las oportunidades externas concentrándose en su capacidad interna. Al unir sus fortalezas con las oportunidades ambientales, una empresa puede enfrentar la competencia y lograr el crecimiento (Cepal, 2012).

- Toma de decisiones estratégicas:

Luego, se generan y evalúan alternativas estratégicas. Después de eso, se realiza una elección estratégica para reducir la brecha de rendimiento. La organización debe seleccionar la alternativa que mejor se adapte a sus capacidades. Por ejemplo, para crecer, una empresa puede ingresar a nuevos mercados o desarrollar nuevos productos o vender más en los mercados actuales (Cepal, 2012).

\subsubsection{Concepto básico de estrategia.}

La estrategia de una empresa determina y revela el propósito de la organización en cuanto a sus objetivos a largo plazo, programas de acción y prioridades en la asignación de recursos. Intenta lograr una ventaja sostenible a largo plazo en cada uno de los negocios (caso de que hubiere más de uno) respondiendo a las oportunidades, amenazas del entorno y a las fuerzas y debilidades del sistema empresarial (Cepal, 2012). 
Su propósito y alcance se ajusta a concretar una visión clara del futuro, a procurar que la disparidad entre recursos y metas sea un desafío y no una limitación, y a facilitar ser el ganador en el mercado.

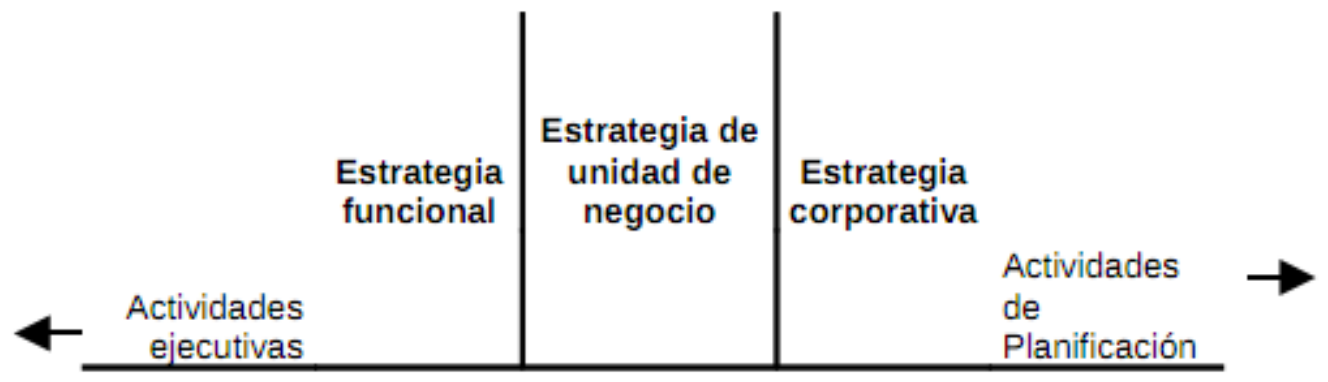

Figura 2. Niveles de estrategia de la empresa

Fuente: Elaboración propia.

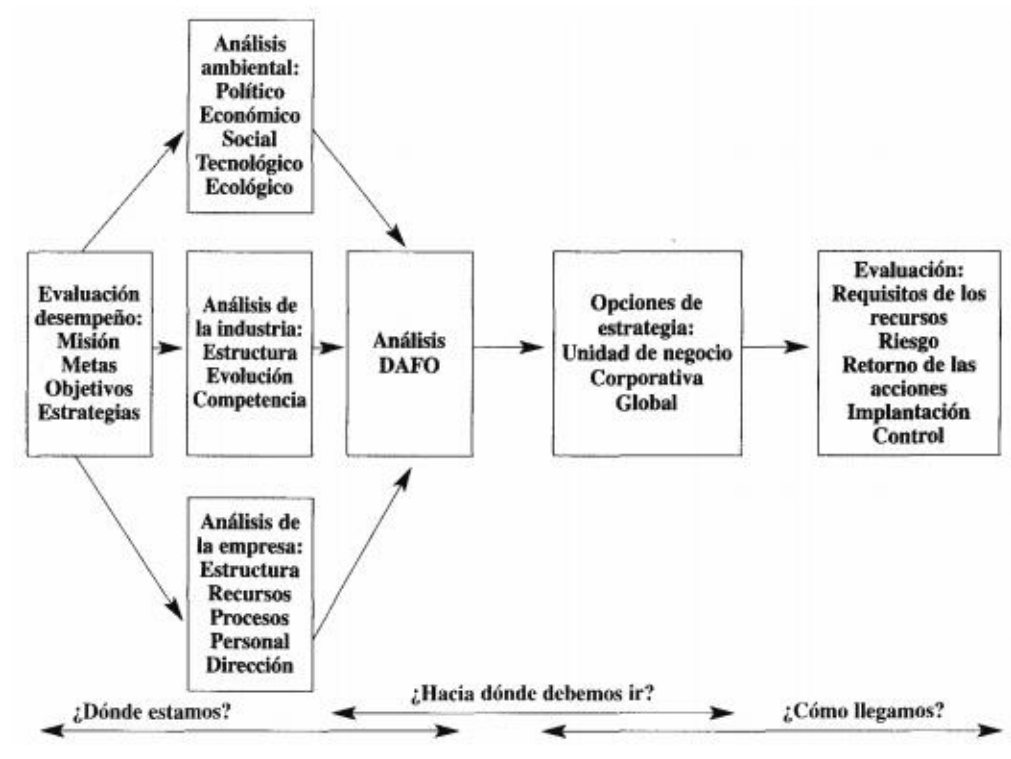

Figura 3. Pasos del pensamiento estratégico

Fuente: Elaboración propia 


\subsubsection{Etapas del proceso de administración estratégica.}

El proceso de gestión estratégica es más que solo un conjunto de reglas a seguir. Es un enfoque filosófico para los negocios. La alta gerencia debe pensar estratégicamente primero, luego aplicar ese pensamiento a un proceso. El proceso de gestión estratégica se implementa mejor cuando todos en el negocio entienden la estrategia. Las cinco etapas del proceso son la fijación de objetivos, el análisis, la formación de estrategias, la implementación de estrategias y la supervisión de estrategias. (Díaz Bernardo, 2007)

El objetivo del establecimiento de objetivos es aclarar la visión de su negocio, esta etapa consiste en identificar tres facetas clave: Primero, definir objetivos a corto y largo plazo. Segundo, identificar el proceso de cómo lograr su objetivo. Finalmente, personalizar el proceso para su personal, otorgue a cada persona una tarea con la que pueda tener éxito. Típicamente, el paso final en esta etapa es escribir una declaración de misión que comunique sucintamente sus objetivos tanto a sus accionistas como a su personal.

\section{Formulación de la estrategia:}

\section{- Búsqueda de Valores:}

La búsqueda de valores constituye un examen de los valores actuales de la organización, su filosofía de trabajo, los supuestos que comúnmente utiliza en sus operaciones, la cultura organizacional predominante y finalmente, los valores de los grupos de interés en su futuro.

\section{- Valores Personales}

Una parte importante implica un examen de los valores personales de los integrantes de la empresa. Definido como "una convicción permanente de que una forma específica de conducta o estado final de existencia se prefiere de manera personal o social ante una forma opuesta o contraria de conducta o condición final de existencia". 


\section{- Formular la misión y visión Empresarial}

La formulación de la misión implica desarrollar un enunciado claro del tipo de negocio en el que se halla la compañía (o planea estar): una definición concisa del propósito que trata de lograr en la sociedad y/o en la economía. Al formular su misión, una empresa debe responder a cuatro preguntas básicas:

- ¿Qué función(es) desempeña la organización?

- ¿Para quién desempeña esta(s) función(es)?

- ¿De qué manera trata de desempeñar la (las) función(es)?

- ¿Por qué existe esta organización?

- La matriz de perfil competitivo

La identificación y evaluación de los objetivos, estrategias, debilidades y fortalezas de nuestros competidores con frecuencia se consideran la porción más importante del proceso de formulación de estrategias. La matriz de perfil competitivo es, por tanto, una herramienta importante de "entrada" que resume información decisiva sobre los competidores. Para el desarrollo de una matriz de perfil competitivo las estrategias deben usar, en lo posible, información objetiva en la escogencia de factores claves, decisiones sobre ponderaciones apropiadas y asignación de clasificaciones. (Russi, 2011).

\subsection{Marco normativo legal}

- Ambiental: Se está implementando la norma NTC - ISO 14001: La norma ISO 14001 proporciona a las organizaciones un marco con el que proteger el medio ambiente y responder a las condiciones ambientales cambiantes, siempre guardando el equilibrio con las necesidades 
socioeconómicas. Se especifican todos los requisitos para establecer un Sistema de Gestión Ambiental eficiente, que permite a la empresa conseguir los resultados deseados.

- $\quad$ Seguridad y Salud en el Trabajo: Se está implementando bajo el Decreto 1072 de 2015; esta norma permite definir las directrices de obligatorio cumplimiento para implementar el Sistema de -SG-SST, que deben ser aplicadas por todos los empleadores públicos y privados, los contratantes de personal bajo modalidad de contrato civil, comercial o administrativo, las organizaciones de economía solidaria y del sector cooperativo, las empresas de servicios temporales y tener cobertura sobre los trabajadores dependientes, contratistas, trabajadores cooperados y los trabajadores en misión.

- El Decreto 1083 de 2015, Único Reglamentario del Sector de Función Pública, modificado por el Decreto 1499 de 2017, desarrolló el Sistema de Gestión, creado en el artículo 133 de la Ley 1753 de 2015, el cual integró los Sistemas de Desarrollo Administrativo y de Gestión de la Calidad.

- Resolución 1471 de 2013: Por la cual se adopta el Sistema Integrado de Gestión SIG en el Servicio Nacional de Aprendizaje - SENA, se conforman sus instancias a nivel Nacional, se definen sus funciones y se establecen otras disposiciones.

\section{$3 \quad$ Metodología}

\subsection{Tipo de Investigación}

El diseño de investigación del presente documento se basará en un enfoque cuantitativo y con un estudio descriptivo, ya que se pretende evaluar a través de un diagnostico la efectividad del 
SIGA en el Centro de Gestión Administrativa y Fortalecimiento Empresarial - CEGAFE Boyacá; formulando con dichos resultados un análisis y estrategias de mejoramiento en la adopción eficiente de los sistemas integrados.

Los datos se recolectan con la finalidad de analizarlos para comprenderlos y responder así a preguntas de investigación o generar conocimiento. La recolección de datos ocurre completamente en los ambientes naturales y cotidianos de los sujetos. Esta clase de datos es muy útil para comprender los motivos subyacentes, los significados y las razones internas del comportamiento humano. (Hernández, Fernández \& Baptista, 2003). Citado por (Monge, 2010) lo cual es fundamental dentro de las organizaciones empresariales, o como bien lo define Orozco (1996) la investigación cualitativa es un proceso de indagación de un objeto al cual el investigador accede a través de interpretaciones sucesivas, con la ayuda de instrumentos y técnicas, que le permiten involucrarse con el objeto para interpretarlo de la forma más integral posible (Monge, 2010), como se desarrolla en el presente estudio a partir de los saberes de las tres áreas de análisis (Procesos Estratégicos, de soporte y misionales).

\subsubsection{Método de investigación.}

El método para utilizar en la presente investigación es inductivo, en el cual se diseñará un instrumento de verificación - cuestionario escala Likert que permita a través de lista de chequeo verificar la efectividad de la integración y los procesos del SIGA en el CEGAFE, generando con ello, una conclusión general del estado actual de dicha integración frente a los indicadores de calidad. Diseño es no experimental, transeccional descriptivo, según Hernández et al. (2010) refirieron que el diseño viene a ser el "Plan o estrategia que se desarrolla para obtener la información que se requiere en una investigación" (p. 162) 
Por otro lado, debe definirse que el alcance del estudio de caso se basa en lo descriptivo puesto que estos estudios son más focalizados que los casos explicativos, su propósito es dar cuenta de una situación problemática en términos de una lógica centrada en un análisis primario del sujeto/objeto de estudio, (Díaz De Salas Sergio Alfaro, 2011)

\subsubsection{Población y muestra}

El Centro de Formación de acuerdo con su perfil empresarial ocasionalmente imparte formación titulada los días domingos a grupos que pertenecen a convenios según disposición de tiempo de los aprendices en formación.

El Centro de gestión Administrativa y Fortalecimiento Empresarial, desarrolla sus acciones de formación enfocado principalmente en la línea CLIENTE, que concentra su tecnología medular, de igual forma realiza procesos en líneas de la Información y de las Comunicaciones, Gestión de la Información, Producción y Transformación y Diseño, todas estas apoyadas por las Redes de Gestión Administrativa y Servicios Financieros, Información Diseño y Desarrollo de Software, Servicios Turísticos, Investigación, Planeación y Desarrollo de Mercados y Medios de Comunicación comercial, Servicios de Salud, Servicios Turísticos, Ventas y Comercialización y Objetos Artesanales.

Tabla 1. Personal del Centro de Formación

PERSONAL

\begin{tabular}{cc|}
\hline Planta & 46 \\
Contratistas & 303 \\
TOTAL & 349 \\
\hline
\end{tabular}

Fuente: CEGAFE. 2018.

\section{NÚMERO}

303 
Para la selección de la muestra solo se tuvieron en cuenta el personal de planta, específicamente los líderes de dependencias, puesto que los contratistas son transitorios y no ofrecen información pertinente por la rotación de estos.

- Selección de la muestra

Se aplica la siguiente formula:

Cálculo de Muestras para Poblaciones Finitas

\begin{tabular}{l|r}
\hline \multicolumn{2}{|c|}{ INGRESO DE PARAMETROS } \\
\hline \multirow{2}{*}{$\begin{array}{l}\text { Tamaño de la Población (N) } \\
\text { Error Muestral (E) }\end{array}$} \\
\cline { 2 - 2 } Proporción de Éxito (P) & $\mathbf{4 6}$ \\
\cline { 2 - 2 } Proporción de Fracaso (Q) & $\mathbf{0 , 0 5}$ \\
Valor para Confianza (Z) (1) & $\mathbf{0 , 9}$ \\
& $\mathbf{0 , 1}$ \\
& $\mathbf{1 , 9 5}$ \\
(1) Si: & $\mathbf{Z}$ \\
$\quad$ Confianza el 99\% & 2,32 \\
$\quad$ Confianza el 97.5\% & 1,96 \\
$\quad$ Confianza el 95\% & 1,65 \\
$\quad$ Confianza el 90\% & 1,28
\end{tabular}

Formulas para el cálculo de muestras

\begin{tabular}{|c|c|}
\hline \multicolumn{2}{|l|}{ Muestra para Poblaciones Infinitas } \\
\hline Variable & Atributo \\
\hline $\mathrm{n}=\frac{\mathrm{s}^{2} * \mathrm{z}^{2}}{\mathrm{E}^{2}}$ & $\mathrm{n}=\frac{\mathrm{z}^{2} * \mathrm{P} * \mathrm{Q}}{\mathrm{E}^{2}}$ \\
\hline \multicolumn{2}{|l|}{ Muestra para Poblaciones Infinitas } \\
\hline $\mathrm{n}=\frac{\mathrm{s}^{2} * \mathrm{z}^{2} * \mathrm{~N}}{\mathrm{~N} * \mathrm{E}^{2}+\mathrm{z}^{2} * \mathrm{~s}^{2}}$ & $\frac{\mathrm{P} * \mathrm{Q} * \mathrm{Z}^{2} * N}{\mathrm{~N}^{*} \mathrm{E}^{2}+\mathrm{z}^{2} * \mathrm{P} * \mathrm{Q}}$ \\
\hline
\end{tabular}

$$
\begin{aligned}
& S^{2}=\text { Varianza } \\
& Z=\text { Valor normal } \\
& E=\text { Error } \\
& N=\text { Población } \\
& P=\text { Proporción } \\
& Q=1-P
\end{aligned}
$$

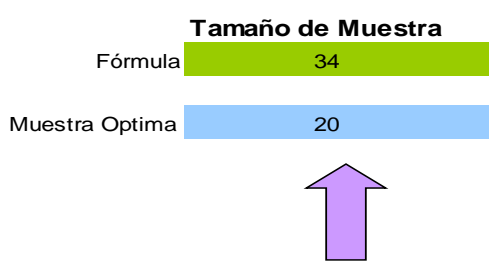

Figura 4. Cálculo de muestras para poblaciones finitas

La población para encuestar para el propósito del presente estudio es de 20 personas. 


\subsection{Fuentes de recolección de información}

En el transcurso del estudio se realizaron fuentes primarias y fuentes secundarias en algunos contextos internas y en otras externas como se refleja a continuación Entendiéndose por fuentes primarias aquellas que son adquiridas de forma directa por el investigador o que constituyen la información de primera mano y las secundarias aquellas que tienen un tratamiento o proceso de transformación por otros autores o como lo define Sampieri lista, compilaciones y resúmenes de referencias o fuentes primarias publicadas en un área de conocimiento en particular, las cuales comentan artículos, libros, tesis, disertaciones y otros documentos especializados. (Roberto Hernando Sampieri, 2014)

\subsubsection{Fuentes primarias internas}

Las fuentes primarias son definidas como las relacionadas con expertos de cada una de las áreas que se estaban analizando dentro de la organización, observación de campo en los procesos desarrollados, entre otros, que contribuirán con la narración y el análisis de las diferentes fases desarrolladas dentro del mismo y que permitirán dar respuesta a las preguntas de reflexión planteadas.

\subsubsection{Fuentes secundarias internas}

En el desarrollo del estudio se encuentra como parte fundamental la revisión documental de la organización que permite desarrollar o explicar algunos apartes como los componentes estratégicos de la organización, planes institucionales, manuales entre otros que permiten revisar 
adicionalmente estructuras del recurso humano, estructuras organizacionales, estudios realizados en la empresa entre otros como se observa en las fichas metodológicas correspondientes.

\subsubsection{Fuentes secundarias externas}

Se puede mencionar que una de las fuentes más importantes que permitirá la construcción del estudio será la documentación revisada en bases de datos académicas, entidades públicas, informes coyunturales entre otros documentos que fortalecieron tanto la fase teórica como la analítica del proceso de construcción del estudio.

\subsection{Herramientas de Análisis y Recolección de la Información}

En los procesos de investigación científica existen diferentes mecanismos de recolección de información dependiendo de si son estudios cualitativos o cuantitativos. Es así que para el desarrollo del estudio de caso presentado se han desarrollado diversas herramientas que han contribuido para la recolección y análisis de la información.

Sin embargo, a continuación, se hace un esbozo en términos generales de las herramientas utilizadas en el desarrollo del proyecto:

\subsubsection{Cuestionario}

El cuestionario es una herramienta utilizada por el investigador para indagar sobre temas precisos que le permiten realizar análisis cuantitativos en la investigación, pueden desarrollarse con preguntas abiertas, cerradas, escalonadas entre otras. Así, se define teóricamente el cuestionario como un conjunto de preguntas respecto de una o más variables a medir que debe 
ser congruente con el planteamiento del problema e hipótesis (Brace, 2013) citado por (Roberto Hernando Sampieri, 2014), para el caso de la construcción de estudio de caso que permita responder a las tres preguntas de reflexión establecidas. Apéndice A y Apéndice B carta validación instrumento.

\section{Estado de implementación de las políticas (Calidad, Ambiental, Seguridad en el trabajo e información) en los subsistemas del SIGA}

Dentro del procedimiento del análisis del cumplimiento de la herramienta de gestión que contribuye a desarrollar el desempeño institucional, SIGA del SENA seccional Boyacá CEGAFE, se implementó un cuestionario estructurado por gestiones estratégicas a través de sus procesos, lo cual se ve reflejado en el perfección continuó de la calidad de los servicios que ofrece y las necesidades, beneficios e intereses de los clientes - usuarios, partes interesadas y grupos de beneficio, ver Apéndice A Cuestionario aplicado.

\subsection{Articulación SIGA y Planeación Estratégica}

Implementar un sistema de gestión de calidad en una organización significa establecer y aceptar completamente todas las reglas y principios que establecen el sistema para alinear todos los procesos y actividades comerciales, comenzando desde el gerente más alto hasta el empleado en el lugar más bajo de la organización. Con la implementación del sistema de gestión de la calidad también se está implementando un concepto completamente nuevo en la organización que requiere que todas las partes respeten completamente a la bruja. El término gestión se refiere 
al control directo de todas las actividades que se llevan a cabo en una organización, y tiene la capacidad de controlar completamente la organización. En este contexto, la administración no se aplica a las personas sino a la coordinación de todas las actividades en la organización, comenzando desde el gerente de la mejor posición. La toma de decisiones por parte de la alta dirección debe estar en correlación directa con el sistema implementado y sus requisitos, es decir, correlacionado con la política de calidad establecida. (Veliz, 2006).

Las demandas que deben afrontar en la actualidad las empresas han dado un fuerte impulso al posicionamiento de la comunicación como una estrategia importante, transversal en la organización, el SENA pensando en esta premisa, se enfoca en el Modelo Integrado de Planeación y Gestión Versión 2, el cual nace como una iniciativa del Gobierno Nacional incluida en el artículo 133 del Plan Nacional de Desarrollo 2014 - 2018, que ordena la integración del Sistema de Desarrollo Administrativo y del Sistema de Gestión de la Calidad en un único modelo de gestión, articulado con el Sistema de Control Interno, como se muestra en la figura 4.

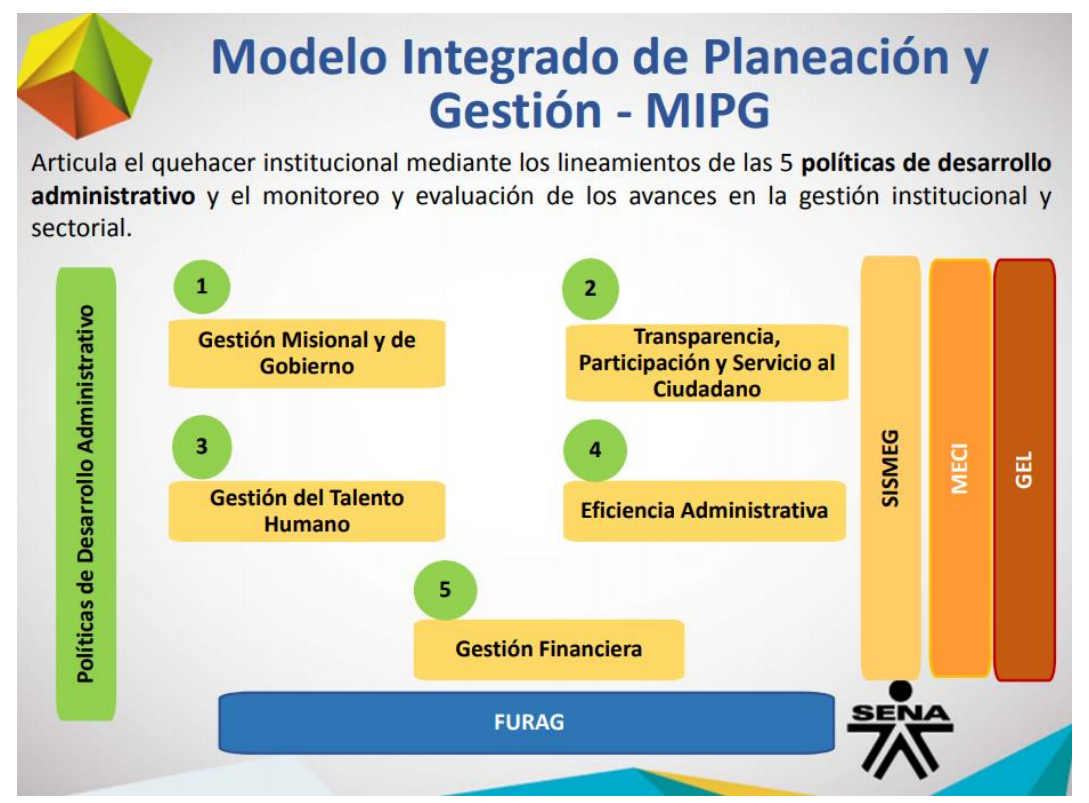

Figura 5. Modelo integrado de planeación

Fuente: SENA (2018). 
Para adoptar este tipo de modelo debe tenerse en cuenta las siguientes herramientas:
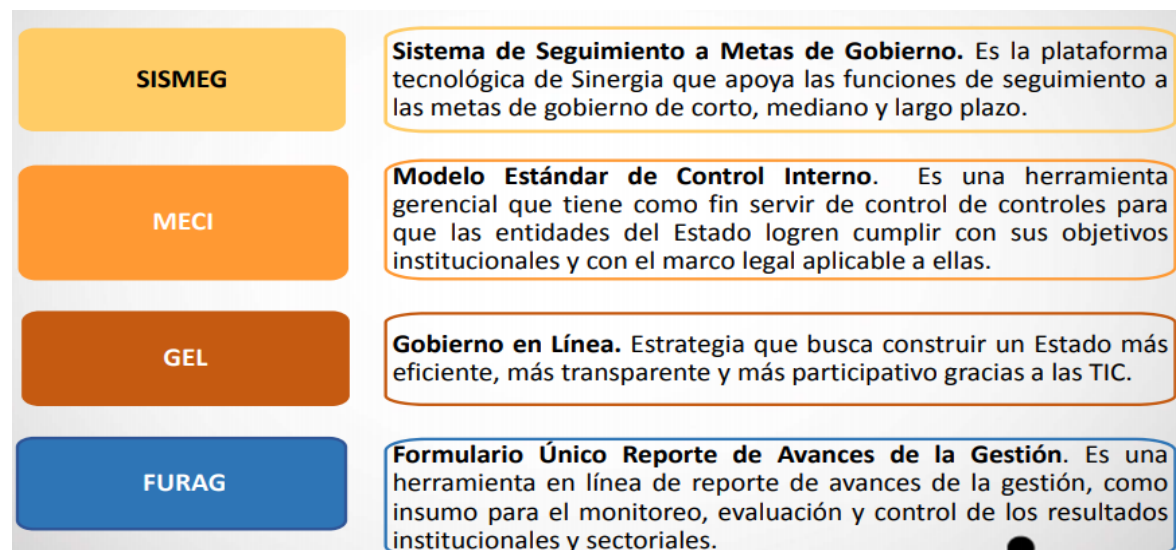

Sistema de Seguimiento a Metas de Gobierno. Es la plataforma tecnológica de Sinergia que apoya las funciones de seguimiento a las metas de gobierno de corto, mediano y largo plazo.

Modelo Estándar de Control Interno. Es una herramienta gerencial que tiene como fin servir de control de controles para que las entidades del Estado logren cumplir con sus objetivos institucionales y con el marco legal aplicable a ellas.

Gobierno en Línea. Estrategia que busca construir un Estado más eficiente, más transparente y más participativo gracias a las TIC.

Formulario Único Reporte de Avances de la Gestión. Es una herramienta en línea de reporte de avances de la gestión, como insumo para el monitoreo, evaluación y control de los resultados institucionales y sectoriales.

Figura 6. Modelo integrado de planeación

Fuente: Sena (2018). Consultado de:

http://compromiso.sena.edu.co/index.php?text=inicio\&id $=28$

Tabla 2. Principales Elementos del Sistemas de Desarrollo Administrativo, de Gestión de la

Calidad y de Control Interno.

\section{SISTEMA DE \\ DESARROLLO \\ ADMINISTRATIVO}

\begin{tabular}{|c|c|c|c|}
\hline Definición & $\begin{array}{l}\text { Conjunto de políticas, } \\
\text { estrategias, metodologías, } \\
\text { técnicas y mecanismos de } \\
\text { carácter administrativo y } \\
\text { organizacional para la gestión } \\
\text { y manejo de los recursos } \\
\text { humanos, técnicos, } \\
\text { materiales, físicos, y } \\
\text { financieros de las entidades } \\
\text { de la Administración Pública. }\end{array}$ & $\begin{array}{l}\text { Herramienta de gestión } \\
\text { sistemática y transparente } \\
\text { que permita dirigir y evaluar } \\
\text { el desempeño institucional, } \\
\text { en términos de calidad y } \\
\text { satisfacción social en la } \\
\text { prestación de los servicios a } \\
\text { cargo de las entidades } \\
\text { públicas. }\end{array}$ & $\begin{array}{l}\text { Sistema integrado por el } \\
\text { esquema de organización y el } \\
\text { conjunto de los planes, } \\
\text { métodos, principios, normas, } \\
\text { procedimientos y } \\
\text { mecanismos de verificación } \\
\text { y evaluación adoptados por } \\
\text { una entidad. }\end{array}$ \\
\hline Propósitos & $\begin{array}{l}\text { El Sistema de Desarrollo } \\
\text { Administrativo está orientado } \\
\text { a fortalecer la } \\
\text { administrativa } \\
\text { capacidad }\end{array}$ & $\begin{array}{l}\text { El Sistema de Gestión de la } \\
\text { calidad es una herramienta } \\
\text { de gestión sistemática y } \\
\text { transparente que permita }\end{array}$ & $\begin{array}{lll}\text { Procurar que todas las } \\
\text { actividades, operaciones } & \mathrm{y} \\
\text { actuaciones, así como } & \text { la } \\
\text { administración } & \text { de } & \text { la }\end{array}$ \\
\hline
\end{tabular}

\section{SISTEMA DE GESTIÓN SISTEMA DE CONTROL DECALIDAD INTERNO}


desempeño institucional, de dirigir y evaluar el información y los recursos, conformidad con la desempeño institucional. se realicen de acuerdo con reglamentación que para tal las normas constitucionales y efecto expida el Gobierno legales dentro de las políticas Nacional. trazadas por la dirección y en atención a las metas $\mathrm{u}$ objetivos previstos.

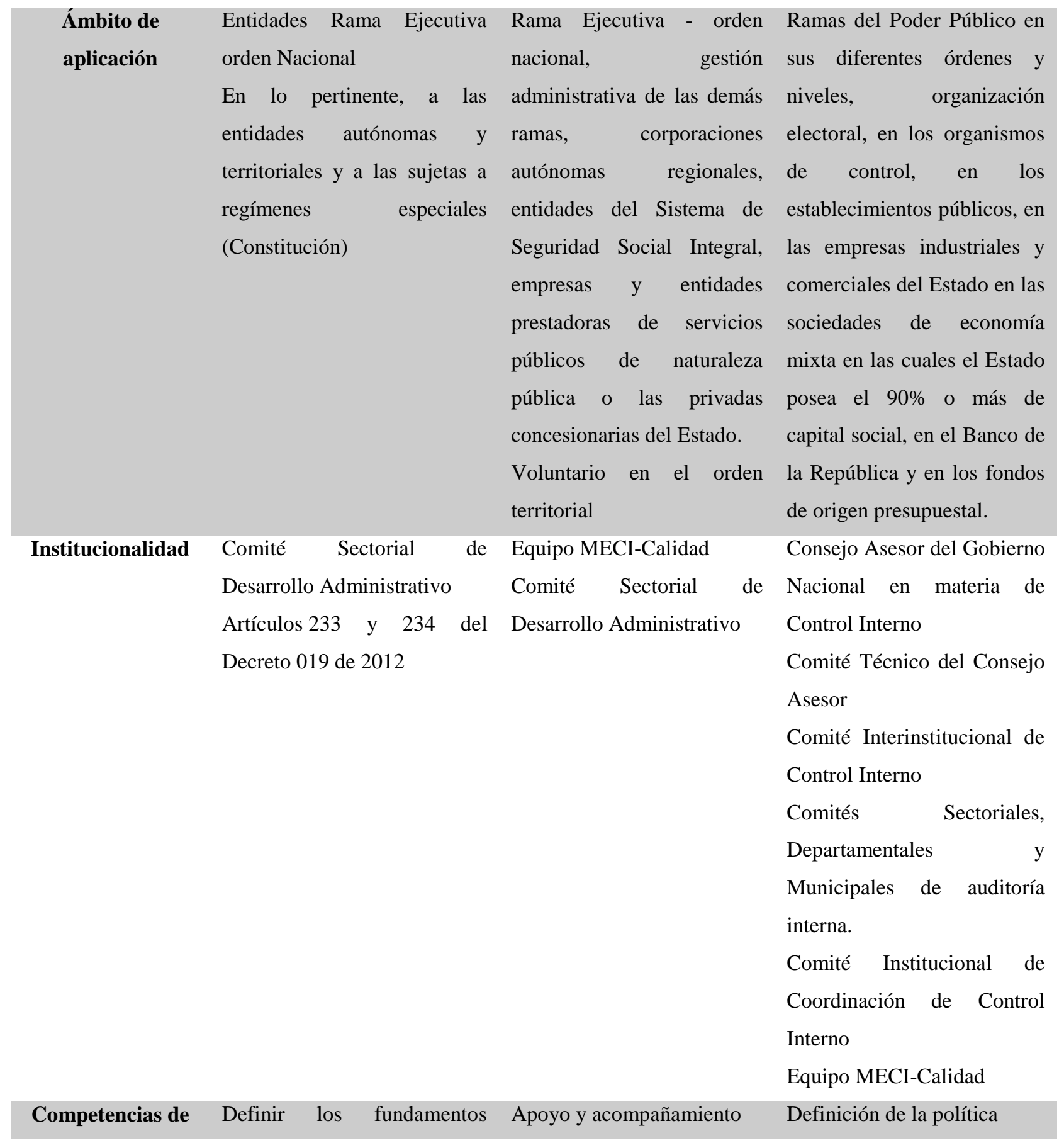




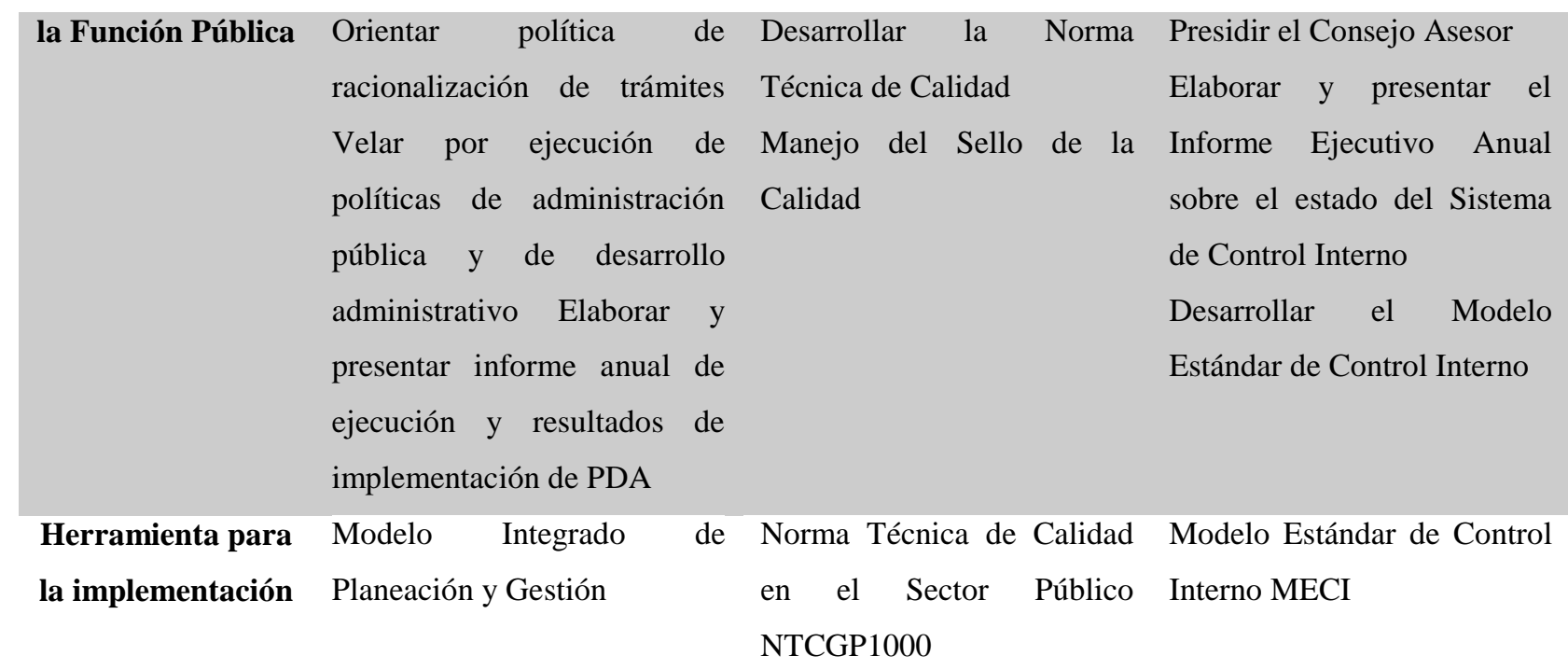

Fuente: SENA 2015.

Una vez establecidos los elementos fundamentales del SIGA, se aplicó un instrumento el cual pretendía determinar el conocimiento por dependencias del estado de implementación de las políticas (calidad, ambiental, seguridad en el trabajo e información) en los subsistemas de este, a través de un cuestionario estructurado, se obtuvo las siguientes respuestas, a lo largo de las cuales se pudo evidenciar las diferentes falencias administrativas en términos de conocimiento y seguimiento. 


\subsection{Resultados de la implementación}

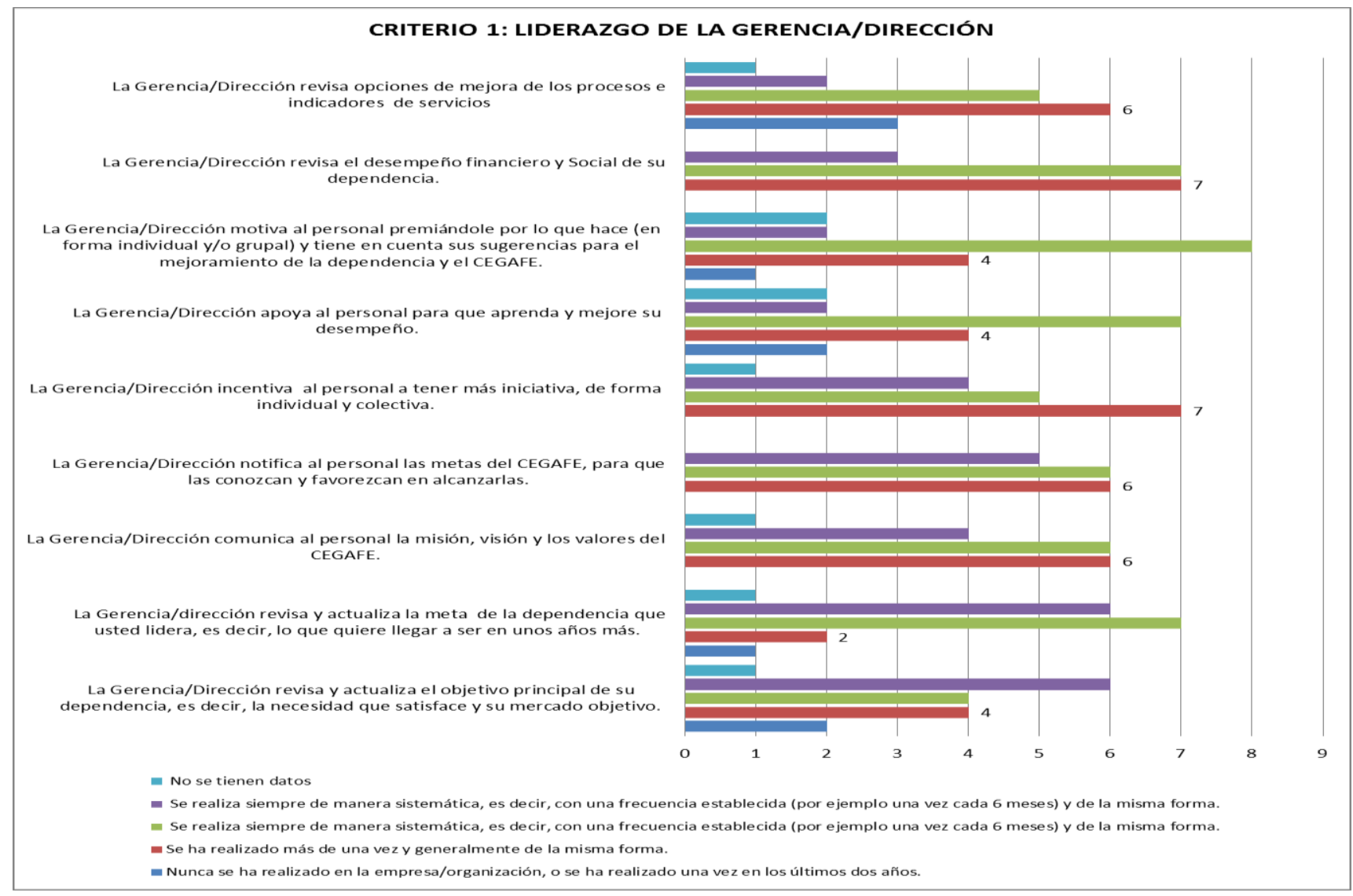

Figura 7. Liderazgo de la Gerencia / dirección

Fuente: Autor.

Teniendo en cuenta que el Sistema Nacional de Aprendizaje -SENA, adoptó un sistema de Gestión y control que le permite centralizar los diferentes reportes de sus diferentes dependencias y sedes circunscritas, este es el caso del Centro de Gestión Administrativa y Fortalecimiento Empresarial - CEGAFE Boyacá, que a través del SENA se ha definido como herramienta para fortalecer su gestión y facilitar el logro de los objetivos institucionales, la implementación e integración de los sistemas de gestión basados en estándares internacionales, sin embargo, en la práctica este tipo de subprocesos no son atendidos de acuerdo a lo planteado 
en el sistema de control, es por ello que al indagar a líderes de área sobre la pertinencia de la implementación, los resultados se allegan a partir de los procesos misionales del centro, obteniendo la percepción del cumplimiento de los mismos en el desarrollo de la actividad de formación, de igual forma se aplicó un instrumento estructurado de acuerdo al SIGA, con base en los lineamientos del SGQ, buscando obtener información de fuentes primarias.

Dentro de la percepción de los Líderes de área, el criterio de liderazgo en la implementación de este tipo de sistemas de gestión, posee diferentes calificaciones siendo la más importante el Proceso Direccionamiento Estratégico por parte de la gerencia, sin embargo, en el concepto sobre si la Gerencia/Dirección comunica al personal la misión, visión y los valores del CEGAFE., que tan pertinente es su evaluación y seguimiento, las respuestas variaron puesto se realiza siempre de manera sistemática, es decir, con una frecuencia establecida (por ejemplo una vez cada 6 meses) y de la misma forma, pero sin que este tenga un impacto en el mejoramiento continuo de una comunicación asertiva, fluida y constructiva, por el contrario, existen falencias de estructura y estrategia. 


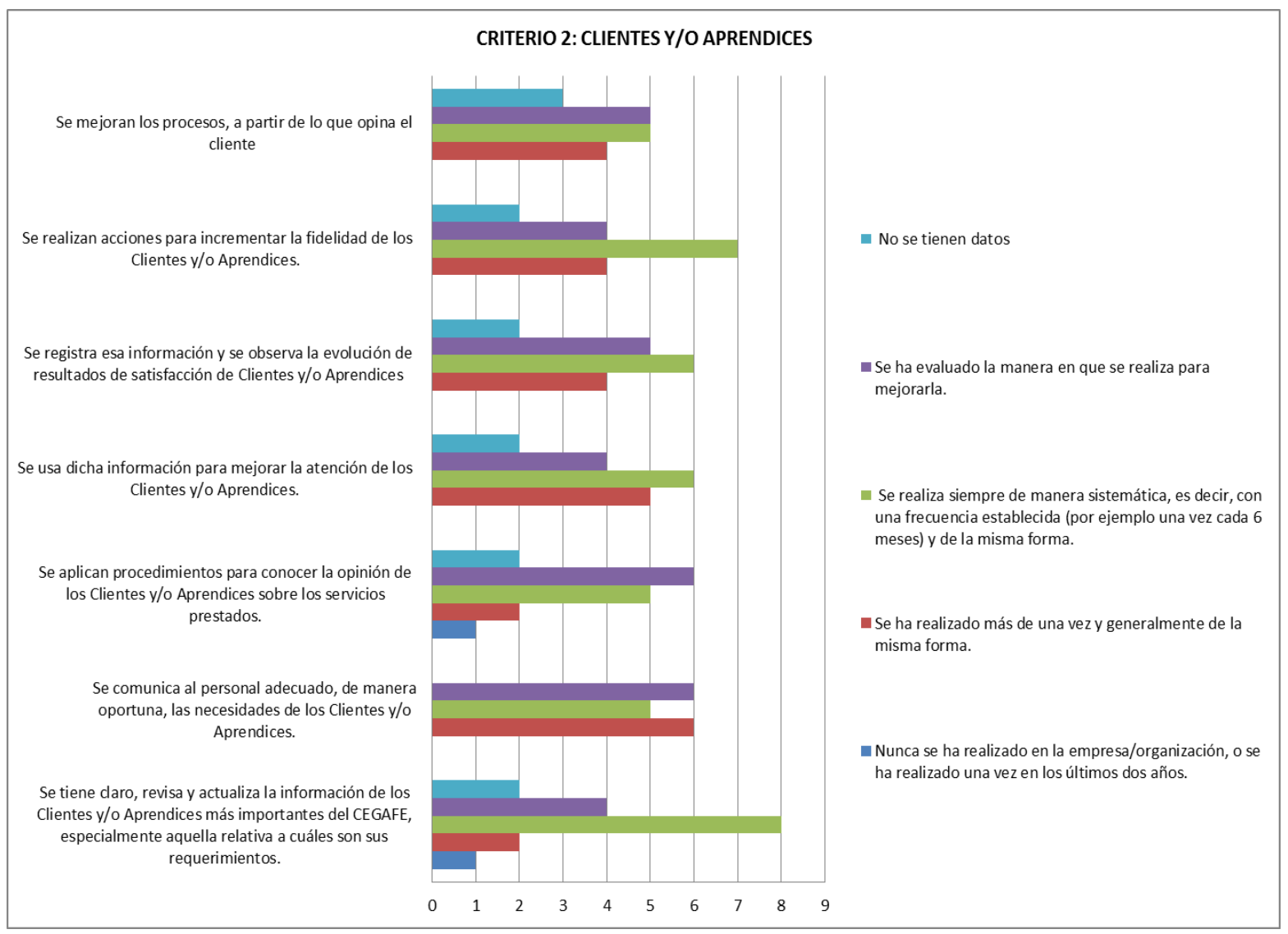

Figura 8. Criterio Clientes Y/o aprendices

Fuente: Autor.

En el criterio de Clientes y /o aprendices, ante la pregunta del mejoramiento de los procesos, a partir de lo que opina el cliente y/o aprendiz, los líderes de área expresaron que dentro del proceso de la revisión y actualización de la información de los Clientes y/o Aprendices más importantes del CEGAFE, especialmente aquella relativa a cuáles son sus requerimientos de los ejes articuladores del Sistema Integrado de Gestión y que tiene como propósito fundamental mantener y fortalecer la gestión, sin embargo, esta revisión se realiza siempre de manera sistemática, es decir, con una frecuencia establecida (por ejemplo una vez cada 6 meses) y de la misma forma, pero nuevamente requiere de un consenso para mejorar teniendo en cuenta la opinión del aprendiz, proveedor y cliente en general del Centro. 


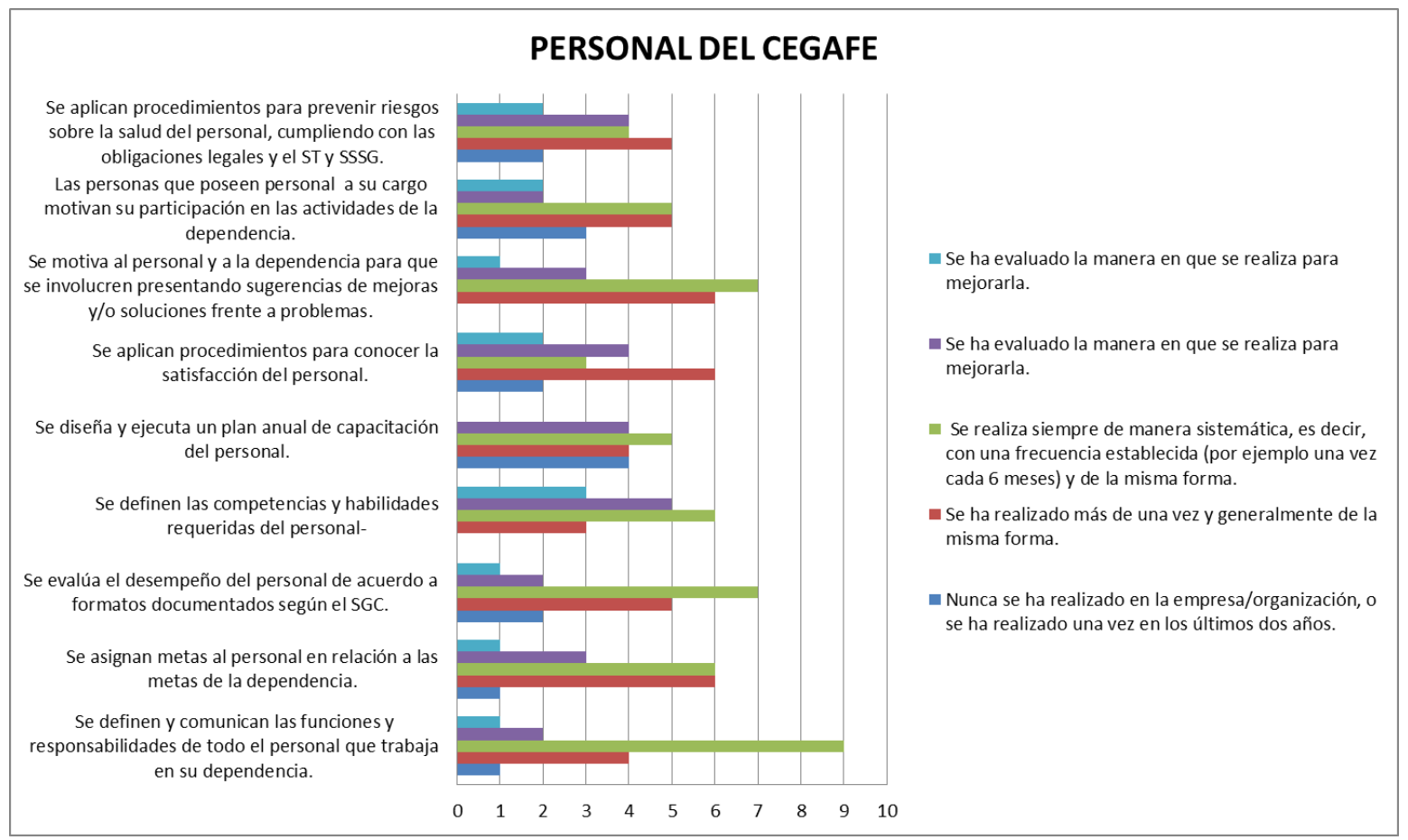

Figura 9. Criterio personal del cegafe

Fuente: Autor.

En cuanto al mejoramiento del desempeño en la entidad, para ofrecer servicios que cumplan con los requisitos de los usuarios, los legales y los reglamentarios con el fin de incrementar la calidad y aumentar la satisfacción de los aprendices y clientes tanto internos como externos, la implementación del Subsistema de Gestión de la Calidad y de su enfoque basado en procesos, contribuye a la planificación de la operación de la entidad, sin embargo en cuanto a la articulación entre las dependencias, la optimización de los recursos y la generación de impacto en las actividades desarrolladas carece de un conocimiento general de quienes laboran en las dependencia, al igual, que la definición y comunicación de las funciones y responsabilidades de todo el personal que trabaja en cada dependencia, tendiente a que se ha realizado más de una vez y generalmente de la misma forma, sin involucrar innovación en los procesos. 


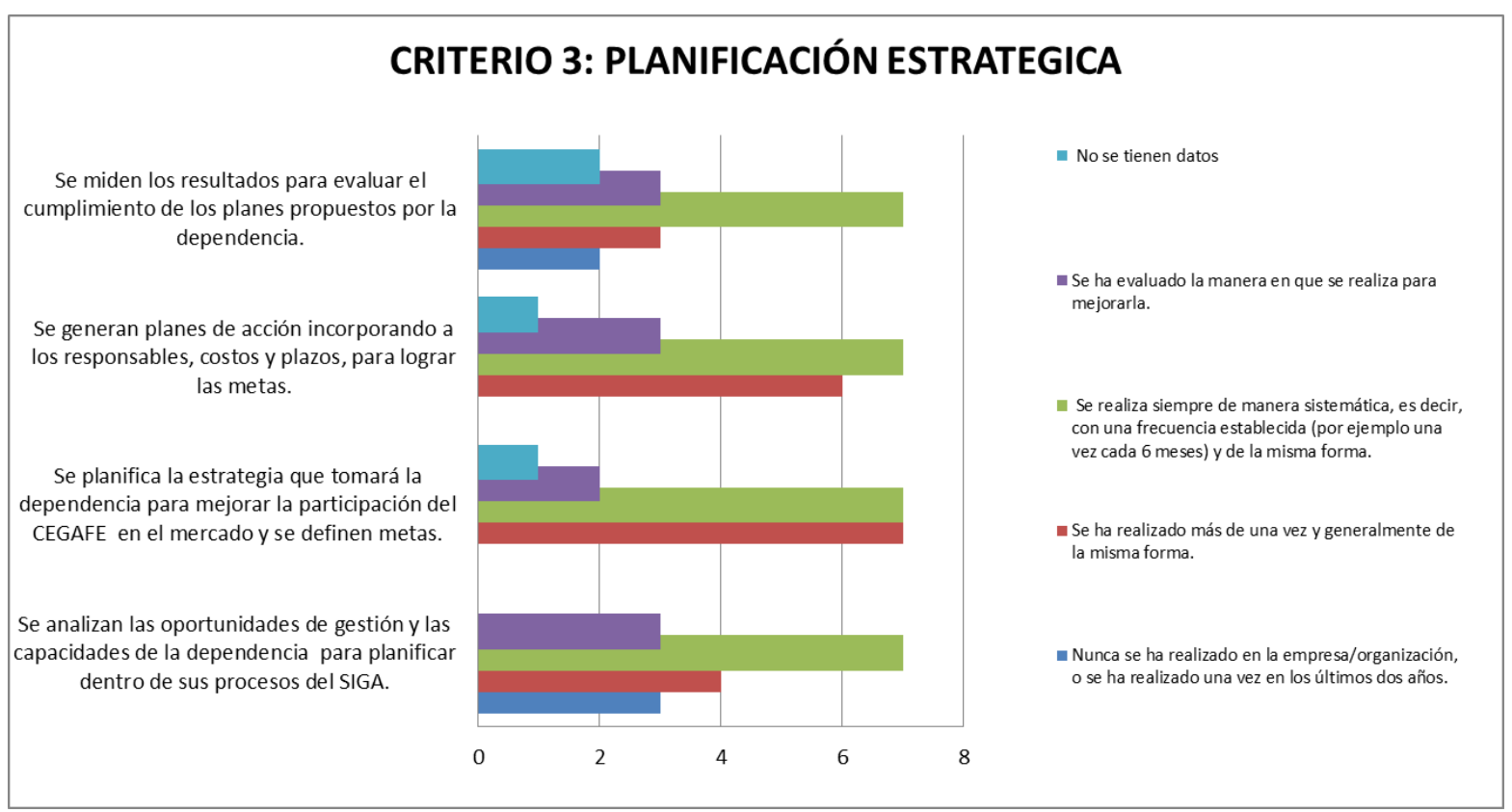

Figura 10. Criterio 4 Planeación estratégica

Fuente: Autor.

Dentro del criterio de planeación estratégica, el CEGAFE se cuenta bien descrito por los líderes de dependencias, puesto que el sistema esta implementado en cada una de las sucursales y sedes a nivel nacional, sin embargo, en términos de gestión y planeación de la misma, las percepciones y respuestas son variadas, en tanto que la mayoría se concentran en los diferentes ítems, que se realizan de manera genérica, en el análisis de las oportunidades de gestión y las capacidades de la dependencia para planificar dentro de sus procesos del SIGA, los líderes expresaron que si se realiza, objetando que se hace una vez cada 6 meses o por periodos de forma sistemática sin mejoras importantes en el proceso integrado. Entre tanto a la pregunta en cuanto a la realización de análisis de oportunidades de gestión y las capacidades de la dependencia para planificar dentro de sus procesos, algunos líderes manifestaron que nunca se ha realizado en la empresa/organización, o se ha realizado una vez en los últimos dos años. En cuanto al subcriterio de la planeación de la estrategia que tomará la dependencia para mejorar la 
participación del CEGAFE en el mercado y se definen metas, los líderes manifestaron que de igual forma se realiza sistemáticamente, sin que ello traiga simplificación o actualización en diferentes dependencias del centro.

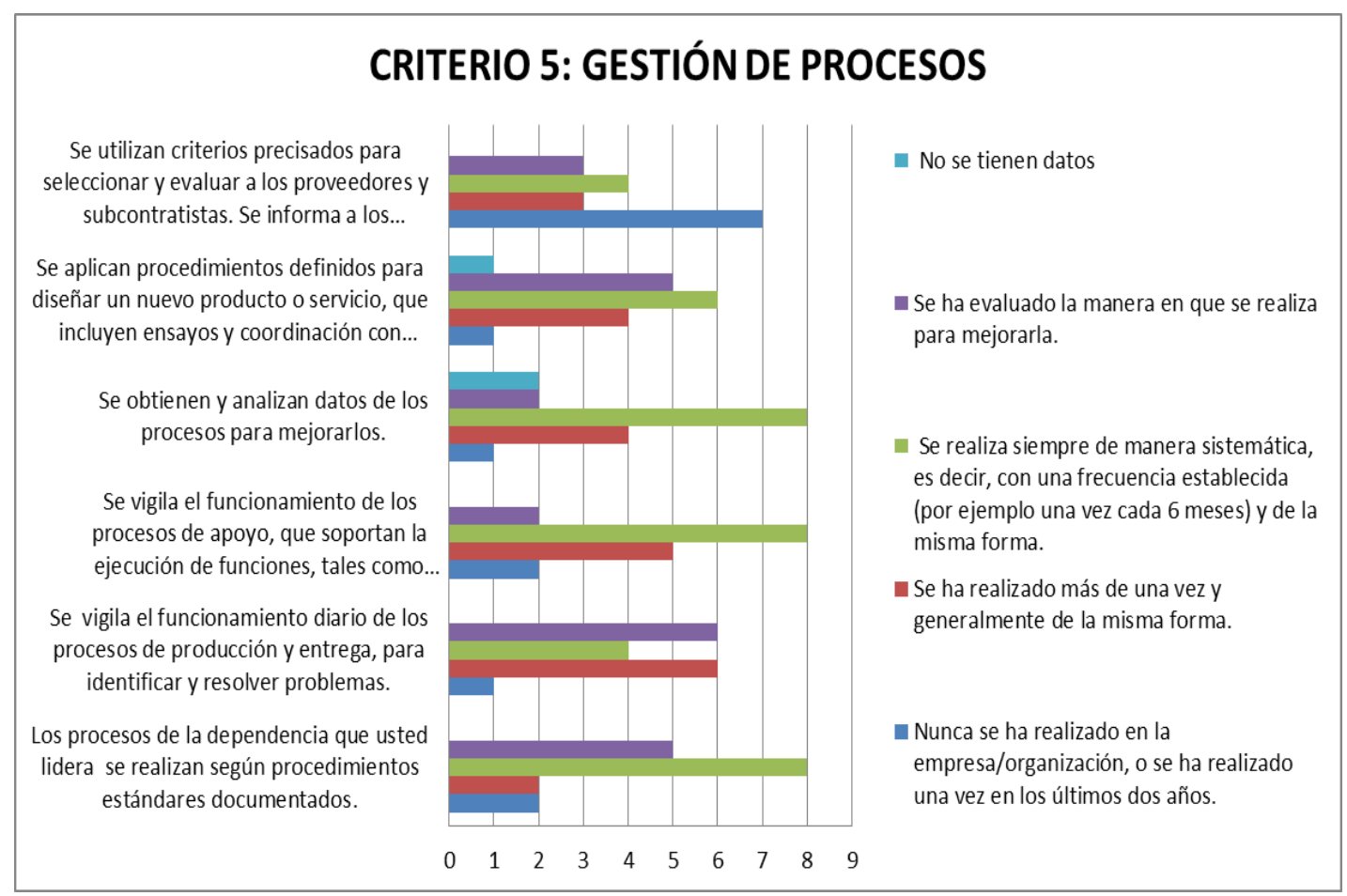

Figura 11. Criterio 5. Gestión de procesos.

Fuente: Autor.

Dentro de los ítems evaluados existe un proceso que pese a que existe control no se ejecuta de acuerdo con los lineamientos del seguimiento y verificación, es decir, en cuanto a los criterios precisados para seleccionar y evaluar a los proveedores y subcontratistas y se informa a los proveedores y subcontratistas el resultado de su evaluación., no se realiza, puesto que algunas dependencias no requieren de insumos específicos, pero en términos de contratación el proceso no está siendo ejecutado con base el análisis a sub contratistas, así mismo, la vigilancia del funcionamiento de los procesos de apoyo, que soportan la ejecución de funciones, tales como procesos de manejo de información, finanzas, contabilidad, mantención, investigación, 
administración, Formación y marketing, para identificar y resolver problemas, se ejecutan de manera sistemática, pero carece de gestión para identificar los elementos clave de mejora.

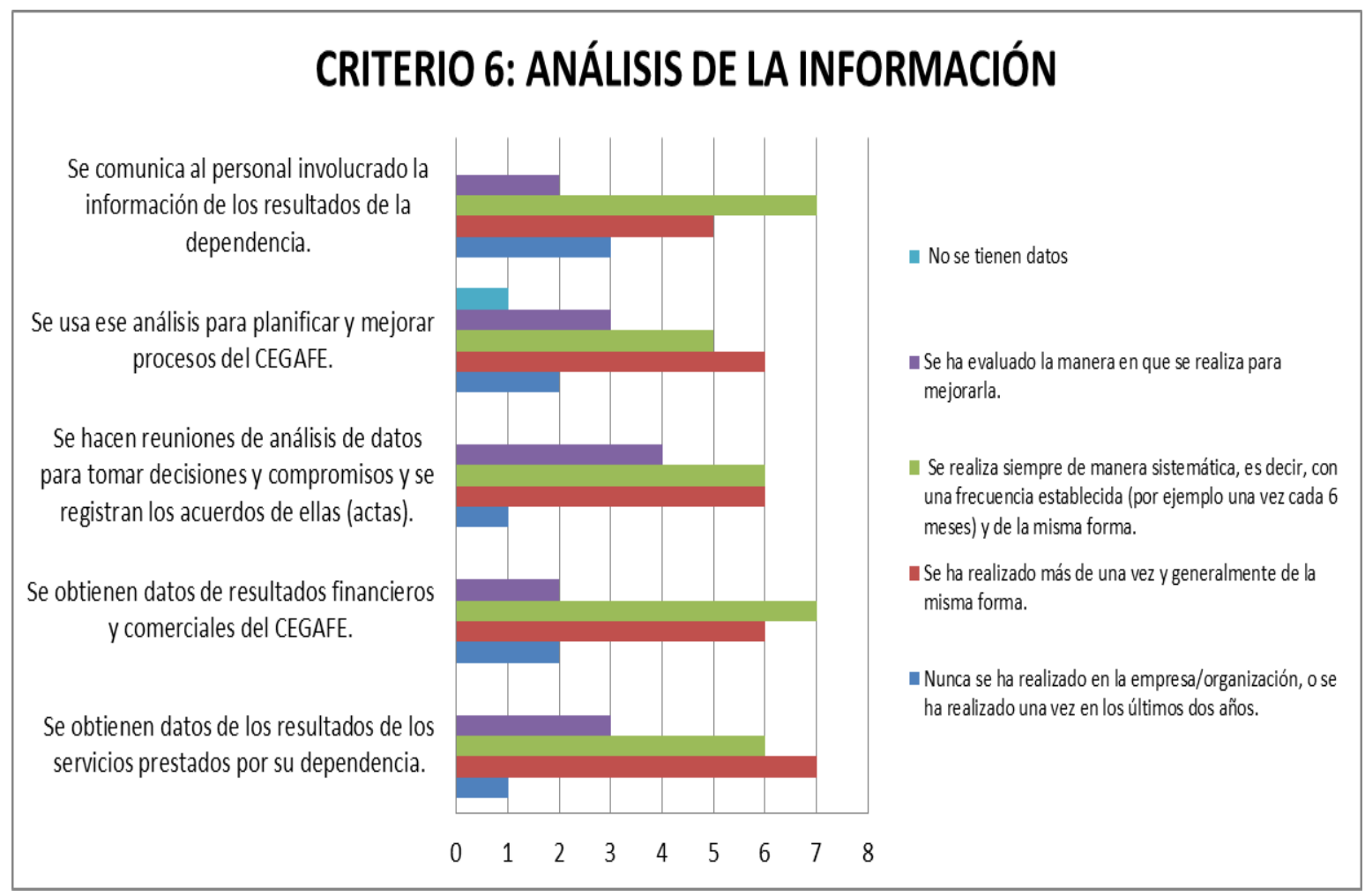

Figura 12. Criterio 6. Análisis de la información.

Fuente: Autor.

Dentro del proceso de simplificación de procesos, se centra su objetivo el cual no es otro que permitir un adecuado nivel de eficiencia operativa y de soporte para la gestión, realizando procesos de cadena logística y patrimonial, de igual manera brindar las herramientas para sintetizar información y usarla para gestionar adecuadamente la integración de procesos en pro de con la priorización o selección del procedimiento a mejorar. Esta primera fase consiste en determinar, cuál de los procedimientos inventariados son los más importantes o necesarios que requieren ser simplificados, o mejorados de acuerdo a los beneficios que ello implique para la institución y para la colectividad, sin embargo los líderes consultados, manifestaron que se realizan reuniones de análisis de datos para tomar decisiones y compromisos y se registran los 
acuerdos de ellas (actas), de forma sistemática pero sin ser continuas, puesto que es semestral este tipo de reuniones, pero pese a ello no es constante ese análisis para planificar y mejorar procesos del CEGAFE.

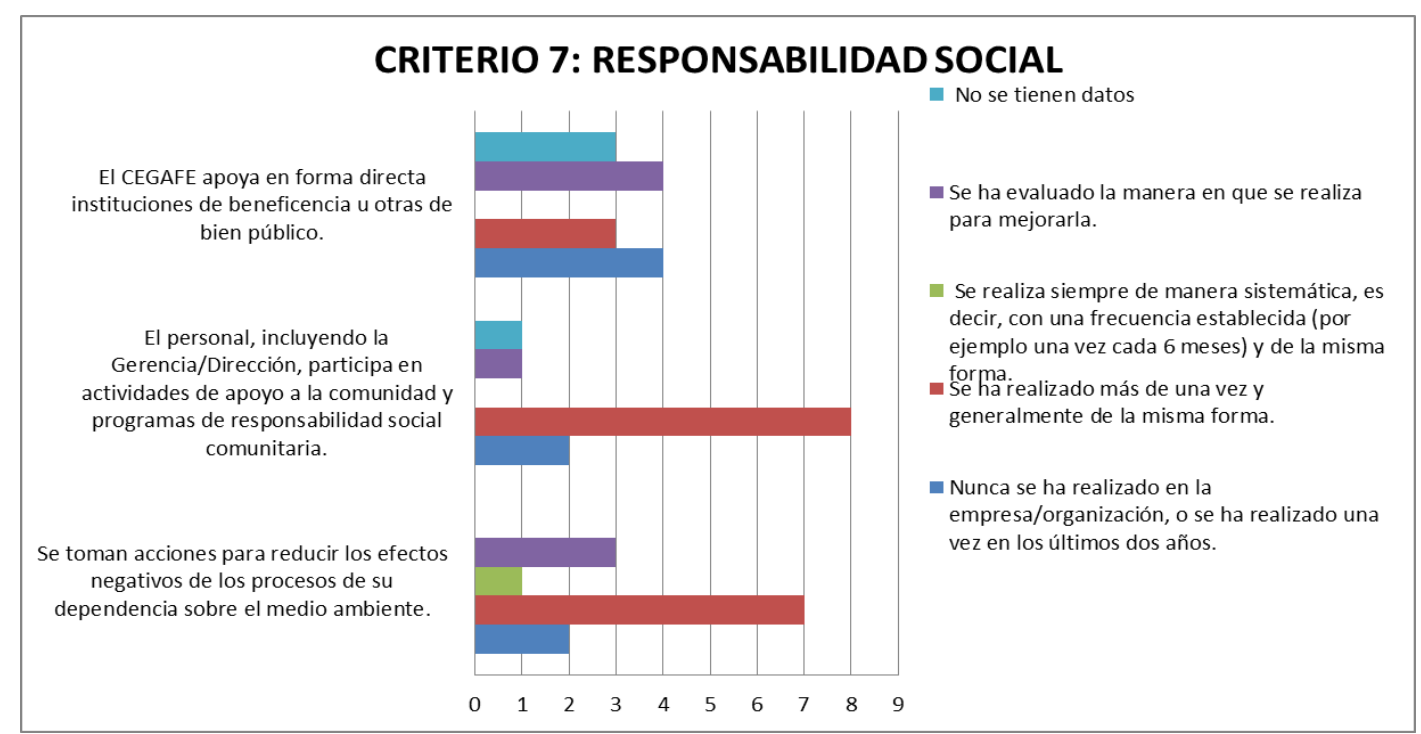

Figura 13. Criterio 7 Responsabilidad social.

Fuente: Autor.

Dentro del compromiso ético de las organizaciones productivas con sus trabajadores, sus accionistas, afiliados o clientes y aprendices, teniendo en cuenta el equilibrio e intereses dentro de la implementación del SIGA, es por tanto que se realizan de forma general, sin tener en cuenta valores la sociedad actual exige, y exigirá cada día más, a las empresas una óptima gestión de la Responsabilidad Social, resguardando el Medio Ambiente y la innovación, sin embargo, y pese a poseer unas políticas y objetivos claros, en la implementación del sistema de gestión, hay vacíos puesto que existen cuellos de botella en los procedimientos y direccionamientos en cuanto al uso de recursos, que impactan en la política del cero papel, el cual se ve reflejado en la percepción de los líderes de dependencias. Es por ello que es preciso gestionar también estos valores de forma óptima, y por razones técnicas, humanas y de coste la 
opción elegida será a partir de Sistemas Integrados que aporten valor a todos estos elementos de forma integral.

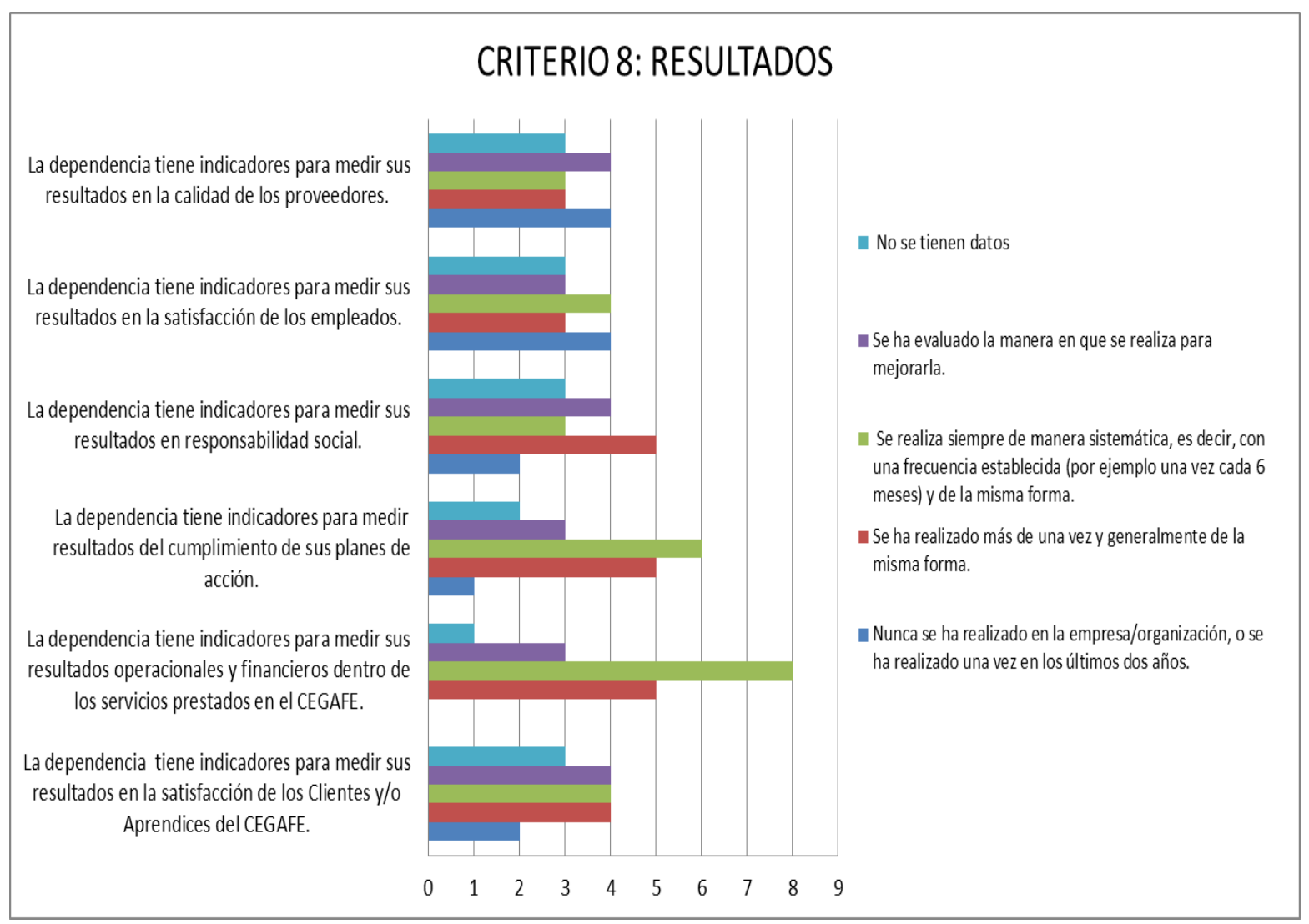

Figura 14. Criterio 8. Resultados.

Fuente: Autor.

En cuanto a los resultados las percepciones de los líderes basadas en la ejecución de la planeación estratégica contemplada en la implementación del sistema SIGA no es muy positiva, fases o pasos a seguir para darle solución a un problema administrativo, requieren de indicadores que sean fáciles de interpretar y a su vez socializar para mejorar los procesos de calidad, así mismo los asuntos de organización, dirección y control, para resolverlos se debe contar con una buena planeación, un estudio previo y tener los objetivos bien claros para poder hacer del proceso lo más fluido posible. Para que el proceso administrativo llevado a cabo sea el más 
indicado se deben tomar en cuenta una serie de pasos que no por ser una parte del todo son menos importantes, por mencionar algunos están, las metas, estrategias, políticas, etc.

Cabe destacar que aún carece de una transparencia en el manejo de sus recursos humanos y materiales, así también sus pocas efectividades en el manejo de la gestión que debe ser contemplada en los manuales de administración. Se presenta a continuación:

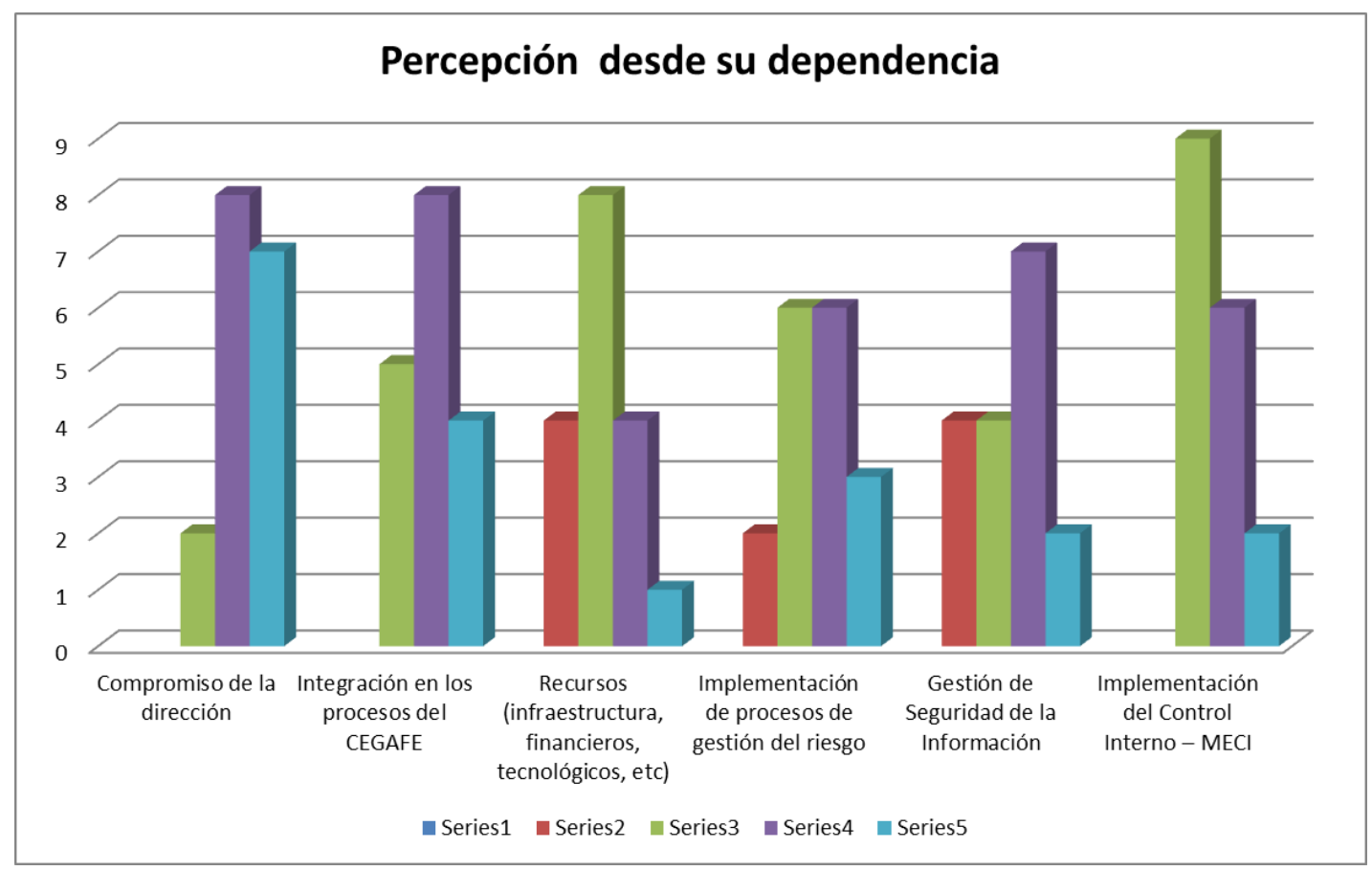

Figura 15. Percepción de la implementación según criterio de lideres

Fuente: Autor.

Una vez se obtuvo la percepción de quienes aplican el desarrollo del sistema SIGA en el CEGAFE, se concluye que aún existen obstáculos gerenciales dentro de la misión de implementación de un sistema real de control y seguimiento, además, la existencia de la normatividad vigente obligatoria ha hecho que los centros de formación técnico, promuevan la implementación de un Sistemas de Gestión de Calidad con los requisitos mínimos para funcionar, pero en el desarrollo de sus objetivos misionales se han definido otros subsistemas integrados teniendo en cuenta la necesidad de implementar sistemas de gestión que vayan más 
allá de los requisitos mínimos y que les permitan alcanzar sus objetivos en el mercado, por tanto, al buscar información pertinente para el proyecto presente, fue necesario establecer compromisos por parte de la alta dirección para lograr el éxito en esta implementación, ya que los aprendices deber ser el objetivo principal del centro, puesto que deben estar preparados para un cambio en la cultura organizacional que permita eliminar la resistencia al cambio por parte de todas las partes involucradas siendo participes de un control verdadero. Por tanto, es fundamental recomendar comenzar un proceso para el despliegue de su estrategia organizacional, enmarcado dentro de una cultura de mejoramiento en su gestión, puesto que se puede lograr un incremento en su productividad, con el propósito de incrementar su competitividad en el mercado.

\section{$5 \quad$ Efectividad del cumplimiento y el seguimiento y control de indicadores}

El objetivo de este análisis no es otro que realizar la evaluación independiente, a la medición y aplicación de los indicadores de gestión en los procesos: estratégicos, misionales, de apoyo y evaluativos de la institución, con el fin de verificar si estos cumplen con el propósito para el cual fueron establecidos, con base en los indicadores de gestión ya establecidos por el centro frente a lo dispuesto con lo diagnosticado en el cuestionario presentado. Este informe comprende el seguimiento a los indicadores de Gestión, correspondiente al segundo semestre del año 2018. Una vez identificados los principales impases de la gestión de seguimiento y control, se presenta una metodología para analizar la efectividad del mismo a través de los indicadores del CEGAFE - Boyacá, teniendo en cuenta que dichos indicadores están ligados con los planes misionales del centro junto al Sistema de Gestión de calidad. Dentro de este proceso el contexto del centro se concentra principalmente en atender las necesidades del mercado laboral, con el fin de brindar al 
mismo aprendiz los perfiles requeridos, es así que el centro de Gestión administrativa cuenta con una red de conocimiento interno que incluye Valoración de los Indicadores de la IES INFOTEP, es resultado de la Evaluación de las Acciones establecidas en el Plan de Acción por Procesos.

Con base en lo anterior el CEGAFE posee los siguientes indicadores enfocados a dar cumplimiento a cada política de calidad dentro de los subprocesos del SIGA, teniendo en cuenta que en términos practicas autores como Juran \& Blanton, Manual de calidad de Juran., 2001, han descrito que la ejecución de un sistema de gestión de calidad se transforma en una ventaja para las empresas, sean estas de producción o servicios, puesto que permite la estandarización de los procesos, proveyendo el control de los recursos, sean estos humanos, materiales, científicos entre otras, lo que sobrelleva a la formación de todos los procesos e integrantes de la empresa, estableciendo parámetros certificables y que sean siempre aptos de mejora continua ya que a través del tiempo, los clientes siempre están demandando a sus proveedores una mejora en la calidad, es por ello y pensando en ella que se diseñaron los siguientes parámetros de medición:

Es de aclarar que actualmente el SIGA - CEGAFE Boyacá, posee indicadores que le permiten hacer seguimiento a la capacidad de respuesta de los aprendices SENA, puesto que su objetivo misional es atender, capacitar y brindar las herramientas para el fomento del empleo y empresa en la región, dejando a un lado indicadores importantes como el número de participantes colaboradores (empleados) en la capacitación y actualización de saberes, la atención de PQRS tanto de funcionarios como aprendices, el control de proveedores que le surten a CEGAFE, el control de procesos y procedimientos de manera que se tenga en cuenta la gestión y el autocontrol.

Es imperioso también explicar que la perspectiva de control "de arriba abajo" ha sido argumentada por diferentes teóricos, llevando que el caso sea expuesto en este capítulo, puesto 
existe una problemática marcada en el centro, como es la problemática con respecto a los empleados debido a la falta de incentivos percibida, que proporciona la "propiedad" y los complejos fenómenos de objetivos y recompensas. Esto refuerza el poder jerárquico y de arriba hacia abajo, que ignora las aspiraciones motivacionales de los empleados y la necesidad de desarrollar un compromiso interno, puesto se carece de indicadores que permitan caracterizar o medir el nivel de actualización de funcionarios y la proyección de estos para brindar atenciones integrales. Sin embargo, ya sea de "arriba hacia abajo" o de "abajo hacia arriba", estas iniciativas demostraron ser deficientes de varias maneras: 


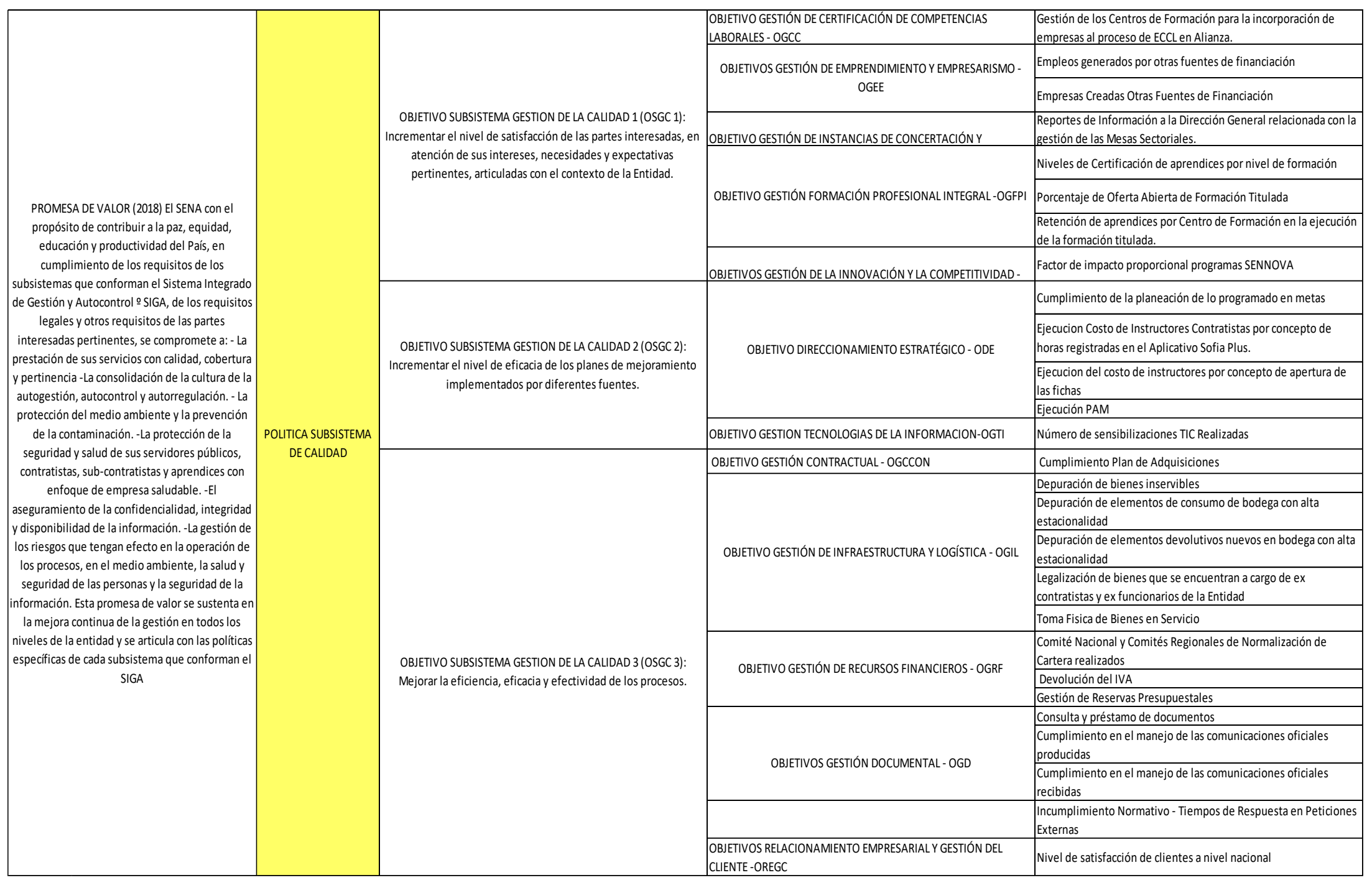

Figura 16. Objetivos del subsistema SIGA

Fuente: Adaptado por el autor. 
En cada uno de los procesos se observan los objetivos de gestión, los cuales el centro posee unos indicadores de gestión para cada una de las dependencias teniendo en cuenta la política y los subprocesos que deben tener el cumplimiento, con su respectiva unidad, meta frente al indicador.

\begin{tabular}{|c|c|c|c|c|c|c|c|}
\hline $\begin{array}{l}\text { NOMBREDEL } \\
\text { INDICADOR }\end{array}$ & $\begin{array}{l}\text { TIPO DE } \\
\text { INDICADOR }\end{array}$ & $\begin{array}{l}\text { PARA QUE SIRVE EL } \\
\text { INDICADOR }\end{array}$ & PROCESO & FORMULA & UNIDAD & META & INDICADOR \\
\hline Convenios & Eficiencia & $\begin{array}{l}\text { Determinar el número de } \\
\text { convenios suscritos por la } \\
\text { Institución en relación a lo } \\
\text { proyectado en el plan } \\
\text { Estratégico. }\end{array}$ & $\begin{array}{c}\text { Direccionamie nto } \\
\text { estratégico }\end{array}$ & $\begin{array}{c}\text { (Número total de convenios } \\
\text { firmados/ Total convenios } \\
\text { proyectados)*100 }\end{array}$ & Porcentaje & $90 \%$ & $100 \%$ \\
\hline $\begin{array}{c}\text { Cumplimiento de } \\
\text { Metas Institucionales }\end{array}$ & Eficacia & $\begin{array}{c}\text { Establecer el número de metas } \\
\text { cumplidas durante el año con } \\
\text { relación a las metas } \\
\text { programadas en el plan de } \\
\text { desarrollo. }\end{array}$ & $\begin{array}{l}\text { Direccionamie nto } \\
\text { estratégico }\end{array}$ & $\begin{array}{l}\text { (Número de metas } \\
\text { cumplidas durante el } \\
\text { año/número de metas } \\
\text { propuestas para el } \\
\text { año)*100 }\end{array}$ & Porcentaje & $90 \%$ & $100 \%$ \\
\hline $\begin{array}{c}\text { Reuniones del Consejo } \\
\text { académico }\end{array}$ & Eficiencia & $\begin{array}{c}\text { Permite determinar el número } \\
\text { de reuniones realizadas por el } \\
\text { Consejo académico con relación } \\
\text { a las reuniones programadas } \\
\text { durante el año. } \\
\end{array}$ & $\begin{array}{l}\text { Direccionamie nto } \\
\text { estratégico }\end{array}$ & $\begin{array}{l}\text { (Número de reuniones } \\
\text { realizadas por el Consejo } \\
\text { Académico /Número de } \\
\text { reuniones programadas } \\
\text { durante el)*100 }\end{array}$ & Porcentaje & $90 \%$ & $133.3 \%$ \\
\hline $\begin{array}{l}\text { Cumplimiento del } \\
\text { Plan Acción }\end{array}$ & Eficacia & $\begin{array}{l}\text { Determina el promedio de } \\
\text { actividades ejecutadas en el } \\
\text { plan de acción versus las } \\
\text { actividades planeadas. }\end{array}$ & Planeación & $\begin{array}{c}\text { (Número de Actividades } \\
\text { realizadas / Numero de } \\
\text { Actividades Planeadas) } \\
* 100 \\
\end{array}$ & Porcentaje & $90 \%$ & $90 \%$ \\
\hline $\begin{array}{c}\text { Costo del Desarrollo } \\
\text { de Actividades del } \\
\text { Plan de Compras }\end{array}$ & Eficiencia & $\begin{array}{l}\text { Determina el promedio de } \\
\text { recursos ejecutados en la } \\
\text { actividad con relación a los } \\
\text { recursos programadas en el } \\
\quad \text { Plan de Compras. }\end{array}$ & Planeación & $\begin{array}{l}\text { (Recursos ejecutados para } \\
\text { el desarrollo de las } \\
\text { actividades/ Recursos } \\
\text { programados para el } \\
\text { desarrollo de las } \\
\text { actividades)*100 } \\
\end{array}$ & Porcentaje & $85 \%$ & $35.54 \%$ \\
\hline $\begin{array}{c}\text { Nivel de cumplimiento } \\
\text { en la difusión } \\
\text { Comunicados } \\
\text { Boletines de Prensa, } \\
\text { eventos y actividades }\end{array}$ & Eficacia & \begin{tabular}{|c|} 
Determinar los porcentajes de \\
cumplimiento de las quejas y \\
reclamos en cada proceso, para \\
determinarlo a nivel \\
institucional y tomar las \\
acciones pertinentes con miras \\
al mejoramiento del \\
servicio.
\end{tabular} & $\begin{array}{l}\text { Comunicación } \\
\text { Institucional }\end{array}$ & $\begin{array}{l}\text { (Número de quejas y } \\
\quad \text { reclamos } \\
\text { solucionados/númer o de } \\
\text { quejas y reclamos } \\
\text { presentadas)*100 }\end{array}$ & Porcentaje & $90 \%$ & $96,20 \%$ \\
\hline $\begin{array}{c}\text { Nivel de cumplimiento } \\
\text { en la difusión de los } \\
\text { Convenios } \\
\text { Interinstitucionales. }\end{array}$ & Eficacia & $\begin{array}{c}\text { Determinar los porcentajes de } \\
\text { cumplimiento de los boletines } \\
\text { de prensa, eventos y } \\
\text { actividades para tomar las } \\
\text { acciones pertinentes con miras } \\
\text { al mejoramiento de la eficacia } \\
\text { de la comunicación } \\
\text { Institucional. } \\
\end{array}$ & $\begin{array}{l}\text { Comunicación } \\
\text { Institucional }\end{array}$ & 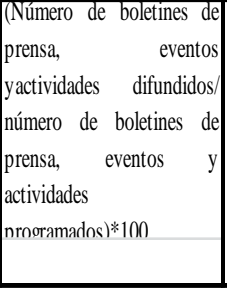 & Porcentaje & $90 \%$ & $100,00 \%$ \\
\hline
\end{tabular}

Figura 17. Indicadores de gestión por áreas

Fuente: CEGAFE - 2018 
Dentro de los indicadores medibles del CEGAFE, se encuentra la cobertura educativa, puesto dentro de su misión de creación, ésta es la que permite medir su capacidad de formación y gestión.

\begin{tabular}{|c|c|c|}
\hline Etiquetas de fila & Suma de Aprendices & Suma de Cupos \\
\hline Adolescente Trabajador & 642 & 770 \\
\hline Adolescentes en conflicto con la ley penal & 91 & 131 \\
\hline Afrocolombianos & 27 & 36 \\
\hline Discapacitados (Incuye atendidos por convenio AGORA) & 231 & 252 \\
\hline Indigenas & 48 & 66 \\
\hline Inpec & 502 & 635 \\
\hline Jovenes Vulnerables & 2313 & 2728 \\
\hline Mujer Cabeza de Hogar & 2167 & 2540 \\
\hline Negritudes & 11 & 12 \\
\hline Palenqueros & 0 & 0 \\
\hline Proceso de reintegración y adolescentes Desvinculados de Grupos Armados Organizados al Margen de la Ley & 5 & 6 \\
\hline Raizales & 0 & 0 \\
\hline Remitidos por el PAL & 16 & 17 \\
\hline Room & 0 & 0 \\
\hline Sobrevivientes Minas Antipersonales & 0 & 0 \\
\hline Tercera Edad & 277 & 378 \\
\hline Total general & 6372 & 7621 \\
\hline
\end{tabular}

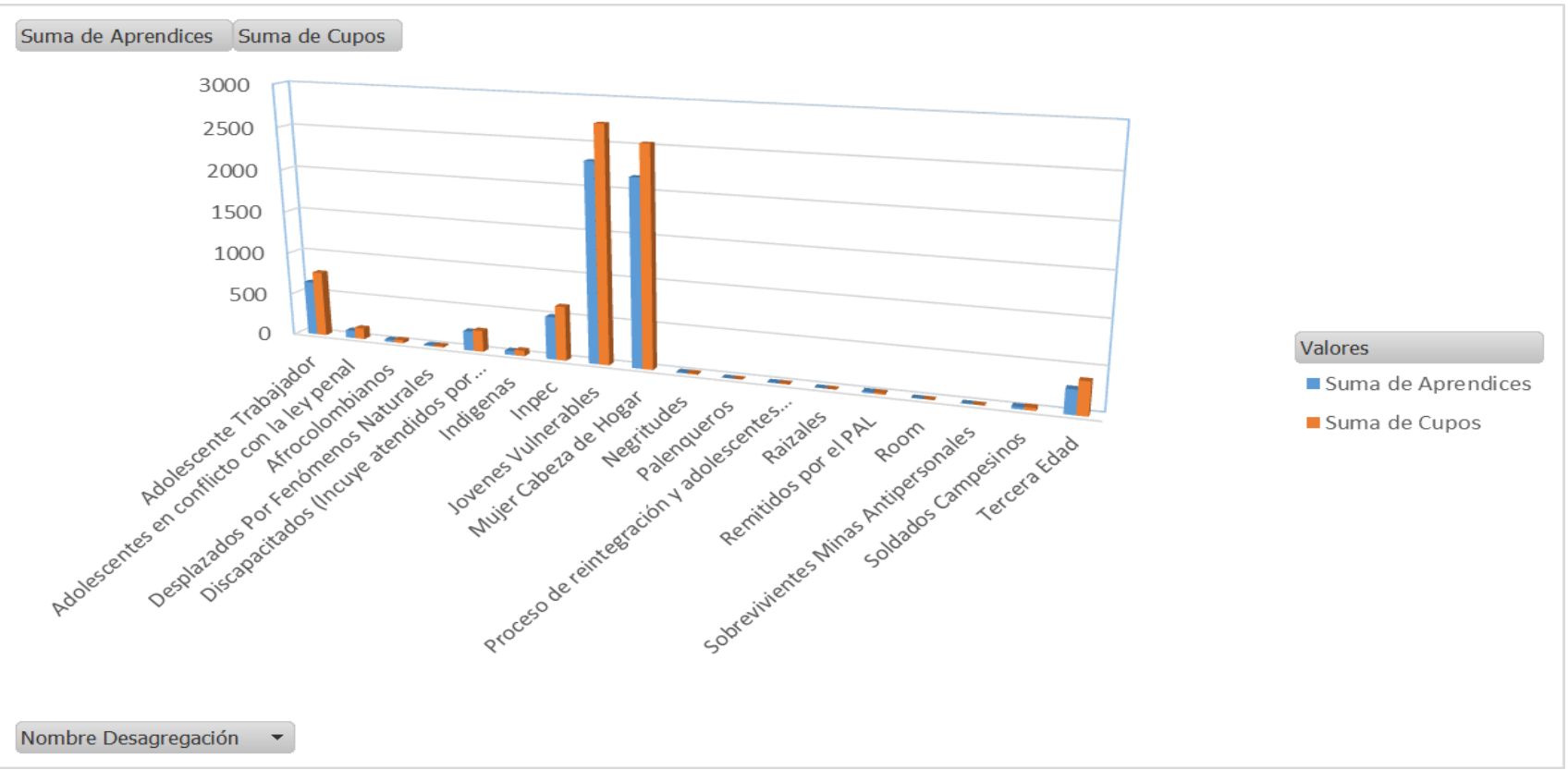

Figura 18. Cobertura versus cupos asignados CEGAFE Boyacá 2018

Fuente: CEGAFE, 2018. 
Otro indicador importante es la certificación de los aprendices, que si bien en el diagnostico uno de los obstáculos de gestión es la política de cero desperdicios en términos de la elaboración de certificados versus las inscripciones del sistema, los errores ocasionan impases que producen perdidas de recursos por reprocesos de impresión, en este aspecto para el año 2018, como se presenta en la siguiente figura el total de certificados fue de 1548.

\begin{tabular}{|l|c|}
\hline \multicolumn{1}{|c|}{ NOMBRE INDICADOR } & METAS \\
\hline $\begin{array}{l}\text { Personas Certificadas en } \\
\text { Competencias Laborales. }\end{array}$ & 1548 \\
\hline $\begin{array}{l}\text { No. de Certificaciones } \\
\text { expedidas en } \\
\text { Competencias Laborales }\end{array}$ & 1616 \\
\hline
\end{tabular}

Figura 19. Certificaciones entregadas versus certificaciones expedidas.

Fuente: CEGAFE 2018

De igual manera se presentan a continuación los diferentes resultados de los informes de gestión que se nutren en la plataforma de cumplimiento del sistema SIGA, teniendo en cuenta los criterios de ejecución de los procesos y subprocesos de este, de igual forma, el cálculo de dichos Indicadores se hace de acuerdo a la frecuencia definida en la hoja del Indicador y el análisis se realiza cotejando el resultado con la meta fijada con lo obtenido en el periodo del indicador. Es necesario guardar registro de los datos de períodos evaluados anteriormente en el informe de desempeño de los Procesos, con el fin de valorar la preferencia del indicador en el tiempo; sin embargo, las observaciones y acciones formuladas que se obtienen en el informe se hacen con respecto a los valores registrados en el período de seguimiento o la tendencia evidenciada a la fecha de corte respectiva. 
Una vez descritos estos indicadores, se procedió a proponer la metodología de análisis de indicadores de acuerdo con el diagnóstico aplicado, de la siguiente manera.
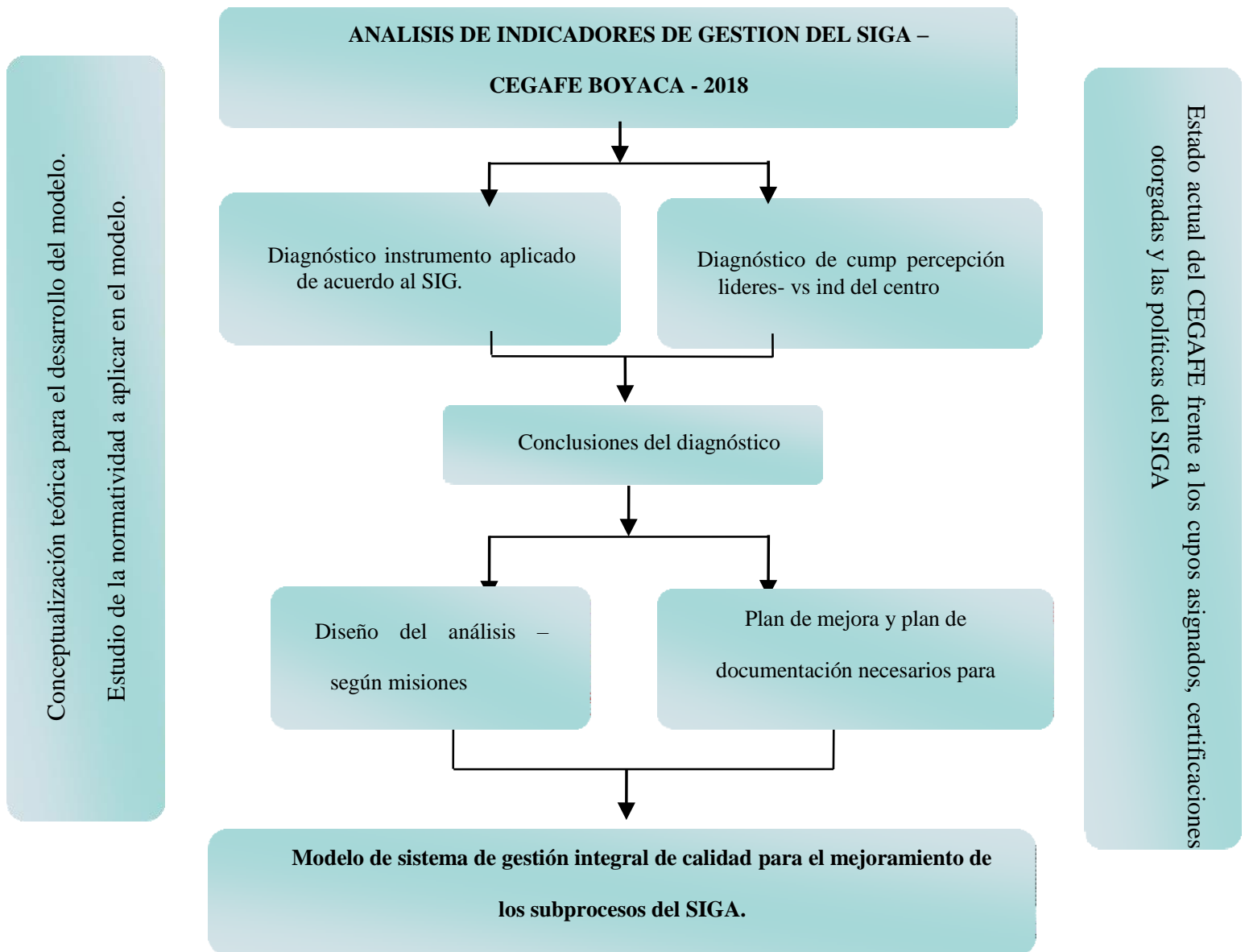

Figura 20. Esquema para el planteamiento de una metodología inicial para el desarrollo de este proyecto de investigación.

Fuente: Autor.

\subsection{Análisis de indicadores}

Los aspectos que son evaluados por el SENA NACIONAL en las auditorias de seguimiento y ampliación del alcance de la implementación del SIGA, ha sido difusión y socialización del S.G.I (Sistema de Gestión integrado), dentro del cual se encuadra el discernimiento de la política 
y objetivos de calidad, gestión de procesos y procedimientos del centro; metodología de la gestión del riesgo respecto a la materialización y calificación de importancia y pertinencias de los mismos; gestión del talento humano específicamente perfiles y competencias para los cargos que ocupa el personal; seguimiento y medición de los procesos a través de los resultados de los diferentes indicadores; planificación de la prestación del servicio y la mejora continua, acciones preventivas y correctivas enfocadas a la eficacia.

Durante los diferentes espacios de tiempo y en especial en los que está introducido la evolución del Sistema de Gestión Integral, han coexistido momentos concluyentes que se han trasformado en lecciones aprendidas y han permitido los logros actuales en materia de gestión y desarrollo organizacional para el centro - CEGAFE.

\subsubsection{Comparativos indicadores de la sede Vs percepción del diagnostico}

Analizar la información generada del desempeño del sistema de gestión integrado y de control en subsistemas dentro del centro de formación empresarial CEGAFE - Boyacá, para establecer las acciones necesarias para consolidar la implementación de mejora, no es un tarea fácil, puesto que existen criterios que no son considerados en los indicadores metas del centro de formación, es ahí donde el reto radica en identificar cuáles son las falencias que deben ser atendidas, los indicadores que deben ser fortalecidos y los planes de mejoramiento para los subprocesos, fortaleciendo así la gestión de la sede. De acuerdo a lo anterior, es fundamental que desde el direccionamiento estratégico se defina la ruta organizacional que debe seguir la entidad para lograr los objetivos institucionales; requiere de revisiones periódicas para ajustarla a los cambios del entorno y al desarrollo de las funciones de la sede, ahora con estos conceptos, los indicadores se han verificado según las percepciones consignadas en el instrumento aplicado para el 
diagnóstico actual de los procesos del SIGA, mostrando a continuación la equivalencia de los mismos versus a las metas alcanzadas en los indicadores del sistema.

\begin{tabular}{|c|c|c|c|c|c|c|}
\hline \multicolumn{7}{|c|}{ COMPARATIVO DE INDICADORES VS PERCEPCION DE FUNCIONARIOS E } \\
\hline \multicolumn{7}{|c|}{ CUMPLIMIENTO SUB PROGRAMAS SIGA SENA CEGAFE BOYACA } \\
\hline \multicolumn{7}{|c|}{ Indicadores } \\
\hline Proceso & Indicador & clase & \% Ejecución & $\begin{array}{l}\text { Promedio } \\
\text { Nacional }\end{array}$ & $\begin{array}{l}\text { Promedio } \\
\text { Regional }\end{array}$ & PERCEPCION \\
\hline \begin{tabular}{c|} 
RELACIONAMIENTO \\
EMPRESARIALY \\
GESTIÓN DEL \\
CLIENTE \\
\end{tabular} & \begin{tabular}{|c|} 
Incumplimiento en \\
tiempos de \\
Respuesta a \\
Peticiones \\
Externas \\
\end{tabular} & EFICACIA & $100 \%$ & $-199.85^{c}$ & $100.00 \%$ & $50 \%$ \\
\hline $\begin{array}{l}\text { GESTIÓN DE } \\
\text { RECURSOS } \\
\text { FINANCIEROS } \\
\end{array}$ & Devolución del IVA & EFICACIA & $100 \%$ & $148.37 \%$ & $59.87 \%$ & NA \\
\hline $\begin{array}{l}\text { GESTIÓN DE } \\
\text { INSTANCIAS DE } \\
\text { CONCERTACIÓNY } \\
\text { COMPETENCIAS } \\
\text { LABORALES }\end{array}$ & \begin{tabular}{|c|} 
Reportes de \\
Información a la \\
Dirección General \\
relacionada con \\
la gestión de las \\
Mesas Sectoriales.
\end{tabular} & EFICACIA & $100 \%$ & $163.25 \%$ & $675.00 \%$ & $70 \%$ \\
\hline $\begin{array}{l}\text { DIRECCIONAMIENT } \\
\text { O ESTRATÉGICO }\end{array}$ & Ejecución PAM & EFICACIA & $133.33 \%$ & $113.89 \%$ & $104.00 \%$ & $60 \%$ \\
\hline $\begin{array}{c}\text { GESTIÓN } \\
\text { DOCUMENTAL }\end{array}$ & $\begin{array}{c}\text { Cumplimiento en } \\
\text { el manejo de las } \\
\text { comunicaciones } \\
\text { oficiales recibidas }\end{array}$ & EFICACIA & $100 \%$ & $88.09^{\circ}$ & $101.46 \%$ & $40 \%$ \\
\hline $\begin{array}{l}\text { DIRECCIONAMIENT } \\
\text { O ESTRATÉGICO }\end{array}$ & $\begin{array}{c}\text { Porcentaje de } \\
\text { implementación } \\
\text { de los programas } \\
\text { ambientales } \\
\end{array}$ & EFICACIA & $100 \%$ & $125.05 \%$ & $101.28 \%$ & $30 \%$ \\
\hline $\begin{array}{c}\text { GESTIÓN } \\
\text { CONTRACTUAL }\end{array}$ & $\begin{array}{l}\text { Cumplimiento } \\
\text { Plan de } \\
\text { Adquisiciones }\end{array}$ & EFICACIA & $100 \%$ & $89.21 \%$ & $104.25 \%$ & $65 \%$ \\
\hline $\begin{array}{c}\text { GESTIÓN DE } \\
\text { TECNOLOGÍAS DE LA } \\
\text { INFORMACIÓN }\end{array}$ & \begin{tabular}{|c|} 
Numero de \\
sensibilizaciones \\
TIC Realizadas
\end{tabular} & EFICACIA & $100 \%$ & $85.84 \%$ & $100.00 \%$ & $50 \%$ \\
\hline
\end{tabular}

Figura 21. Comparativo de indicadores SIGA Vs instrumento diagnostico percepción Fuente: SIGA CEGAFE 2019- Autor.

En cuanto al cumplimiento del indicador de respuesta del PQRS, la eficacia de la sucursal en términos de cumplimientos de tiempos es del 100\% sin embargo, la percepción de los funcionarios quienes lideran y gestionan el desarrollo de los mismos, poseen un $50 \%$ de cumplimiento, puesto que es un protocolo establecido sin innovación en la ejecución, esto hace que reclamaciones puedan ser atrasadas en las respuestas, o la satisfacción de la respuesta no sea la requerida por el usuario, esto hace que deba revisarse el desempeño de la gestión aportada al 
indicador. En términos de competencias laborales, hay una falencia en el reconocimiento de atributos de valor en el personal que desempeña el proceso, puesto que estos indicadores se basan en el cumplimiento de reuniones de mesas sectoriales, sin embargo, los resultados obtenido en el instrumento diagnostico solo un $70 \%$ se ejecuta de la manera correcta, cuya meta es sobre pasada en $675 \%$, algo complejo de determinar en los complementos de los procesos de gestión. En términos de comunicación, la meta del indicador se cumple en un 101\% frente a un 40\% determinado en el diagnóstico del desarrollo del proceso de comunicación, esto quiere decir, que la medición establece un vínculo con la planeación estratégica o institucional y en este indicado el proceso merece revisión. Por tanto, estos resultados obtenidos a través de la medición permiten mejorar la planificación, dado que es posible observar hechos en tiempo real, logrando tomar decisiones con mayor certeza y confiabilidad. Ante el indicador del Direccionamiento estratégico, la meta ha sido cumplida en $100 \%$ pero al analizar las preguntas realizadas en el diagnostico el $30 \%$ de los consultados perciben que aún se carece de dirección, puesto que existen procesos, sub procesos, documentación pero se falta en comunicación, los datos solo se analizan para informarlos pero no se estudian para mejorarlos, es decir no se planifica la estrategia que tomará la dependencia para mejorar la participación del CEGAFE en el mercado y se definen metas. Existe un cumplimiento en reuniones sobre la importancia de las herramientas Tic en el caso de la aplicación en los subprogramas y procesos, hay una falencia importante en el cotejo de estas frente al volumen de información pertinente y veraz, ejemplo los datos para certificación de aprendices, esto genera reproceso y evita un indicador que permita medir la eficiencia versus la política del centro. 


\begin{tabular}{|c|c|c|c|c|c|c|}
\hline $\begin{array}{l}\text { GESTIÓN DE } \\
\text { CERTIFICACIÓN DE } \\
\text { COMPETENCIAS } \\
\text { LABORALES }\end{array}$ & \begin{tabular}{|c|} 
Gestión de los \\
Centros de \\
Formación para la \\
incorporación de \\
empresas al \\
proceso de ECCL \\
en Alianza. \\
\end{tabular} & EFICACIA & $100 \%$ & $319.44 \%$ & $100.00 \%$ & $60 \%$ \\
\hline $\begin{array}{c}\text { GESTIÓN DE } \\
\text { EMPRENDIMIENTO } \\
\text { Y EMPRESARISMOO }\end{array}$ & $\begin{array}{c}\text { Empresas Creadas } \\
\text { Otras Fuentes de } \\
\text { Financiación }\end{array}$ & EFECTIVIDAD & $116.67 \%$ & $141.18 \%$ & $105.70 \%$ & NA \\
\hline $\begin{array}{l}\text { GESTIÓN DE } \\
\text { FORMACIÓN } \\
\text { PROFESIONAL } \\
\text { INTEGRAL }\end{array}$ & $\begin{array}{c}\text { Retención de } \\
\text { aprendices por } \\
\text { Centroo de } \\
\text { Formación en la } \\
\text { ejecución de la } \\
\text { formación } \\
\text { titulada. }\end{array}$ & EFICIENCIA & $120.91 \%$ & $121.71 \%$ & $115.30 \%$ & $60 \%$ \\
\hline $\begin{array}{l}\text { DIRECCIONAMIENT } \\
\text { O ESTRATÉGICO }\end{array}$ & $\begin{array}{c}\text { Sensibilizaciones } \\
\text { ambientales }\end{array}$ & EFICACIA & $100 \%$ & $177.47 \%$ & $100.00 \%$ & $40 \%$ \\
\hline $\begin{array}{l}\text { DIRECCIONAMIENT } \\
\text { OESTRATÉGICO }\end{array}$ & $\begin{array}{c}\text { Ejecucion del } \\
\text { costo de } \\
\text { instructores por } \\
\text { concepto de } \\
\text { apertura de las } \\
\text { fichas }\end{array}$ & EFICIENCIA & $101.6 \%$ & $468.67 \%$ & $101.98 \%$ & NA \\
\hline $\begin{array}{c}\text { RELACIONAMIENTO } \\
\text { EMPRESARIAL Y } \\
\text { GESTION DEL } \\
\text { CLIENTE }\end{array}$ & $\begin{array}{c}\text { Nivel de } \\
\text { satisfacción de } \\
\text { clientes a nivel } \\
\text { nacional }\end{array}$ & EFECTIVIDAD & $100 \%$ & $83.49 \%$ & $88.58 \%$ & $50 \%$ \\
\hline $\begin{array}{l}\text { GESTIIÓN DE } \\
\text { FORMACIÓN } \\
\text { PROFESIONAL } \\
\text { INTEGRAL }\end{array}$ & $\begin{array}{c}\text { Niveles de } \\
\text { Certificación de } \\
\text { aprendices por } \\
\text { nivel de formación }\end{array}$ & EFICACIA & 89.7. & $103.71 \%$ & $111.22 \%$ & $25 \%$ \\
\hline $\begin{array}{l}\text { GESTIÓN DE } \\
\text { FORMACIÓN } \\
\text { PROFESIONAL } \\
\text { INTEGRAL }\end{array}$ & \begin{tabular}{|c|} 
Porcentaje de \\
Oferta Abierta de \\
Formación \\
Titulada
\end{tabular} & EFECTIVIDAD & & $158.29 \%$ & $143.38 \%$ & $40 \%$ \\
\hline $\begin{array}{l}\text { DIRECCIONAMIENT } \\
\text { OESTRATÉGICO }\end{array}$ & $\begin{array}{c}\text { Ejecucion Costo de } \\
\text { Instructores } \\
\text { Contratistas por } \\
\text { concepto de horas } \\
\text { registradas en el } \\
\text { Aplicativo Sofia } \\
\text { Plus. }\end{array}$ & EFICIENCIA & $94.1 \%$ & $102.65 \%$ & $96.33 \%$ & NA \\
\hline $\begin{array}{c}\text { GESTIÓN DE } \\
\text { EMPRENDIMIENTO } \\
\text { YEMPRESARISMO }\end{array}$ & $\begin{array}{l}\text { Empleos } \\
\text { generados por } \\
\text { otras fuentes de } \\
\text { financiación }\end{array}$ & EFICACIA & 10.91 & $197.90 \%$ & 59.78 & NA \\
\hline $\begin{array}{l}\text { GESTIÓN DE } \\
\text { RECURSOS } \\
\text { FINANCIEROS }\end{array}$ & $\begin{array}{c}\text { Gestión de } \\
\text { Reservas } \\
\text { Presupuestales }\end{array}$ & EFICIENCIA & & $756.99 \%$ & 40.00 & NA \\
\hline $\begin{array}{c}\text { GESTIÓN } \\
\text { DOCUMENTAL }\end{array}$ & $\begin{array}{c}\text { Cumplimiento en } \\
\text { el manejo de las } \\
\text { comunicaciones } \\
\text { oficiales } \\
\text { producidas }\end{array}$ & EFICACIA & $99.54 \%$ & & $99.66 \%$ & $30 \%$ \\
\hline $\begin{array}{l}\text { DIRECCIONAMIENT } \\
\text { OESTRATÉGICO }\end{array}$ & $\begin{array}{l}\text { Cumplimiento de } \\
\text { la planeación de } \\
\text { lo programado en } \\
\text { metas }\end{array}$ & EFECTIVIDAD & & $144.31 \%$ & $91.98 \%$ & $50 \%$ \\
\hline
\end{tabular}

Figura 22. Continuación comparación de indicadores.

Fuente: SIGA CEGAFE 2019- Autor.

Entre tanto en el indicador partiendo del indicador anterior las certificaciones son realizas, sin embargo, el proceso de su impresión y posterior entrega tiende a tener impases al no cotejar dicha información por el subproceso de este como se explicó anteriormente, esto quiere decir que pese al 100\% de la meta de certificación, la gestión de los mismos posee falencias que deben ser analizadas para su mejoramiento.

De igual forma en el indicador sensibilizaciones ambientales de la dirección estratégica, el indicador refleja el $100 \%$ de cumplimiento, mientras que el diagnostico muestra un $40 \%$ pues no 
se analizan las oportunidades de gestión y las capacidades de la dependencia para planificar dentro de sus procesos del SIGA.

Frente a un indicador sobre el nivel de certificación de aprendices, la meta en eficacia fue cumplida en un $100 \%$ pero la percepción obtenida en los instrumentos de diagnóstico solo obtiene un $25 \%$, puesto que aún se carece de mecanismos que protejan los recursos de la organización, buscando su adecuada administración ante posibles riesgos que lo afecten, es decir perdidas de papelería, tiempos de impresión, entre otros, así como la carencia de estrategias que busquen crear conciencia en todos los servidores sobre la importancia del control, mediante la generación, mantenimiento y mejora continua de un entorno favorable que permita la aplicación de los principios del modelo estándar de control interno

En este orden de datos, es importante tener en cuenta que los indicadores que engloben fácilmente el desempeño total de la entidad deben recibir la máxima prioridad, sin embargo, existen algunos que no se miden o se establecen metas importantes de cumplimiento, como es el caso de la notificación al personal las metas del CEGAFE, para que las conozcan y favorezcan en alcanzarlas, así de igual forma como la vigilancia en el funcionamiento de los procesos de apoyo, que soportan la ejecución de funciones, tales como procesos de manejo de información, finanzas, contabilidad, mantención, investigación, administración, Formación y marketing, para identificar y resolver problemas. Es por ello que el número de indicadores depende del tipo de entidad, de sus necesidades y características específicas de control, de tal manera que no es necesario establecer un gran número de indicadores, lo importante es construirlos de tal manera que generen información suficiente para la toma de decisiones, lo que sugiere que el CEGAFE aún requiere de planes de mejora medibles. 


\section{Plan de mejora para efectuar un seguimiento efectivo en los subsistemas del SIGA}

El modelo de mejora proporciona un marco para desarrollar, probar e implementar cambios que conducen a la mejora. Se basa en el método científico y modera el impulso de tomar acción inmediata con la sabiduría de un estudio cuidadoso. El uso de ciclos de PDSA le permite probar los cambios a pequeña escala, aprovechando el aprendizaje de estos ciclos de prueba de una manera estructurada antes de la implementación total. Esto brinda a los interesados la oportunidad de ver si el cambio propuesto tendrá éxito y es una herramienta poderosa para aprender de ideas que funcionan y no funcionan. De esta manera, el proceso de cambio es más seguro y menos perjudicial para los pacientes y el personal.

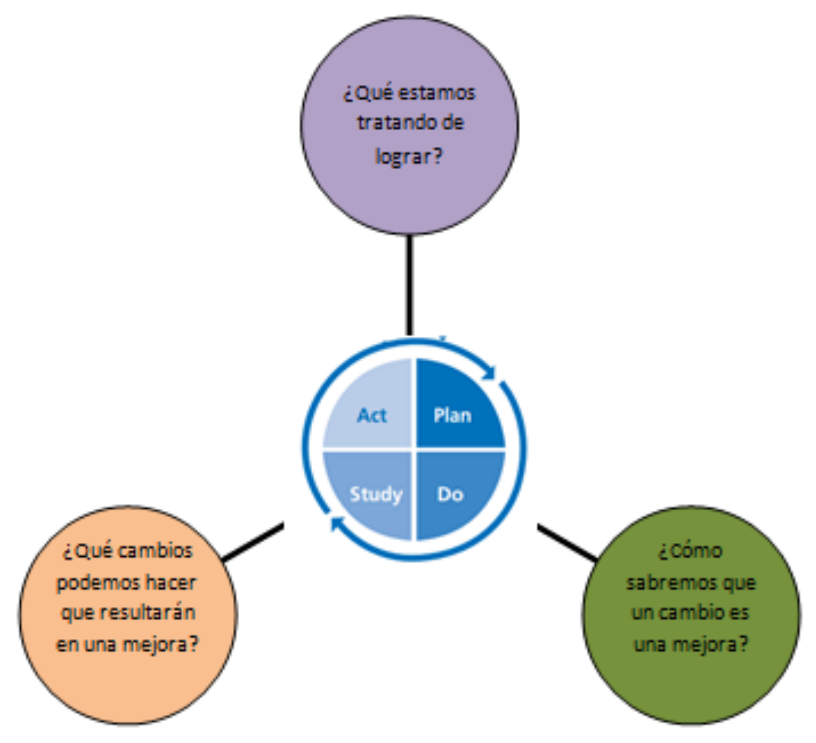

Figura 23. El modelo de mejora.

Fuente: Adaptado por el Autor.

Este enfoque ha sido inusual en un entorno de atención médica porque tradicionalmente, las ideas nuevas a menudo se presentan sin pruebas suficientes. Las cuatro etapas del ciclo PDSA son: 
- Plan - el cambio a ser probado o implementado

- Hacer - realizar la prueba o cambiar

- Estudio - basado en los resultados medibles acordados antes de comenzar, recopilar datos antes y después del cambio y reflexionar sobre el impacto del cambio y lo que se aprendió

- Actuar: planificar el próximo ciclo de cambio o la implementación completa.

Al planificar cualquier mejora o cambio en los procesos de trabajo, es esencial saber qué quiere lograr, cómo medirá la mejora y ser explícito sobre la idea que se va a probar. Es posible que no obtenga los resultados que espera, por lo que es más seguro y efectivo probar las mejoras a pequeña escala antes de implementarlas en forma general.

Es importante recordar que el compromiso SENA, articula el quehacer institucional mediante los lineamientos de las 5 políticas de desarrollo administrativo y el monitoreo y evaluación de los avances en la gestión institucional y sectorial, por lo tanto, dentro de las recomendaciones teniendo en cuenta el análisis anterior se centra en:

- Cada Líder con el personal que estime pertinente debe concretar los Indicadores que reconozcan valorar los objetivos de su proceso, de acuerdo con las actividades que demandan seguimiento a través de la medición de variables.

- Hacer seguimiento a los Indicadores oportunamente, estos son un medio y no un fin, todo se puede medir y por tanto todo se puede controlar, "Lo que no se mide, no se puede administrar", por lo anterior se sugiere revisar si los controles realmente son efectivos y están documentados.

- Revisar las metas de los indicadores, y realizar los ajustes de acuerdo a los resultados obtenidos en las mediciones anteriores, debido a que se evidencia que algunas son muy altas o muy bajas y no se pueden alcanzar o quedan muy por encima de la meta. 
- Enviar oportunamente los resultados de la mediación a Planeación, Control Interno y Gestión de la Calidad.

- Formular Plan Mejoramiento por procesos, cuando no se alcance la meta en los indicadores establecidos, el responsable de los procesos, éstos son el resultado de un conjunto de procedimientos, acciones y metas diseñadas y orientadas de manera planeada, organizada y sistemática para corregir las falencias y debilidades encontradas en las actividades de los procesos.

En cuanto al proceso ambiental de responsabilidad social, el CEGAFE debe enfocar sus procedimientos teniendo en cuenta:

Por esto se compromete a:

- Organizar estrategias que permitan advertir la contaminación, mitigar y/o compensar los impactos ambientales significativos y proteger el medio ambiente, con la política CERO PAPEL.

- Identificar los peligros y prevenir los factores de riesgo que afecten la salud y seguridad de los servidores públicos, contratistas y terceros, incluyendo los generados por eventos de emergencia; para implementar estrategias encaminadas a mejorar las condiciones del entorno laboral, previniendo los accidentes y enfermedades laborales: Ser una organización que estimule a las personas a desarrollar su mayor potencial profesional y personal.

- Salvaguardar la confidencialidad, integridad y disponibilidad de los activos de información, dando cumplimiento a los requisitos técnicos, normativos, regulatorios y operativos, con base en un proceso de gestión de riesgos permanente y mejora continua que le permita CEGAFE, contar con un Sistema de Gestión de Seguridad de la Información suficiente y eficaz. 
- Gestionar la continuidad del negocio, a través de la identificación de estrategias e implementación de planes que permitan salvaguardar la integridad física de las personas, mitigar los impactos operacionales y financieros asociados a la interrupción del servicio.

- Administrar y conservar los documentos de archivo producidos en el ejercicio de su gestión y preservar la memoria institucional.

Para lograr lo anterior, se promueve un ambiente de responsabilidad social a la vez que fortalecemos el desarrollo de nuestro personal, la participación de los usuarios y partes interesadas, destinando los recursos necesarios para consolidar nuestra cultura de autocontrol, mejoramiento continuo y la sostenibilidad de nuestro Sistema Integrado de Gestión.

En la siguiente tabla se documenta el plan de mejora con indicadores y plan de acción para cada uno de los criterios de gestión de los subsistemas del SIGA: 


\begin{tabular}{|c|c|c|c|c|c|c|c|c|}
\hline \multicolumn{4}{|c|}{ SIGA } & \multicolumn{5}{|c|}{ MEJORAMIENTO CONTINUO } \\
\hline \multicolumn{4}{|c|}{ OBJETIVO DEL PROCESO: } & \multicolumn{5}{|c|}{$\begin{array}{l}\text { Asesorar y coordinar la planificaciòn, ejecución, desarrollo, mantenimiento, seguimiento y } \\
\text { mejora del Sistema Integrado de Gestión y sus diferentes componentes a través del } \\
\text { acopañamiento y operativización de estrategias que fortalezcan el CEGAFE - BOYACA. }\end{array}$} \\
\hline \multicolumn{4}{|c|}{ RESPONSABLE DEL PROCESO: } & \multicolumn{5}{|c|}{ LIDER DE GESTIÓN DE LA CALIDAD Y MEJORAMIENTO CONTINUO } \\
\hline \multicolumn{4}{|c|}{ REFERENTE DE PLANEACION: } & \multicolumn{5}{|c|}{ LIDER SIGA - CALIDAD - DIRECCION CEGAFE } \\
\hline AREA DE GESTION & $\begin{array}{c}\text { Persona(s) } \\
\text { Responsable(s)/Oficina/ } \\
\text { Centro }\end{array}$ & Acción(es) a tomar & $\begin{array}{l}\text { Actividades/ tareas para el } \\
\text { mejoramiento(Estrategias de } \\
\text { mejoramiento) }\end{array}$ & $\begin{array}{c}\text { Fecha de } \\
\text { implementaci } \\
\text { ón }\end{array}$ & $\begin{array}{c}\text { Fecha de } \\
\text { finalizacióndel } \\
\text { cumplimiento }\end{array}$ & $\begin{array}{l}\text { Fecha de } \\
\text { seguimiento } \\
\text { de las } \\
\text { actividades }\end{array}$ & Resultados esperados & $\begin{array}{l}\text { INDICADORES DE } \\
\text { SEGUIMIETNO }\end{array}$ \\
\hline $\begin{array}{l}\text { La Gerencia/dirección revisa y } \\
\text { actualiza la meta de la } \\
\text { dependencia que usted lidera, es } \\
\text { decir, lo que quiere llegar a ser en } \\
\text { unos años más. }\end{array}$ & $\begin{array}{l}\text { Direccion del cegafe - } \\
\text { lider de SIGA. }\end{array}$ & $\begin{array}{l}\text { Revisión de la } \\
\text { caracterización por } \\
\text { proceso identificando sus } \\
\text { entradas y salidas, } \\
\text { además de analizar la } \\
\text { secuencia e interacción } \\
\text { entre procesos }\end{array}$ & $\begin{array}{l}\text { Diseñar instrumentos } \\
\text { estandarizados }\end{array}$ & jul-19 & dic-19 & ene-20 & \begin{tabular}{|l|} 
Realizar identificación de \\
necesidades en cada \\
objetivo misional del \\
CEGAFE
\end{tabular} & $\begin{array}{l}\text { Numero de instrumentos } \\
\text { estandarizados de } \\
\text { seguimiento aplicados / } \\
\text { numero total de } \\
\text { instrumentos } \\
\text { estandarizados en el } \\
\text { CEGAFE. }\end{array}$ \\
\hline $\begin{array}{l}\text { La Gerencia/Dirección apoya al } \\
\text { personal para que aprenda y } \\
\text { mejore su desempeño. }\end{array}$ & $\begin{array}{l}\text { Direccion del cegafe - } \\
\text { lider de SIGA. }\end{array}$ & $\begin{array}{l}\text { Caracterizar perfil } \\
\text { profesional de todo el } \\
\text { personal }\end{array}$ & $\begin{array}{l}\text { Determinar cuantas } \\
\text { personas colaboradores } \\
\text { del CEGAFE poseen titulo } \\
\text { profesional, tecnico, } \\
\text { tecnologico, post grados - } \\
\text { para caracterizar el perfil } \\
\text { del personal. }\end{array}$ & jul-19 & dic-19 & ene-20 & \begin{tabular}{|l} 
\\
Documentar los perfiles \\
de colaboradores y \\
personal del CEGAFE con
\end{tabular} & $\begin{array}{l}\text { Numero de personas } \\
\text { profesionales con post } \\
\text { grados / total de } \\
\text { colaboradores CEGAFE; } \\
\text { Numero de personas con } \\
\text { titulo profesional / total de } \\
\text { personal del CEGAFE }\end{array}$ \\
\hline \begin{tabular}{|l|} 
La Gerencia/Dirección motiva al \\
personal premiándole por lo que \\
hace (en forma individual y/o \\
grupal) y tiene en cuenta sus \\
sugerencias para el mejoramiento \\
de la dependencia y el CEGAFE.
\end{tabular} & Lider SIGA - Calidad & Generación de registros & 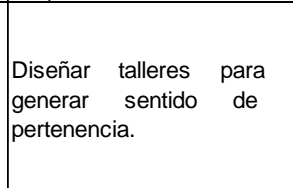 & jul-19 & dic-19 & ene-20 & $\begin{array}{l}\text { el fin de especilizar el } \\
\text { servicio con caldiad del } \\
\text { talento humano. }\end{array}$ & $\begin{array}{l}\text { Numero de capacitaciones } \\
\text { sobre sentido de } \\
\text { pertenencia y compromiso } \\
\text { institucionesl }\end{array}$ \\
\hline
\end{tabular}




\begin{tabular}{|c|c|c|c|c|c|c|c|c|}
\hline CRITERIO 2: CLIENTES & & & & & & & & \\
\hline $\begin{array}{l}\text { Se comunica al personal adecuado, } \\
\text { de manera oportuna, las } \\
\text { necesidades de los Clientes y/o } \\
\text { Aprendices. }\end{array}$ & $\begin{array}{l}\text { Lider SIGA } \\
\text { Formación. }\end{array}$ & $\begin{array}{l}\text { Crear una urna virtual de } \\
\text { PQRS por parte de los } \\
\text { aprendices. }\end{array}$ & $\begin{array}{l}\text { Generar un conglomerado } \\
\text { de solicitudes por tipo de } \\
\text { PQRS para dar } \\
\text { segumiento a las mismas. }\end{array}$ & jul-19 & dic-19 & ene-20 & $\begin{array}{l}\text { Definir la metodologia y } \\
\text { periodicidad del } \\
\text { seguimiento a quejas para } \\
\text { el CEGAFE }\end{array}$ & $\begin{array}{l}\text { Número De requerimientos } \\
\text { con respuesta oportuna/ } \\
\text { Número total de } \\
\text { requerimientos del proceso } \\
\text { * } 100\end{array}$ \\
\hline $\begin{array}{l}\text { Se realizan acciones para } \\
\text { incrementar la fidelidad de los } \\
\text { Clientes y/o Aprendices. }\end{array}$ & $\begin{array}{l}\text { Lider SIGA } \\
\text { Formación. }\end{array}$ & $\begin{array}{l}\text { Crear un comité de } \\
\text { captacion de aprendices } \\
\text { satisfechos. }\end{array}$ & $\begin{array}{l}\text { Lograr oportunidad al } 100 \% \\
\text { de respuesta a los } \\
\text { requerimientos (PQRS) } \\
\text { expuestos por los } \\
\text { aprendices, personal del } \\
\text { CEGAFE, empresarios } \\
\text { que participen de los } \\
\text { procesos del centro }\end{array}$ & jul-19 & dic-19 & ene-20 & $\begin{array}{l}\text { Proporción de } \\
\text { requerimientos con } \\
\text { respuesta oportuna del } \\
\text { proceso }\end{array}$ & $\begin{array}{l}\text { Disminuir en un } 1 \% \text { en las } \\
\text { quejas de usuarios. }\end{array}$ \\
\hline CRITERIO 3: PERSONAS & & & & jul-19 & & & & \\
\hline $\begin{array}{l}\text { Se definen y comunican las } \\
\text { funciones y responsabilidades de } \\
\text { todo el personal que trabaja en su } \\
\text { dependencia. }\end{array}$ & Lider SIGA - Calidad & $\begin{array}{l}\text { Establecer uniformidad en } \\
\text { criterios - responsabilidad }\end{array}$ & $\begin{array}{l}\text { Reuniones con el personal } \\
\text { perfeccionar comunicación }\end{array}$ & jul-19 & dic-19 & ene-20 & $\begin{array}{l}\text { Contar al } 2020 \text { con el } 80 \% \\
\text { del talento humano } \\
\text { necesario y capacitado } \\
\text { para la implemenación de } \\
\text { las rutas del CEGAFE y } \\
\text { sus planes de } \\
\text { capacitacion tecnica. }\end{array}$ & $\begin{array}{l}\text { Número de colaboradores } \\
\text { capacitados / Total de } \\
\text { colaboradores del proceso } \\
{ }_{*} 100\end{array}$ \\
\hline $\begin{array}{l}\text { Se diseña y ejecuta un plan anual } \\
\text { de capacitación del personal. }\end{array}$ & Lider SIGA - Calidad & $\begin{array}{l}\text { Diseñar un plar de } \\
\text { capacitaciones y y } \\
\text { actualizaciones }\end{array}$ & \begin{tabular}{|l} 
Crear un comité \\
evaluador en cada \\
dependencia para analizar \\
la satisfaccin del mercado \\
desde su oficina
\end{tabular} & jul-19 & dic-19 & ene-20 & \multirow{2}{*}{$\begin{array}{c}\text { A } 2020 \text { establecer la } \\
\text { bercha entre la cultura real } \\
\text { y la cultura deseada del } \\
\text { centro }\end{array}$} & \multirow{2}{*}{$\begin{array}{c}\text { Número de colaboradores } \\
\text { del proceso que asisten a } \\
\text { reinducción / Total de } \\
\text { colaboradores del proceso } \\
{ }^{*} 100\end{array}$} \\
\hline $\begin{array}{l}\text { Se aplican procedimientos para } \\
\text { prevenir riesgos sobre la salud del } \\
\text { personal, cumpliendo con las } \\
\text { obligaciones legales y el ST y } \\
\text { SSSG. }\end{array}$ & Lider SIGA - Calidad & $\begin{array}{l}\text { Crear un comité de } \\
\text { riesgos laborales }\end{array}$ & $\begin{array}{l}\text { Crear un mapa de riesgos } \\
\text { laborales en el CEGAFE - } \\
\text { evaluar los procesos de } \\
\text { alto riesgo }\end{array}$ & jul-19 & dic-19 & ene-20 & & \\
\hline
\end{tabular}




\begin{tabular}{|c|c|c|c|c|c|c|c|c|}
\hline \multicolumn{2}{|c|}{ CRITERIO 4: PLANIFICACIÓN ESTRATÉGICA } & \multirow[b]{2}{*}{$\begin{array}{l}\text { Gestionar comité de } \\
\text { revision de procesos de } \\
\text { planificacion }\end{array}$} & \multirow[b]{2}{*}{$\begin{array}{l}\text { Evaluar los resultados de } \\
\text { cada comité, presentar } \\
\text { actas firmadas por los } \\
\text { lideres de procesos. }\end{array}$} & \multirow[b]{2}{*}{ jul-19 } & \multirow[b]{2}{*}{ dic-19 } & \multirow[b]{2}{*}{ ene-20 } & & \\
\hline $\begin{array}{l}\text { Se analizan las oportunidades de } \\
\text { gestión y las capacidades de la } \\
\text { dependencia para planificar dentro } \\
\text { de sus procesos del SIGA. }\end{array}$ & $\begin{array}{l}\text { Lider SIGA } \\
\text { Direccion }\end{array}$ & & & & & & \multirow{4}{*}{$\begin{array}{l}\text { Proporción de } \\
\text { cumplimiento del Plan de } \\
\text { Mejoramiento del proceso }\end{array}$} & NA \\
\hline $\begin{array}{l}\text { Se planifica la estrategia que } \\
\text { tomará la dependencia para } \\
\text { mejorar la participación del } \\
\text { CEGAFE en el mercado y se } \\
\text { definen metas. }\end{array}$ & \multirow[t]{3}{*}{$\begin{array}{l}\text { Direccion del cegafe } \\
\text { lider de SIGA - } \\
\text { Calidad }\end{array}$} & \multirow{3}{*}{$\begin{array}{l}\text { Alcanzar estándares } \\
\text { superiores de calidad a } \\
\text { través del mejoramiento } \\
\text { continuo y la gestión } \\
\text { eficiente y socialmente } \\
\text { responsable de los } \\
\text { procesos, encaminado a } \\
\text { la satisfacción de los } \\
\text { grupos de interés y el } \\
\text { posicionamiento del } \\
\text { CEGAFE en Boyaca. }\end{array}$} & $\begin{array}{l}\text { Realizar } \quad \text { seguimiento a } \\
\text { diario a } \quad \text { a las } \\
\text { manifestaciones } \\
\text { al proceso. }\end{array}$ & jul-19 & dic-19 & ene-20 & & \multirow{3}{*}{$\begin{array}{c}\text { Número de acciones } \\
\text { mejora cumplidas en el } \\
\text { periodo evaluado / Total de } \\
\text { acciones de mejora } \\
\text { programadas en el periodo } \\
\text { *100 }\end{array}$} \\
\hline $\begin{array}{l}\text { Se generan planes de acción } \\
\text { incorporando a los responsables, } \\
\text { costos y plazos, para lograr las } \\
\text { metas. }\end{array}$ & & & $\begin{array}{l}\text { Acompañamineto en la } \\
\text { elaboración y seguimiento } \\
\text { al } 100 \% \text { de los Planes de } \\
\text { Mejoramiento }\end{array}$ & jul-19 & dic-19 & ene-20 & & \\
\hline $\begin{array}{l}\text { Se miden los resultados para } \\
\text { evaluar el cumplimiento de los } \\
\text { planes propuestos por la } \\
\text { dependencia. }\end{array}$ & & & $\begin{array}{l}\text { Cumplir mayor o igual al } \\
90 \% \text { los planes de } \\
\text { mejoramiento inscritos } \\
\text { para el proceso. }\end{array}$ & jul-19 & dic-19 & ene-20 & & \\
\hline \multicolumn{9}{|l|}{$\begin{array}{l}\text { CRITERIO 5: GESTIÓN DE } \\
\text { PROCESOS }\end{array}$} \\
\hline $\begin{array}{l}\text { Se vigila el funcionamiento de los } \\
\text { procesos de apoyo, que soportan la } \\
\text { ejecución de funciones, tales como } \\
\text { procesos de manejo de } \\
\text { información, finanzas, contabilidad, } \\
\text { mantención, investigación, } \\
\text { administración, Formación y } \\
\text { marketing, para identificar y } \\
\text { resolver problemas. }\end{array}$ & Lider SIGA - Calidad & \multirow{3}{*}{$\begin{array}{c}\text { Gestionar al } 100 \% \text { las } \\
\text { acciones de seguimiento } \\
\text { a procesos de gestion del } \\
\text { SIGA. }\end{array}$} & $\begin{array}{l}\text { Gestionar el } 90 \% \text { de los } \\
\text { procedimientos a } \\
\text { fortalecer, categorizados e } \\
\text { identificados en el proceso. }\end{array}$ & jul-19 & dic-19 & ene-20 & \multirow{3}{*}{$\begin{array}{l}\text { Proporción de } \\
\text { cumplimiento del Plan de } \\
\text { Mejoramiento del proceso }\end{array}$} & \multirow{3}{*}{$\begin{array}{c}\text { Número de actividades } \\
\text { realizadas / Número de } \\
\text { actividades programadas * } \\
100\end{array}$} \\
\hline $\begin{array}{l}\text { Se obtienen y analizan datos de los } \\
\text { procesos para mejorarlos. }\end{array}$ & Calidad & & $\begin{array}{l}\text { Aprobación cronograma } \\
\text { auditorias, seguimientos, } \\
\text { evaluaciones y monitoreos } \\
\text { internos por parte de } \\
\text { calidad }\end{array}$ & jul-19 & dic-19 & ene-20 & & \\
\hline $\begin{array}{l}\text { Se utilizan criterios precisados para } \\
\text { seleccionar y evaluar a los } \\
\text { proveedores y subcontratistas. Se } \\
\text { informa a los proveedores y } \\
\text { subcontratistas el resultado de su } \\
\text { evaluación. }\end{array}$ & Compras & & $\begin{array}{l}\text { Cumplir mayor o igual al } \\
90 \% \text { de la evaluacion de } \\
\text { proveedores. }\end{array}$ & jul-19 & dic-19 & ene-20 & & \\
\hline
\end{tabular}

Figura 24. Tabla 5 Plan de mejora - plan de acción - indicadores CEGAFE - SENA

Fuente: Autor. 
Una vez se establece el plan de mejora con criterios de evaluación, indicadores, responsables y fechas de aplicación, se presenta una propuesta de dirección estratégica, esto permitirá a Al realizar la herramienta por parte de los procesos, los funcionarios identificar las debilidades al realizar sus actividades, los aspectos positivos y negativos (valores, cultura, conocimientos, desempeño del proceso) de su plan de mejoramiento y tomar decisiones en la siguiente revisión por la Dirección, se propone entonces un direccionamiento más integral.

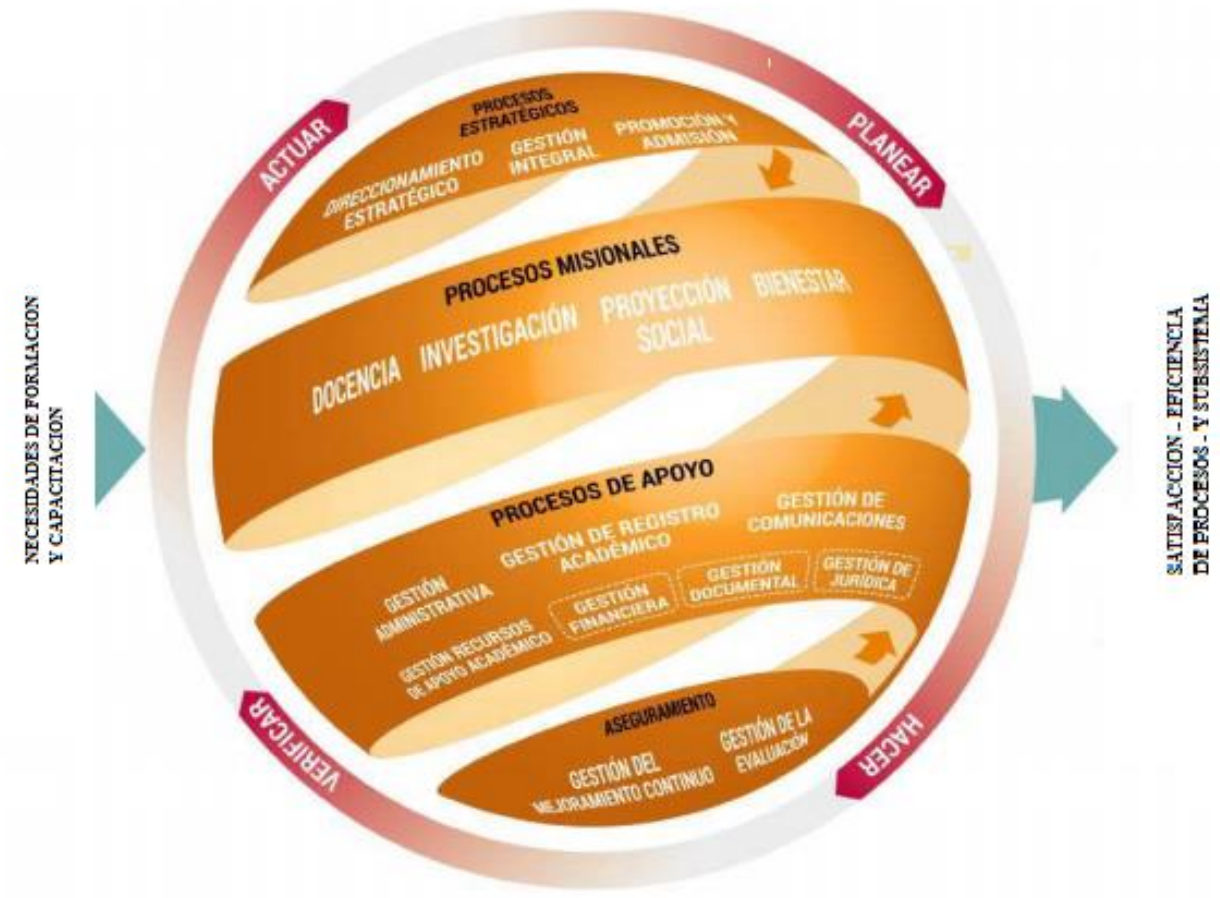

Figura 25. Plan de mejoras procesos estratégicos SIGA

Fuente: Adaptado por el autor.

Teniendo en cuenta los procesos que requieren fortalecimiento se propone que desde el diagnóstico de la planeación estratégica del CEGAFE - Boyacá, se pueda identificar el concepto de las políticas, los lineamientos, los criterios y los procesos sobre flexibilidad, diseño, gestión, 
evaluación y renovación curricular, conceptos importantes para alinear el funcionamiento como centro de formación técnica y tecnológica, como un todo y organización.

La comunicación de la interpretación de estos conceptos permite identificar la cultura organizacional, tema principal de la propuesta de mejora desde la unidad de talento humano; está, alineada al conocimiento de las políticas institucionales que incluyen la misión, visión y valores, permitirán al personal de la organización generar mejores resultados frente a los cambios que se presentan en el entorno académico y administrativo.

\section{$7 \quad$ Conclusiones}

A lo largo de la construcción del documento, se permitió la utilización del instrumento el cual buscó evaluar variables clasificadas de acuerdo con las cuatro dimensiones comunes encontradas en el estado del arte: Modelos de gestión estratégica, sistemas de control y seguimiento, la nueva gestión pública, entre otros.

Dentro del análisis realizado se puede destacar que la nueva gestión pública aplicada a la adopción de un sistema integrado de gestión y control hace énfasis en el sector público a la gobernanza y administración, que involucran la transformación de estatutos en regulaciones, mecanismos de cumplimiento y supervisión, y otras acciones públicas y privadas necesarias para implementar reformas; capital humano y físico, que incluye el nivel, la combinación y la distribución adecuada de profesionales, instalaciones y equipos con capital humano actualizado en pro de cumplir con otros objetivos de reforma; y políticas y programas que se centran en la comunidad en lugar de los servicios simples poco personales que son la preocupación central de un centro de formación. 
Es importante generar un plan de acción frente a la socialización de los planes corporativos, de los objetivos institucionales, las metas y el compromiso cumplible y medible que deben tener las áreas y los departamentos del centro de formación. Desde la unidad de talento humano se debe apoyar en la consecución, inducción, capacitación, desarrollo y mantenimiento del personal alineado a las políticas organizacionales con el fin de trabajar mancomunadamente alineados a un fin común.

El objetivo del proyecto se cumplió puesto que evaluar la efectividad del cumplimiento de las políticas de los subsistemas del SIGA dentro de los procesos misionales y de soporte del CEGAFE Boyacá, permitió desarrollar un plan de acción estratégico que permita medir desde la gestión, teniendo en cuenta que el recurso humano es el bien más importante de toda organización, ahora esta propuesta se encuentra diseñada para ser desarrollada en un año; se busca ser socio estratégico frente a las necesidades de la institución, focalizando de manera sistémica las exigencias del entorno, del cliente, de los colaboradores, y todo el grupo de interés.

Es importante que la plataforma estratégica y sus directivas puedan mantener y hacer partícipe a esta unidad frente a los cambios de políticas y lineamientos institucionales, para que deje de ser una unidad operativa y se pueda convertir en el socio estratégico que mantenga a un personal acorde a las necesidades de la institución. El Plan de Mejoramiento desarrollado fue inspirado en las normas NTC ISO: 9001 y la NTCGP1000:2009, creando herramientas que permitieran conocer y analizar el desempeño del proceso.

Cabe destacar que el nuevo plan de procesos teniendo en cuenta el ciclo PDAV, plantea desde la política de calidad una forma de sintetizar y analizar la información para generar el Plan de Mejoramiento, las herramientas desarrolladas que pudiesen ser gran impacto en los procesos ya 
que no se habían generado círculos prácticos donde participaran todos colaboradores del CEGAFE. 


\section{Referencias Bibliográficas}

Arboleda, O; Balcázar, A y Estupiñán, F (2013). Evaluación institucional y de resultados del Subsistema Nacional de la Calidad. Fedesarrollo. En línea. Consultado en julio de 2018. Recuperado de: http://www.repository.fedesarrollo.org.co/bitstream/handle/11445/207/Repor_Noviembre _2013_Castro_et_al.pdf?sequence=3\&isAllowed=y

Arellano, D; Cabrero, E. (2005). La Nueva Gestión Pública y su teoría de la organización:¿son argumentos antiliberales? Justicia y equidad en el debate organizacional público Gestión y Política Pública, vol. XIV, núm. 3. Centro de Investigación y Docencia Económicas, A.C. Distrito Federal, México

Atehortua, F. (2008). Modelos de Gestión. En F. Atehortúa, R. Bustamante, \& J. Valencia, Sistema de gestión integral. Una sola gestión, un solo equipo (págs. 14 - 63). Universidad de Antioquia.

Baca, G. (2010). Evaluación de Proyectos 5 edición, Editorial Mcgraw-Hill. P. 5.

Bueno Campos, E. (2007). Estrategia y Dirección Estratégica. En J. L. Alvares, J. M. Amat, O. Amat, J. D. Barquero, E. Bueno, L. Cuatrecasas, y otros, Lo que se aprende en los mejores MBA (págs. 15-52). Barcelona: Gestión 2000.

Camejo, A (2008). Titulado El modelo de gestión por competencias y la evaluación del desempeño en la gerencia de los recursos humanos. En línea. Recuperado de: http://www.eumed.net/entelequia/pdf/2008/e08a09.pdf

Cepal (2012) Planificación estratégica. En línea. Recuperado de: https://www.cepal.org/ilpes/noticias/paginas/6/34296/MANUAL_PES.pdf 
Chica Vélez, (2011). Una mirada a los nuevos enfoques de la gestión pública. Administración \& Desarrollo 39 Escuela Superior de Administración Pública, ESAP, Sala de Profesores. Bogotá, D.C.

De la cruz, C. (2003). La nueva gestión pública en México: un enfoque prospectivo para la toma de decisiones y la planeación estratégica del gobierno. VIII Congreso Internacional del CLAD sobre la Reforma del Estado y de la Administración Pública, Panamá. En publicación: Institución: Instituto Tecnológico y de Estudios Superiores de Monterrey (ITESM)-Campus Monterrey.

Díaz B, Bernardo. (2007). Guía didáctica y módulo de planeación estratégica. Facultad de Ciencias Administrativas, Económicas y Contables. Fundación Universitaria Luís Amigó, Medellín, Colombia.

Fontalvo Herrera, T. (2007). Herramientas efectivas para el diseño e implantación de un sistema de gestión de la calidad ISO 9000:2000. Corporación para la gestión del conocimiento ASD 2000.

García I (2007). La nueva gestión pública. Presupuesto y Gasto Público Secretaría General de Presupuestos y Gastos, Instituto de Estudios Fiscales. Bogotá.

Gitlow, H. S., Oppenheim, A. J., Oppenheim, R., y Levine, D. M. (2005). Gestión de calidad (3 edición). ESTADOS UNIDOS. La compañía McGraw-Hill, Inc.

Hammer Michael y Champyjames. (2005). Reingeniería. Editoriales Norma. Bogotá.

Hernández, R., Fernández, C., \& Baptista, M. (2010). Metodología de la investigación. Santiago de CHile: Mc Graw Hill Educación.

Hurtado Pedraza (2017), Fortalecimiento a la implementación del subsistema Interno de gestión documental y archivos (SIGA) en el Instituto para la investigación educativa y el 
desarrollo pedagógico - IDEP. Tesis de grado. Universidad Nacional Abierta y a Distancia. UNAD. En línea. Consultado en julio de 2018. Recuperado de: https://repository.unad.edu.co/handle/10596/13427

ICONTEC. (2008). Norma Técnica Colombiana ISO 9001.

ISO 9001:2015. Evolución a través de los años - www.calidad.pucp.edu.pe. (2014). Calidad.pucp.edu.pe. Recuperado de http://200.16.4.26/el-asesor/iso-9001-2015evolucion-a-traves-de-los-anos\#sthash.DWb1DFAz.dpbs

Jörgensen, T. H. \& Remmen, A. \& Mellado, M. D. (2006). Sistemas de gestión integrados: tres niveles diferentes de integración. Diario de la producción más limpia.

Juran, J., \& Blanton, G. (2001). Manual de calidad de Juran. En Capítulo 5. El proceso de mejora de la calidad. (pág. 7). Madrid: Interamericana de España.

Kaplan Robert S y David P. Norton. (2001). Transforming the Balanced Scorecard from Performance Measurement to Strategic Management: Part I. Accounting Horizons: March 2001, Vol. 15, No. 1, pp. 87-104.

Leiber Albeiro (sf). Estilos de planeación y tipos de planes. En línea. Consultado en febrero de 2015. Disponible en: http://es.slideshare.net/lorenaalvarez12/estilos-de-planeacin-y-tiposde-planes-32615547

Marín, Y, (2007), Aprendiendo a ser el mejor, Instituto Tecnológico Metropolitano, fondo editorial ITM, Medellín Colombia.

Mejía O (2015). Importancia de la implementación de un sistema de gestión integral en las empresas colombianas. En línea. Consultado de: http://bibliotecadigital.usb.edu.co/bitstream/10819/4397/1/Importancia\%20implementaci on\%20sistema\%20gesti\%C3\%B3n_Oscar\%20mej\%C3\%ADa\%20C_2015.pdf 
Meriño Córdoba Et al (2018). Gestión del Conocimiento. Perspectiva Multidisciplinaria", $\begin{array}{lllll}\text { volumen } & 9 . & \text { En } & \text { línea. }\end{array}$ https://www.researchgate.net/publication/330797300_De_la_idea_a_la_oportunidad_de_ negocio_Metodologias_distintas_al_plan_de_empresa_en_el_estudio_y_analisis_de_las_ iniciativas_emprendedoras

Monge, E. C. (2010). El estudio de Casos como metodología de Investigación y su importancia en la dirección y Administración de Empresas. Revista Nacional de Administración ( RNA), 31-54.

Moyano C (2003). Gestión pública y calidad: hacia la mejora continua y el rediseño de las instituciones del sector público. VII Congreso Internacional del CLAD sobre la Reforma del Estado y de la Administración Pública, Lisboa, Portugal.

Ortiz y Martínez (2003). El impacto de los sistemas de gestión en el cambio institucional. En: http://www.chi.itesm.mx/icm/wpcontent/uploads/2014/12/1599992_EL_IMPACTO_DE_LOS_SISTEMAS_DE_GESTIO N_EN_EL_CAMBIO_INSTITUCIONAL.pdf

Pelayo, M (2012). Determinación del grado de calidad de una empresa a partir de los indicadores de gestión. En línea. Consultado en julio de 2018. Recuperado de: https://www.inti.gob.ar/incalin/pdf/tesis/MarceloPelayo.pdf

RussiO., Alfonso. (2011). Gerencia de la planificación estratégica. Bucaramanga, Universidad Industrial de Santander.

Sampieri, R. (2014). Metodología de la Investigación. México: McGRAW-HILL. 
Sánchez J (2013). Un Sistema de Indicadores de Calidad para el Mejoramiento de Programas Universitarios en Administración. En línea. Recuperado de: https://www.mineducacion.gov.co/1621/articles-342685_recurso_2.pdf

SENA (2015). Sistema SIGA. En línea. Consultado en junio de 2018. Recuperado de: http://compromiso.sena.edu.co/ http://senacentrogestiontunja.blogspot.com/p/laentidad.html

Seppälä R (2015), Implementando un Sistema de Gestión de Calidad para una empresa de ingeniería y servicios. Tesis de grado. Ucrania. en línea. Consultado de: https://core.ac.uk/download/pdf/38121444.pdf

Serna, H. (2008). Gerencia Estratégica Bogotá: 3R. P. 55

Slaughter, Richard y Marcus Bussey, (2006). Futures thinking for social foresight, Taiwan, Tamkang University Press,

Stavileci, E .; Sokoli, A. y Batalli, M. (2010). Derecho administrativo, administración, control del trabajo de la administración y su responsabilidad política e informatización del derecho administrativo / administrativo, administración, control de las actividades administrativas y su responsabilidad política y la informatización de la administración. Universidad de Prishtina.

Torralba Chaves, X., Betancourth Romero, H., \& Fandiño Benavides, R. (2016). Impacto de los sistemas de gestión integrados en la competitividad de las mipymes. Gestión Ingenio Y $\begin{array}{llll}\text { Sociedad, } & \text { 1(1), } & \text { 48-54. } & \text { Recuperado }\end{array}$ http://gis.unicafam.edu.co/index.php/gis/article/view/13

Torres Becerra J y Suna Landino (2012). Sistema integrado de gestion al sistema de gestion integral: la gestion del conocimiento como estrategia en el cuerpo oficial de Bomberos de 
Bogota. En línea. Consultado de: https://revistas.usantotomas.edu.co/index.php/signos/article/view/1940

Véliz, F. (2006). Cambio de mirada en las organizaciones: Comunicación en 360 grados. Revista Latinoamericana de Comunicación Chasqui, 93, 62-65. 


\section{Apéndices}

\section{Apéndice A. Cuestionario diagnostico SIGA}

\section{CENTRO DE GESTIÓN ADMINISTRATIVA Y FORTALECIMIENTO EMPRESARIAL - \\ CEGAFE BOYACA 2018.}

DIAGNOSTICO SIGA.

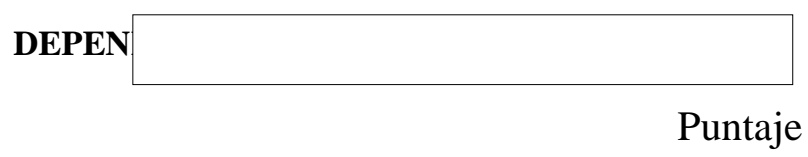

$0=$ Nunca se ha realizado en la empresa/organización, o se ha realizado una vez en los últimos dos años. 1= Se ha realizado más de una vez y generalmente de la misma forma.

$2=$ Se realiza siempre de manera sistemática, es decir, con una frecuencia establecida (por ejemplo una vez cada 6 meses) y de la misma forma.

$3=$ Se ha evaluado la manera en que se realiza para mejorarla.

$4=$ No se tienen datos

\begin{tabular}{|l|l|l|l|}
\hline & CRITERIO 1: LIDERAZGO DE LA GERENCIA/DIRECCIÓN & PUNTAJE & OBSERVACIONES \\
\hline & $\begin{array}{l}\text { La Gerencia/Dirección revisa y actualiza el objetivo principal de } \\
\text { su dependencia, es decir, la necesidad que satisface y su mercado } \\
\text { objetivo. }\end{array}$ & $\begin{array}{l}\text { La Gerencia/dirección revisa y actualiza la meta de la } \\
\text { dependencia que usted lidera, es decir, lo que quiere llegar a ser } \\
\text { en unos años más. }\end{array}$ & \\
\hline $\begin{array}{l}\text { La Gerencia/Dirección comunica al personal la misión, visión y } \\
\text { los valores del CEGAFE. }\end{array}$ & $\begin{array}{l}\text { La Gerencia/Dirección notifica al personal las metas del } \\
\text { CEGAFE, para que las conozcan y favorezcan en alcanzarlas. }\end{array}$ & & \\
\hline
\end{tabular}




\begin{tabular}{|l|l|l|} 
& $\begin{array}{l}\text { La Gerencia/Dirección incentiva al personal a tener más } \\
\text { iniciativa, de forma individual y colectiva. }\end{array}$ & \\
\hline $\begin{array}{l}\text { La Gerencia/Dirección apoya al personal para que aprenda y } \\
\text { mejore su desempeño. }\end{array}$ & $\begin{array}{l}\text { La Gerencia/Dirección motiva al personal premiándole por lo que } \\
\text { hace (en forma individual y/o grupal) y tiene en cuenta sus } \\
\text { sugerencias para el mejoramiento de la dependencia y el } \\
\text { CEGAFE. }\end{array}$ & \\
\hline $\begin{array}{l}\text { La Gerencia/Dirección revisa el desempeño financiero y Social } \\
\text { de su dependencia. } \\
\text { La Gerencia/Dirección revisa opciones de mejora de los procesos } \\
\text { e indicadores de servicios }\end{array}$ & & \\
\hline
\end{tabular}

\begin{tabular}{|l|l|l|l|}
\hline & CRITERIO 2: CLIENTES Y/O APRENDICES & PUNTAJE & OBSERVACIONES \\
\hline & $\begin{array}{l}\text { Se tiene claro, revisa y actualiza la información de los Clientes } \\
\text { y/o Aprendices más importantes del CEGAFE, especialmente } \\
\text { aquella relativa a cuáles son sus requerimientos. }\end{array}$ & \\
\hline $\begin{array}{l}\text { Se comunica al personal adecuado, de manera oportuna, las } \\
\text { necesidades de los Clientes y/o Aprendices. }\end{array}$ & \\
\hline $\begin{array}{l}\text { Se aplican procedimientos para conocer la opinión de los Clientes } \\
\text { y/o Aprendices sobre los servicios prestados. }\end{array}$ & & \\
\hline $\begin{array}{l}\text { Se usa dicha información para mejorar la atención de los Clientes } \\
\text { y/o Aprendices. }\end{array}$ & & \\
\hline $\begin{array}{l}\text { Se registra esa información y se observa la evolución de } \\
\text { resultados de satisfacción de Clientes y/o Aprendices }\end{array}$ & & \\
\hline $\begin{array}{l}\text { Se realizan acciones para incrementar la fidelidad de los Clientes } \\
\text { y/o Aprendices. }\end{array}$ & & \\
\hline
\end{tabular}




\begin{tabular}{|c|c|c|c|}
\hline & CRITERIO 3: PERSONAL DEL CEGAFE & & \\
\hline & & PUNTAJE & OBSERVACIONES \\
\hline & $\begin{array}{l}\text { Se definen y comunican las funciones y responsabilidades de } \\
\text { todo el personal que trabaja en su dependencia. }\end{array}$ & & \\
\hline & $\begin{array}{l}\text { Se asignan metas al personal en relación a las metas de la } \\
\text { dependencia. }\end{array}$ & & \\
\hline & $\begin{array}{l}\text { Se evalúa el desempeño del personal de acuerdo a formatos } \\
\text { documentados según el SGC. }\end{array}$ & & \\
\hline & $\begin{array}{l}\text { Se definen las competencias y habilidades requeridas del } \\
\text { personal- }\end{array}$ & & \\
\hline & Se diseña y ejecuta un plan anual de capacitación del personal. & & \\
\hline & $\begin{array}{l}\text { Se aplican procedimientos para conocer la satisfacción del } \\
\text { personal. }\end{array}$ & & \\
\hline & $\begin{array}{l}\text { Se motiva al personal y a la dependencia para que se involucren } \\
\text { presentando sugerencias de mejoras y/o soluciones frente a } \\
\text { problemas. }\end{array}$ & & \\
\hline & $\begin{array}{l}\text { Las personas que poseen personal a su cargo motivan su } \\
\text { participación en las actividades de la dependencia. }\end{array}$ & & \\
\hline & $\begin{array}{l}\text { Se aplican procedimientos para prevenir riesgos sobre la salud } \\
\text { del personal, cumpliendo con las obligaciones legales y el ST y } \\
\text { SSSG. }\end{array}$ & & \\
\hline 10 & $\begin{array}{l}\text { Existen mecanismos para mejorar la comunicación entre las } \\
\text { dependencias y la dirección general. }\end{array}$ & & \\
\hline
\end{tabular}

\begin{tabular}{|l|l|l|l|}
\hline & CRITERIO 4: PLANIFICACIÓN ESTRATÉGICA & PUNTAJE & OBSERVACIONES \\
\hline & & & \\
\hline & $\begin{array}{l}\text { Se analizan las oportunidades de gestión y las capacidades de la } \\
\text { dependencia para planificar dentro de sus procesos del SIGA. }\end{array}$ & & \\
\hline
\end{tabular}




\begin{tabular}{|c|}
\hline $\begin{array}{l}\text { Se planifica la estrategia que tomará la dependencia para mejorar } \\
\text { la participación del CEGAFE en el mercado y se definen metas. }\end{array}$ \\
\hline $\begin{array}{l}\text { Se generan planes de acción incorporando a los responsables, } \\
\text { costos y plazos, para lograr las metas. }\end{array}$ \\
\hline $\begin{array}{l}\text { Se miden los resultados para evaluar el cumplimiento de los } \\
\text { planes propuestos por la dependencia. }\end{array}$ \\
\hline
\end{tabular}

\begin{tabular}{|c|c|c|c|}
\hline & CRITERIO 5: GESTIÓN DE PROCESOS & PUNTAJE & OBSERVACIONES \\
\hline 1 & $\begin{array}{l}\text { Los procesos de la dependencia que usted lidera se realizan según } \\
\text { procedimientos estándares documentados. }\end{array}$ & & \\
\hline 2 & $\begin{array}{l}\text { Se vigila el funcionamiento diario de los procesos de producción } \\
\text { y entrega, para identificar y resolver problemas. }\end{array}$ & & \\
\hline 3 & $\begin{array}{l}\text { Se vigila el funcionamiento de los procesos de apoyo, que } \\
\text { soportan la ejecución de funciones, tales como procesos de } \\
\text { manejo de información, finanzas, contabilidad, mantención, } \\
\text { investigación, administración, Formación y marketing, para } \\
\text { identificar y resolver problemas. }\end{array}$ & & \\
\hline 4 & Se obtienen y analizan datos de los procesos para mejorarlos. & & \\
\hline 5 & $\begin{array}{l}\text { Se aplican procedimientos definidos para diseñar un nuevo } \\
\text { producto o servicio, que incluyen ensayos y coordinación con } \\
\text { proveedores. }\end{array}$ & & \\
\hline & $\begin{array}{l}\text { Se utilizan criterios precisados para seleccionar y evaluar a los } \\
\text { proveedores y subcontratistas. Se informa a los proveedores y } \\
\text { subcontratistas el resultado de su evaluación. }\end{array}$ & & \\
\hline
\end{tabular}

\begin{tabular}{|l|l|l|l|}
\hline & CRITERIO 6: ANÁLISIS DE LA INFORMACIÓN & PUNTAJE & OBSERVACIONES \\
\hline & & & \\
\hline
\end{tabular}




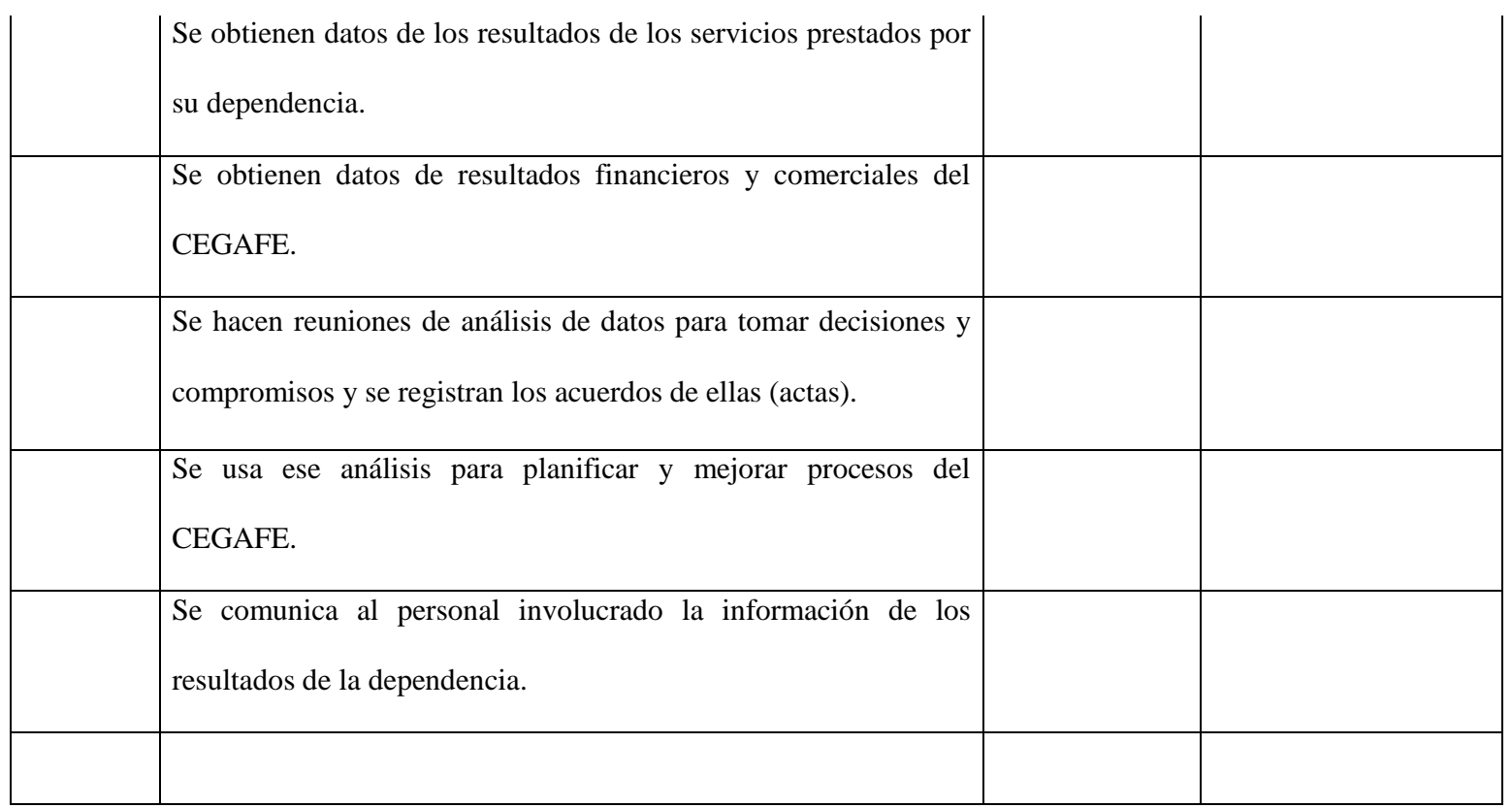

\begin{tabular}{|l|l|l|l|}
\hline & CRITERIO 7: RESPONSABILIDAD SOCIAL & PUNTAJE & OBSERVACIONES \\
\hline & $\begin{array}{l}\text { Se toman acciones para reducir los efectos negativos de los } \\
\text { procesos de su dependencia sobre el medio ambiente. }\end{array}$ & & \\
\hline $\begin{array}{l}\text { El personal, incluyendo la Gerencia/Dirección, participa en } \\
\text { actividades de apoyo a la comunidad y programas de } \\
\text { responsabilidad social comunitaria. }\end{array}$ & & \\
\hline $\begin{array}{l}\text { El CEGAFE apoya en forma directa instituciones de beneficencia } \\
\text { u otras de bien público. }\end{array}$ & & \\
\hline
\end{tabular}

\begin{tabular}{|l|l|l|l|}
\hline CRITERIO 8: RESULTADOS - SERVICIOS PRESTADOS & PUNTAJE & OBSERVACIONES \\
\hline & $\begin{array}{l}\text { La dependencia tiene indicadores para medir sus resultados en la } \\
\text { satisfacción de los Clientes y/o Aprendices del CEGAFE. }\end{array}$ & $\begin{array}{l}\text { La dependencia tiene indicadores para medir sus resultados } \\
\text { operacionales y financieros dentro de los servicios prestados en el } \\
\text { CEGAFE. }\end{array}$ & \\
\hline
\end{tabular}




\begin{tabular}{|l|l|l|l|} 
& $\begin{array}{l}\text { La dependencia tiene indicadores para medir resultados del } \\
\text { cumplimiento de sus planes de acción. }\end{array}$ & \\
\hline & $\begin{array}{l}\text { La dependencia tiene indicadores para medir sus resultados en } \\
\text { responsabilidad social. }\end{array}$ & & \\
\hline $\begin{array}{l}\text { La dependencia tiene indicadores para medir sus resultados en la } \\
\text { satisfacción de los empleados. }\end{array}$ & & \\
\hline $\begin{array}{l}\text { La dependencia tiene indicadores para medir sus resultados en la } \\
\text { calidad de los proveedores. }\end{array}$ & & \\
\hline
\end{tabular}

\section{PREGUNTAS PARA CADA LIDER}

1. Cuáles son los principales problemas en términos de gestión integrada de su dependencia?

2. En su opinión cuales son los indicadores que faltarían en su dependencia para realizar un adecuado control y seguimiento de la gestión integrada?

3. De qué manera desde su dependencia se logra la satisfacción de las necesidades, expectativas y requisitos de los clientes, partes interesadas, usuarios, comunidad, beneficiarios o destinatarios del servicio del CEGAFE?

4. Su dependencia posee gestión de riesgos asociado al SIGA?

5. Que propuestas creería ud que se necesitan para mejorar el Sistema integrado de Gestión? 
6. Como evaluaría ud desde su dependencia los siguientes ítems:

Compromiso de la dirección

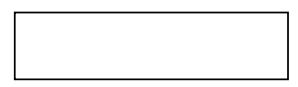

5 es excelente.

Integración en los procesos del CEGAFE

5 es excelente.

Recursos (infraestructura, financieros, tecnológicos, etc)

Donde 1 es pésimo y 5 es excelente.

Implementación de procesos de gestión del riesgo pésimo y 5 es excelente.

Gestión de Seguridad de la Información excelente.

Implementación del Control Interno - MECI 5 es excelente. de 1 a 5 Donde 1 es pésimo y

de 1 a 5 Donde 1 es pésimo y

de 1 a 5 de 1 a 5 Donde 1 es pésimo y 5 es

de 1 a 5 Donde 1 es pésimo y 


\section{Apéndice B. Carta validación instrumento}

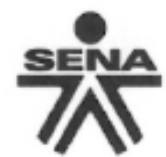

Tunja, 28 de noviembre de 2018

Señor

Pierre Harviary Amaya Plata

Estudiante de Maestría en Administración

Universidad Santo Tomás

Bucaramanga

pierreharviarv@gemail.com

Respetado Pierre

Una vez revisado el instrumento "Lista de chequeo para la evaluación de los procesos SIGA - CEGAFE Boyací $2018^{*}$ propuesto para la tesis de grado de la maestría en Administración en la Universidad Santo Tomás la cual se titula "EVALUACIÓN DE LOS SUBSISTEMAS DEL SIGA EN LOS PROCESOS DEL CENTRO DE GESTIÓN ADMINISTRATIVA Y FORTALECIMIENTO EMPRESARIAL - CEGAFE BOYACA 2018" me permito mencionar que este instrumento se considera pertinente de acuerdo al Sistema Integrado de Gestión y Autocontrol que se implementa en el SENA, por lo tanto se valida su aplicación a los líderes de procesos del Centro de Gestión Administrativa y Fortalecimiento Empresarial de la Regjonal Boyacá con el fin de participar activamente del proyecto de investigación, puesto que dichos resultados serán presentados ante la Subdirección del Centro de Formación.

Agradezco su atención quedando a la espera de tan valiosa información.

ANEXOS

1. Instrumento aprobado

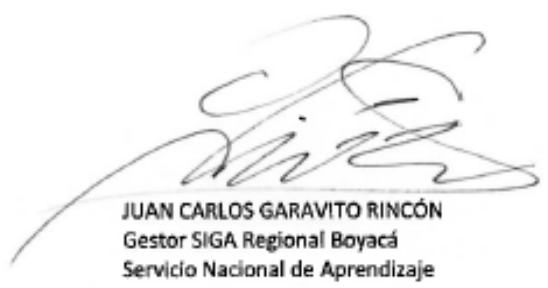

